\title{
SMAD2 OVEREXPRESSION RESCUES THE TGF-B3 NULL MUTANT MICE CLEFT \\ PALATE BY INCREASED APOPTOSIS
}

by

\author{
Abdullah M AlMegbel \\ B.D.S., King Saud University, 2003 \\ AEGD, University of Southern California, 2008 \\ A THESIS SUBMITTED IN PARTIAL FULFILLMENT OF \\ THE REQUIREMENTS FOR THE DEGREE OF \\ MASTER OF SCIENCE \\ in \\ THE FACULTY OF GRADUATE AND POSTDOCTORAL STUDIES \\ (Craniofacial Science) \\ THE UNIVERSITY OF BRITISH COLUMBIA \\ (Vancouver)
}

December 2016

(C) Abdullah M AlMegbel, 2016 


\section{Abstract}

Objectives: Cleft lip/palate is a common birth defect. It occurs in about one in 700 live births worldwide. In non-syndromic cleft lip/palate, a linkage to TGF- $\beta 3$ has been shown. Signaling of TGF- $\beta 3$ is mediated in the cell through the Smad2 protein. During secondary palate fusion TGF$\beta 3$ signaling leads to the disappearance of the epithelial midline seam and the confluence of the palatal mesenchyme. TGF- $\beta 3$ null mice are born with a cleft in the secondary palate, a phenotype that has been rescued by targeted overexpression of Smad2 in the MEE. The goal of this research was to understand the mechanism of palatal fusion in the rescue mice.

Methods: The heads of embryos of four different mice models (wild-type, rescue, K14-Smad2 overexpression and TGF- $\beta 3$ null) were collected at gestational age E14.5 genotyped, fixed and embedded in paraffin. Serial sections were studied for detection of apoptosis and epithelial mesenchymal transition using immunofluorescence. Images were captured with confocal laser microscopy.

Results: TGF- $\beta 3$ null mice developed a cleft in the secondary palate while mice that had both the TGF- $\beta 3$ null and overexpression K14-Smad2 genotypes had fusion of the secondary palate. The medial edge epithelium of the rescue mice had a much higher ratio of cells with cleaved caspase (31.7\% anterior, $33 \%$ middle and $35.6 \%$ posterior), than in the wild-type mice ( $0.0 \%$ anterior, $5.31 \%$ middle and $0.0 \%$ posterior). The K14-Smad2 overexpression genotype mice had an increased number of apoptosis positive MEE when compared to the wild-type mice (13.7\% anterior, $10.1 \%$ middle and $17.6 \%$ posterior). The increase in apoptosis was correlated with increased p-Smad2 in the MEE. 
Conclusions: Smad2 overexpression may have rescued the cleft in the secondary palate by increasing apoptosis in the medial edge epithelium. Thus, the mechanism of rescue is not identical to the events that occur normally during palatal fusion. 


\section{Preface}

Dr. Shuler and Dr. Almegbel defined the research theme and designed the research methods. Dr. Almegbel carried out the laboratory experiments and analyzed the data. Dr. Almegbel wrote the manuscript. Dr. Shuler reviewed and edited the final manuscript.

The Animal Care Committee of the University of British Columbia approved the studies (A090227). 


\section{Table of contents}

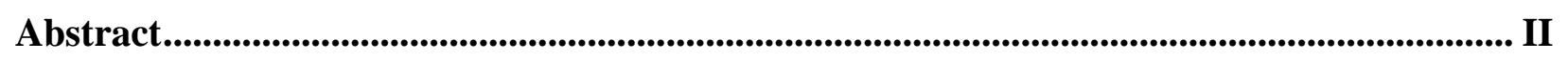

Preface

Table of contents ......................................................................................................................................................

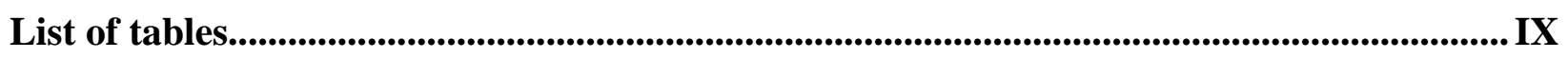

List of figures...........................................................................................................................................X

List of abbreviations ................................................................................................................... XI

Acknowledgements .................................................................................................................................... XIV

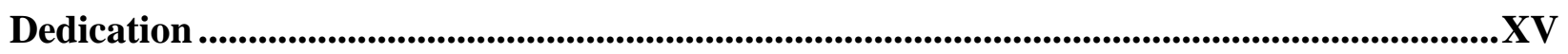

Chapter 1: Introduction: .......................................................................................................1

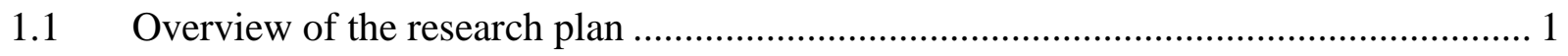

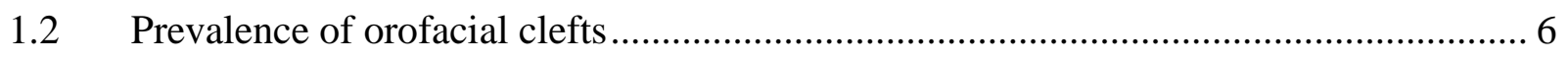

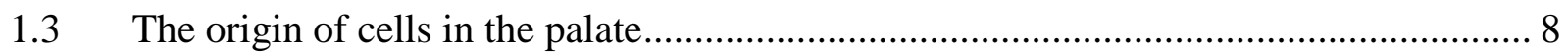

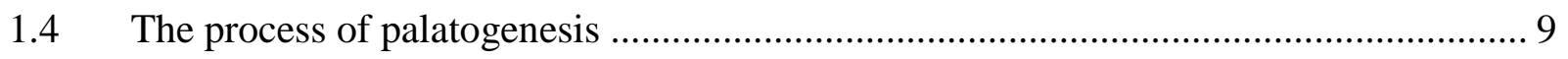

1.4.1 Human palatal development ……………….................................................. 9

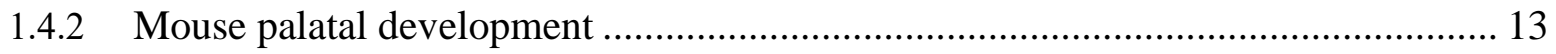

1.4.3 Disparities between mouse and human anatomical development............................. 16

1.5 Syndromic cleft lip, with or without cleft palate …….............................................. 17

1.6 Non-syndromic cleft lip, with or without cleft palate.................................................. 19

1.6.1 Epidemiology of non-syndromic cleft lip, with or without cleft palate.................... 19

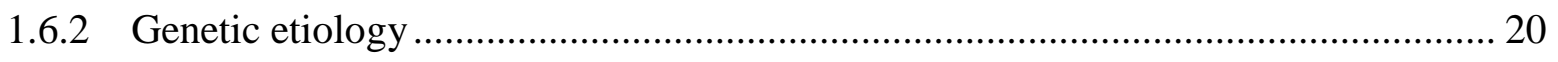

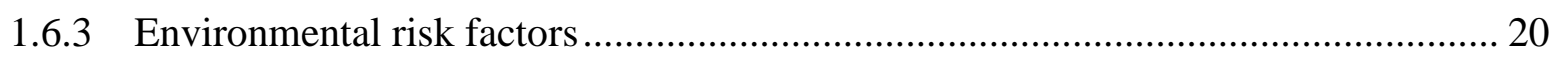




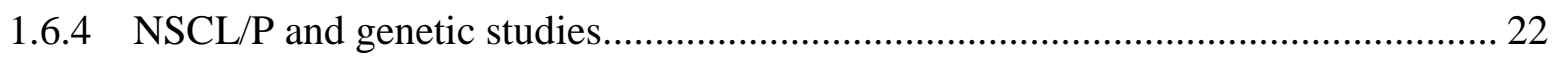

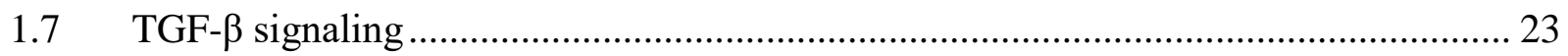

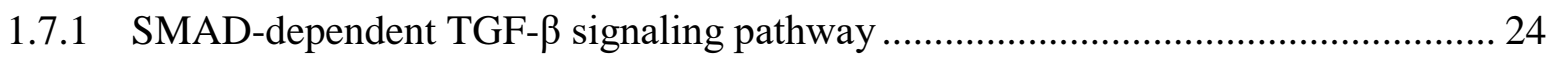

1.7.2 SMAD-independent TGF- $\beta$ signaling pathway ………............................................. 24

1.8 Mouse craniofacial phenotypes and deletion of TGF- $\beta$ signaling genes ...................... 25

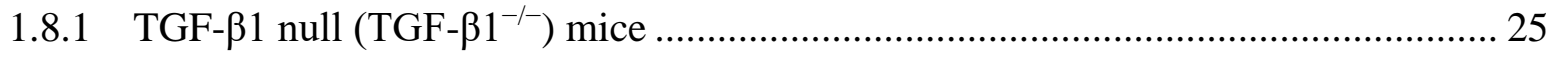

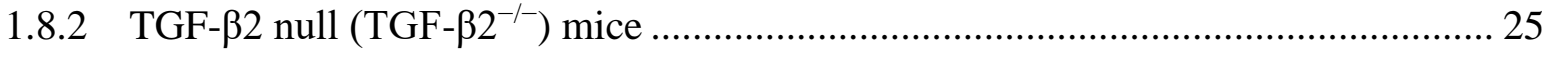

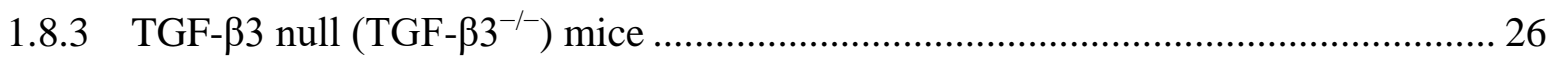

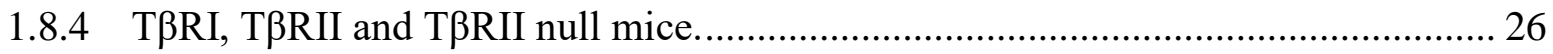

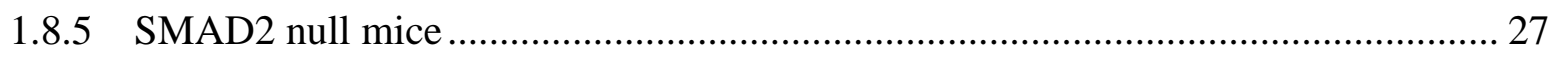

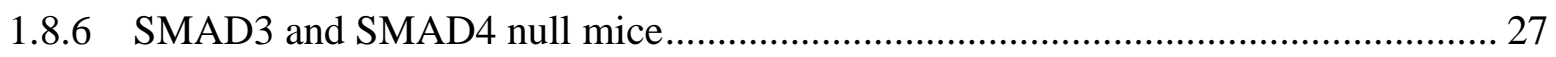

1.9 Experimental mammalian models: mice in the study of cleft lip and palate ................ 28

1.9.1 Experimental mammalian models: K14-SMAD2 mouse phenotype......................... 29

1.9.2 TGF- $\beta 3^{(--)}$and K14-SMAD2/TGF- $\beta 3^{(--)}$mice phenotype …................................. 29

Chapter 2: Medial edge epithelium ....................................................................................................31

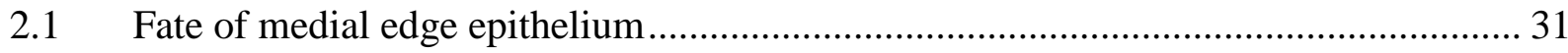

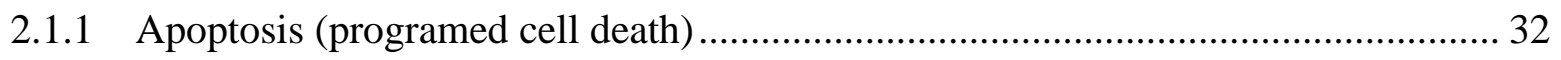

2.1.2 Epithelial-mesenchymal transdifferentiation ....................................................... 33

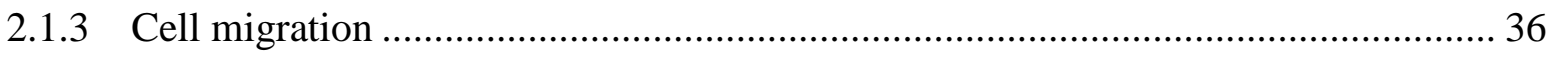

2.2 The role of twist1 and collagen IV during palatal development.................................. 37

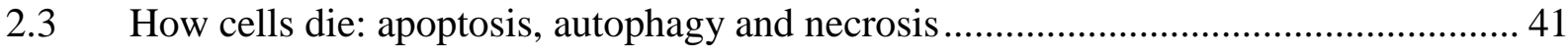

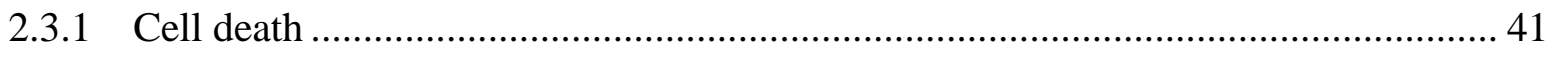

2.3.2 Differences between mechanism of cell death....................................................... 42 


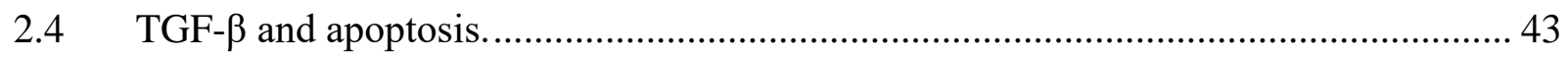

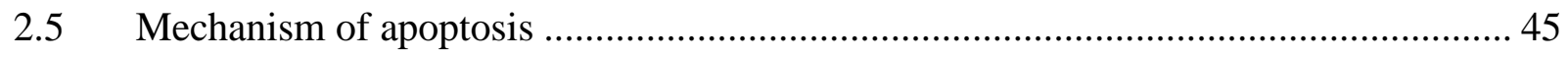

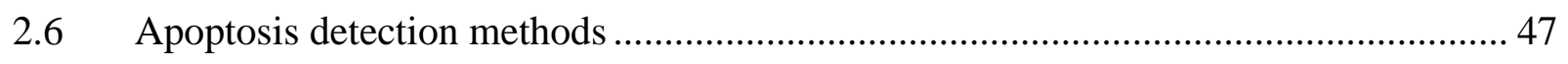

2.6.1 TUNEL technique ......................................................................................... 47

2.6.2 Immunohistochemistry detection of apoptosis related caspase-3 …......................... 48

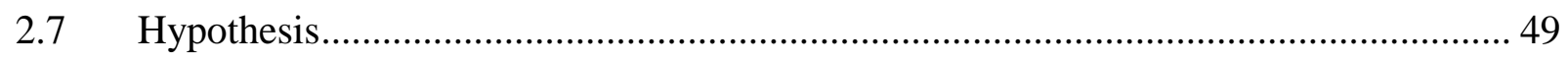

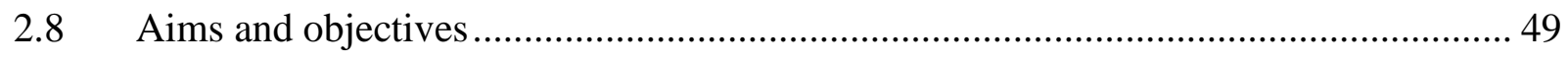

Chapter 3: Materials and methods...............................................................................50

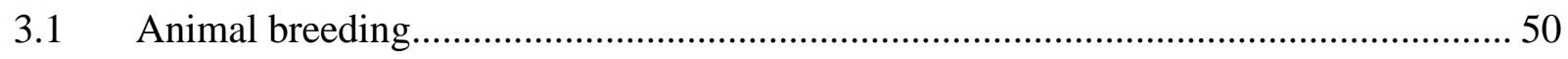

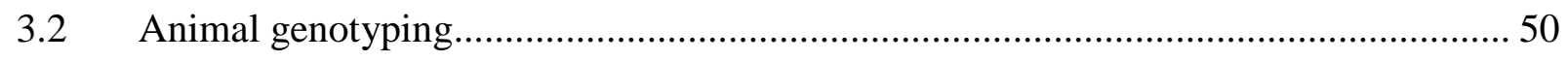

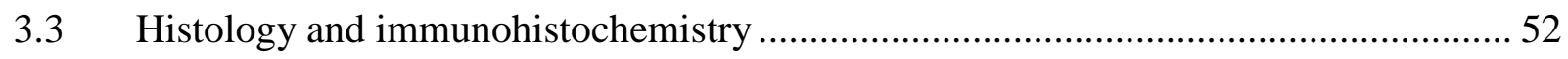

3.3.1 Fixation and paraffin embedding of the samples .................................................. 52

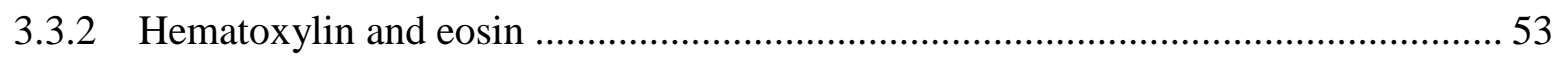

3.3.3 Deparaffinization of tissue sections and rehydration ............................................. 54

3.3.4 Antigen retrieval and background stain blocking ................................................ 54

3.3.5 Analysis of MEE apoptosis rate TUNEL technique ............................................... 55

3.3.6 Analysis of MEE apoptosis rate ccaspase 3 technique ……...................................... 56

3.3.7 Analysis of MEE phosphorylated-SMAD2 rate ………………............................ 57

3.3.8 Analysis of MEE twist1 and collagen IV expression .............................................. 58

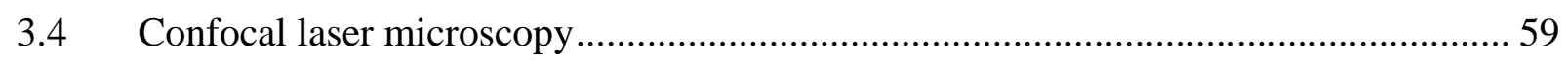

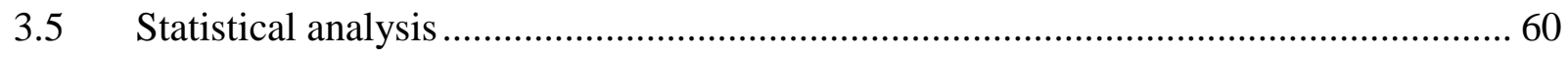

Chapter 4: Results and conclusion .............................................................................................................61

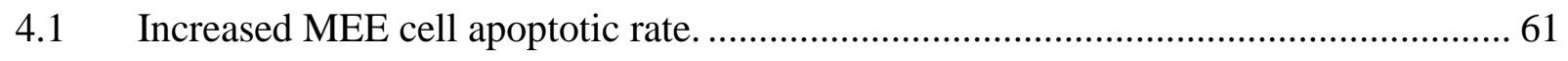


4.2 Increased levels of activated "phosphorylated" SMAD2 in the MEE

4.3 Loss of basement membrane in the MEE cell and twist1 positive cells.................... 69

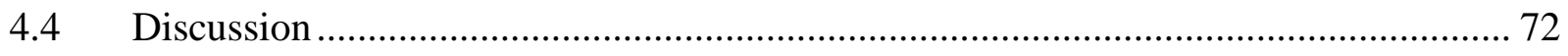

4.4.1 SMAD2 overexpression rescues palatal fusion by inducing apoptosis .................. 73

4.4.2 Evidence of EMT mechanism and basement membrane degradation................... 74

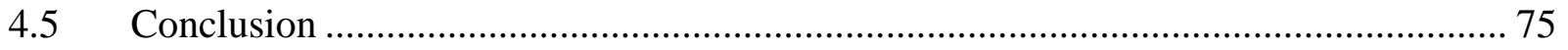

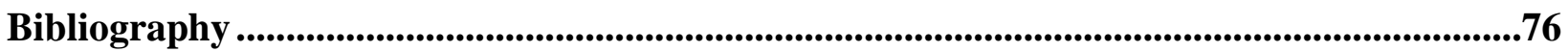




\section{List of tables}

Table 1: Fate of medial edge epithelium (MEE) in literature ............................................... 40

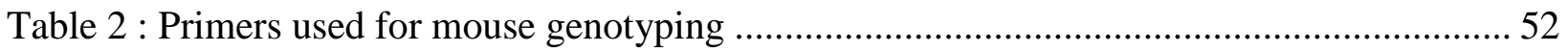




\section{List of figures}

Figure 1 Palatal fusion in TGF- $\beta 3^{(-/-)} / \mathrm{K} 14-\mathrm{Smad} 2$ mice...................................................... 2

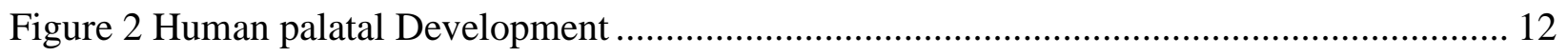

Figure 3 Failure in the process of palatal development. .................................................... 14

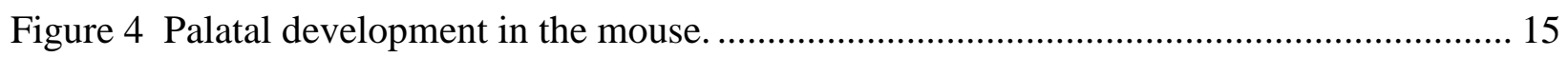

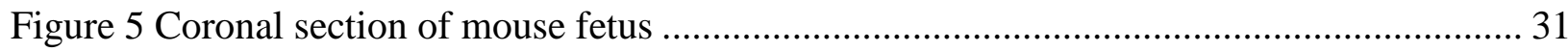

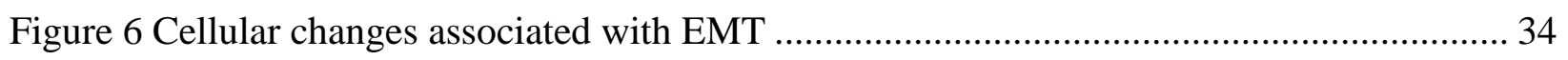

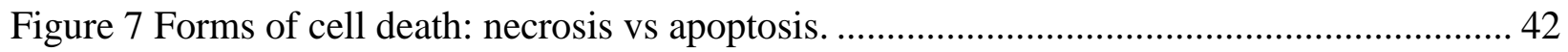

Figure 8 Ccaspase3 expression in coronal E14.5 palatal sections ...................................... 63

Figure 9 Apoptosis ratio in MEE of wild type mice, K14-Smad2 mice and TGF-ß33 ${ }^{(-/-)}$

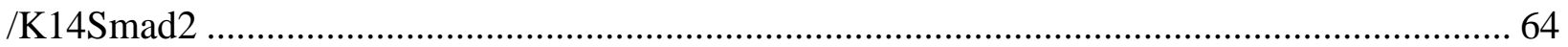

Figure 10 Apoptosis detection in coronal E14.5 palatal sections by TUNEL assay. ................. 65

Figure 11 Apoptosis ratio in MEE of wild type mice, K14-Smad2 mice and TGF- $33^{(-/-)}$

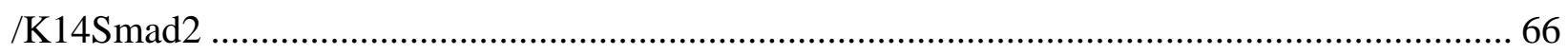

Figure 12 Phospho-Smad2 expression in coronal palatal sections ....................................... 68

Figure 13 Twist1 expression in coronal palatal sections .................................................... 70

Figure 14 Twist1 and Phospho-Smad2 expression in coronal palatal sections ........................ 71 


\section{List of abbreviations}

\begin{tabular}{|c|c|}
\hline $\mathrm{ADH} 1 \mathrm{C}$ & Alcohol dehydrogenase $1 \mathrm{C}$ gene \\
\hline Apaf-1 & apoptotic protease activating factor 1 \\
\hline Bcl-2 & B-cell lymphoma 2 \\
\hline $\mathrm{BM}$ & basement membrane \\
\hline $\mathrm{BMP}$ & bone morphogenic proteins \\
\hline CCFSE & carboxydichlorofluorescein diacetate succinimidyl ester \\
\hline $\mathrm{CL} / \mathrm{P}$ & cleft lip with or without cleft palate \\
\hline CLPTM1 & cleft lip and palate transmembrane protein 1 \\
\hline ColIV & collagen type IV \\
\hline $\mathrm{CPO}$ & cleft palate only \\
\hline DAPI & 4',6-diamidino-2-phenylindole \\
\hline Dil & 1,1'-Dioctadecyl-3,3,3',3'-Tetramethylindocarbocyanine Perchlorate \\
\hline E-cadherin & epithelial cadherin \\
\hline $\mathrm{ECM}$ & extracellular matrix \\
\hline EMT & Epithelial-mesenchymal Transdifferentiation \\
\hline ERK & extracellular signal-regulated kinases \\
\hline FBN-1 & Fibrillin-1 \\
\hline FGFR1 & fibroblast growth factor receptor 1 \\
\hline IRF6 & Interferon regulatory factor 6 \\
\hline LOD score & logarithm (base 10) of odds \\
\hline
\end{tabular}




\begin{tabular}{ll} 
MAPK & Mitogen-activated protein kinases \\
MEE & medial edge epithelium \\
MES & midline epithelial seam \\
MSX1 & Msh homeobox 1 \\
NSCL/P & non-syndromic cleft lip with or without cleft palate \\
PCR & polymerase chain reaction \\
PHF8 & Plant homeodomain (PHD) finger protein 8 \\
P-SMAD2 & phosphorylated-SMAD2 \\
SATB2 & Special AT-rich sequence-binding protein 2 \\
SMAD2 & Mothers against decapentaplegic homolog 2 (Drosophila) \\
Snail1 & Zinc finger protein 1 \\
SUMO1 & Small ubiquitin-related modifier 1 \\
TBX10 & T-box 10 \\
TEM & transmission electron microscope \\
TGF & Transforming growth factor \\
TGF- $\beta 1$ & Transforming growth factor beta 1 \\
TGF- $\beta 2$ & Transforming growth factor beta 2 \\
TGF- $\beta 3$ & Transforming growth factor beta 3 \\
TGF- $\beta$ R 1 & Transforming Growth Factor Beta Receptor 1 \\
TGF- $\beta$ R2 & Transforming Growth Factor Beta Receptor 2 \\
TNF & tumor necrosis factor \\
\hline
\end{tabular}

TUNEL Terminal deoxynucleotidyl transferase (Tdt) mediated dUTP nick-end labeling 
TWIST1 Twist-related protein 1 [class A basic helix-loop-helix protein 38 (bHLHa38)] 


\title{
Acknowledgements
}

\author{
"In the Name of Allah, the Most Beneficent, the Most Merciful. All the praises and thanks be \\ to Allah, the Lord of the 'Alamin."
}

(The Qur'an- Surah Al-Fatihah)

I would like to express my deepest gratitude to my supervisor Professor Charles Shuler for his unwavering support, collegiality and mentorship throughout this project. I would like to thank Dr. Shuler for his help, sincere guidance, and his patience during my time at UBC.

I would like also to thank my advisory committee, Dr. Clive Roberts, Dr. Edward E. Putnins, and Dr. Virginia Diewert, for their support, valuable comments that helped me develop this thesis, keeping me going when times were tough, asking insightful questions, and offering invaluable advice.

Special thanks are extended to the Saudi government and to the Saudi Cultural Bureau for their academic and financial support during my studies at UBC. 


\title{
Dedication
}

This dissertation is dedicated to

My Beloved Parents Megbel and Nora

All that I am, or hope to be, I owe to you.

\begin{abstract}
My Beloved Wife Nada
If I did anything right in my life it was when I gave my heart to you.

Your sacrificial care for me and our children made it possible for me to complete this work.
\end{abstract}

\section{My Children Deemah and Meshari}

Who are indeed a treasure from Allah

Thank you all for helping to give me the life I love today. 


\section{Chapter 1: Introduction:}

\subsection{Overview of the research plan}

This thesis is focused on the fate of the medial edge epithelium cells (MEE) and the mechanism of disintegration of the midline epithelial seam (MES) during palatal fusion. This was analyzed in the TGF- $\beta 3$ null mutant mouse model that has cleft palate as part of the phenotype. TGF- $\beta 3^{(-/-)}$mice with K14-SMAD2 overexpression rescue the cleft palate phenotype. The disappearance of the MEE during palatal fusion in the rescue mice was compared to the results with wild type mice, TGF- $\beta 3^{(--)}$mice and K14-SMAD2 overexpression mice.

The fetal development of the secondary palate is a tightly regulated process in mammals (Ferguson, 1988). This process requires precise interaction between several cells and tissues (Shuler, Guo, Majumder \& Luo, 1991). Temporal and spatial specialization of extracellular matrix (Brinkley \& Morris-Wiman, 1984), mesenchymal cells (Ferguson, 1988), and epithelial cells (Ferguson, 1988) are necessary in order to achieve palatal fusion prior to birth. Failure of this process results in cleft palate.

In a mouse model, palatal development (see section 1.4.2) begins with palatal shelves growing from the inner aspect of each maxillary process at embryonic day (E11.5). Initially at day (E13.5), the shelves protrude vertically along either side of the tongue. As the tongue begins to grow and form, the shelves reorient horizontally above the tongue at day (E14.0). The shelves make contact in the midline at E14.5, initiating fusion and forming the temporary midline epithelial seam (MES) (Bush JO, Jiang R. 2012). Histologically, the palatal shelves are composed of mesenchyme which is derived from the neural crest (Ferguson, 1988; Shuler, 1995). The mesenchyme is surrounded by a layer of oral epithelial cells, derived from the ectoderm. The MES 
must eventually degrade in order to permit mesenchymal confluence of the palatal shelves to complete fusion (Figure 1).

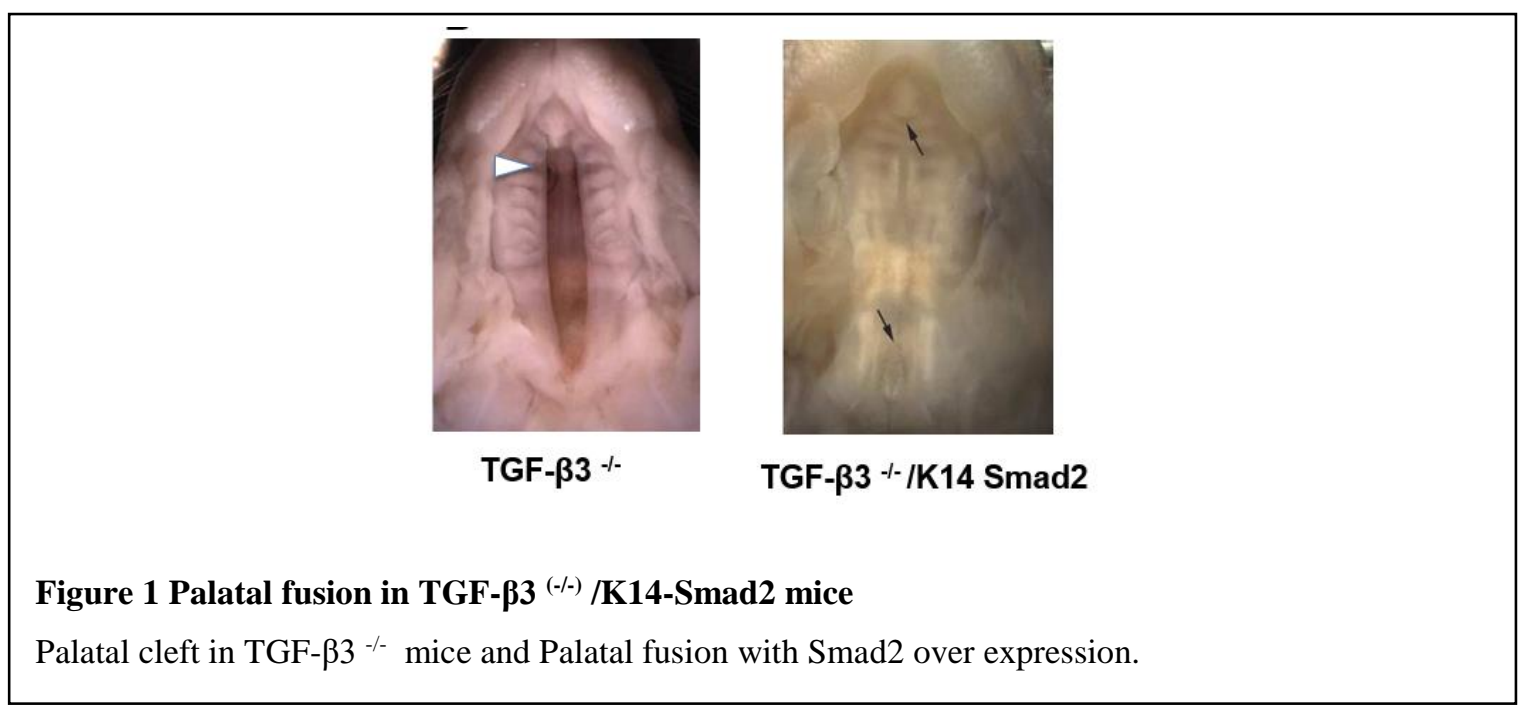

Although recent studies have managed to identify the possible molecular and cellular mechanisms involved in the critical process of MES disappearance, some aspects remain controversial (Gritli-Linde, 2007). Three different theories (see section 2.1) of processes regulating the fate of MES have been proposed; 1) apoptosis (DeAngelis and Nalbandian, 1968; Farbman, 1969; Hayward, 1969; Shapiro and Sweney, 1969; Cuervo and Covarrubias, 2004; Vaziri Sani et al., 2005; Dudas et al., 2006, Dudas, Li, Kim, Yang, \& Kaartinen, 2007; Xu et al., 2006); 2) epithelial mesenchymal transdifferentiation (EMT) (Fitchett \& Hay 1989; Griffith \& Hay 1992; Shuler et al.,1991, 1992; Kaartinen et al., 1997; Nawshad, \& Hay, 2003; Takigawa and Shiota, 2004; Kang, \& Svoboda, 2005; Jin and Ding, 2006); 3) cell migration (Carette \& Ferguson (1992). Recent studies have shown that both apoptosis and EMT may be involved in the disappearance of the MES (Nawshad, 2008; Martinez-Alvarez et al., 2000; Ahmed, Liu \& Nawshad, 2007). 
Transforming growth factor beta 3 (TGF- $\beta 3$ ) is a cytokine involved in many cellular functions including cell cycle control, cell development, differentiation, hematopoiesis and apoptosis (Schuster \& Krieglstein, 2002) (see section 1.7). TGF- $\beta 3$ is involved in the repression of growth of epithelial cells and is expressed in the MES (Schuster \& Krieglstein, 2002; Fitzpatrick, Denhez, Kondaiah \& Akhurst, 1990). TGF- $\beta 3$ null mutant mice have a phenotype that includes a cleft secondary palate due to the MES remaining intact during development (Kaartinen et al., 1995; Proetzel et al., 1995). TGF- $\beta 3$ utilizes SMAD proteins (SMAD2/SMAD3) to transmit regulatory signals inside target cells (Schuster \& Krieglstein, 2002). SMAD2 and SMAD3 are extremely homologous sharing nearly $95 \%$ of their amino acid sequence but they differ in function (Liu et al., 2016; Shiomi et al., 2006). The concept that SMAD3 null mutant mice develop normally while SMAD2 null mutant mice embryos are non-viable indicate the important role that SMAD2 plays during embryonic development (Brown et. al, 2007). SMAD2 and SMAD3 are both expressed in the MEE but during the process of palatal fusion but only SMAD2 is phosphorylated (Cui et al., 2003). The inhibition and inactivation of SMAD signaling and specifically SMAD2 during palatal fusion by all-trans retinoic acid (atRA) resulted in maintenance of MEE and failure of palatal fusion (Wang et al., 2011). The inhibition of SMAD2 in MEE cells by SMAD2 siRNA maintained the proliferation of MEE and prevented the fusion of the palatal shelves (Shiomi et al., 2006). Furthermore, the addition of exogenous TGF- $\beta 3$ to the siRNA treated MEE cells failed to rescue the palatal fusion indicating the critical role of SMAD2 signaling pathway during palatal fusion (Shiomi et al., 2006). Interestingly, SMAD2 overexpression in TGF- $\beta 3$ null mutant mice has been found to rescue palatal fusion (Cui et al., 2005). SMAD2 overexpression has also been found to increase the apoptosis rate in junctional epithelium and downregulates Bcl-2 (Fujita et al., 2012), in prostate epithelial cells (Yang, Wahdan-Alaswad, \& Danielpour, 2009), human 
gingival epithelial cells (Yoshimoto et al., 2015), and human ocular lens epithelial cells (Lee et al., 2002). The following list, which summarizes the literature that has been reviewed, provides an overview of the rationale for examining the mechanism of MEE disappearance as a result of K14SMAD2 overexpression in the TGF- $\beta 3$ null mutant mice:

1. TGF- $\beta 3$ is specifically expressed in the medial edge epithelium and is spatiotemporally correlated to fusion of the palatal shelves during fetal development.

2. TGF- $\beta 3$ has been shown to be involved in regulating multiple cellular processes which occur surrounding medial edge epithelium during palatal fusion, including cell proliferation, extracellular matrix homeostasis, programmed cell death and epithelialmesenchymal transformation.

3. Inhibition of TGF- $\beta 3$ signaling in vivo by gene knockout mice results in a failure of palatal fusion that has been shown to inhibit the disintegration of the MES, resulting in cleft palate

4. TGF- $\beta 3$ null mutant mice secondary palate clefting can be rescued by overexpression of SMAD2 by the cytokeratin-14 promoter.

5. SMAD2 activation in the medial edge epithelium by phosphorylation is a crucial intracellular signaling event subsequent to TGF- $\beta 3$ binding to the receptor in order to initiate the palatal fusion cascade of events.

6. SMAD2 overexpression in other epithelial cells has been found to induce apoptosis.

7. The mechanism of MES disintegration induced by SMAD2 overexpression during palatal fusion in the rescue mice model has not been investigated. 
Those finding have led to the following hypothesis for our proposal: SMAD2 overexpression rescues the TGF-ß3 null mutant mice by increased apoptosis of $M E E$. The aim of this study was to investigate the TGF- $\beta 3$ and SMAD2-regulated mechanism of MES disappearance in a rescue mouse model [K14-SMAD2/TGF- $\left.\beta 3^{(-/-)}\right]$compared to wild type mice, null mutant $\left[\right.$ TGF- $\left.\beta 3^{(-/)}\right]$and SMAD2 overexpression [K14-SMAD2/TGF- $\left.\beta 3^{(+-)}\right]$. 


\subsection{Prevalence of orofacial clefts}

Birth defects are anatomical errors that occur during the development of a fetus. They are a leading cause of death in infants, attributing to one in every 5 deaths (Centers for Disease Control and Prevention [CDC], 2014). In the United States alone, one out of every 33 babies born is diagnosed with a birth defect which amounts to approximately 120,000 babies each year. Infants who survive often face lifelong medical and developmental challenges (Centers for Disease Control and Prevention [CDC], 2014).

Orofacial clefts are classified as a group of congenital birth defects (Canfield et al., 2006). These defects include cleft lip (CL), cleft palate (CP) and cleft lip with palate (CL/P) (Genisca et al., 2009). CL is the congenital failure of fusion between the maxillary and median nasal processes, forming a groove or fissure in the upper lip (Centers for Disease Control and Prevention [CDC], 2014). CP is defined as the congenital failure of the palatal shelves to fuse properly, forming a grooved depression or fissure in the roof of the mouth (Centers for Disease Control and Prevention [CDC], 2014). Clefts of the lip and palate can occur individually, together, or in conjunction with other defects (syndromic).

Orofacial clefts are among the most common congenital birth defects. Seventy percent of all orofacial clefts are non-syndromic (Tolarova \& Cervenka, 1998). The global birth prevalence of non-syndromic orofacial clefts (NSOFC) is 12.5 per 10,000 live births, CL, with or without CP, is less prevalent at 9.4 per 10,000 live births, while CP alone only occurs in 3.1 of every 10,000 live births (Mastroiacovo et al., 2011; Tolarova \& Cervenka, 1998). However, the prevalence of orofacial clefts varies across geographic areas and ethnic groups (Mossey PA, Modell B., 2012). High rates of non-syndromic CL, with or without CP, are seen among those who are Chinese (14.23 per 10,000; Dai et al., 2010) and Japanese (11.8 per 10,000 live births; Cooper, Ratay, \& 
Marazita, 2006) while lower rate are seen among babies of Korean decent (5.1 per 10,000 live births; Lee, Hwang, Lee, Kim \& Seo, 2015). Interestingly, Canada has one of the highest orofacial clefts birth rates in the world at 12.7 per 10,000 live births, $42 \%$ of which are CL with CP, $41 \%$ CP only, and 17\% CL only (Pavri S, Forrest CR., 2013). These prevalence rates are signifiantly higher among First Nations in Canada at 27 per 10,000 live births (Vrouwe S. et al., 2013).

In Saudi Arabia, prevalence of NSOFC in general is 8 per 10,000 live births, where cleft lip with or without cleft palate: 6.8 per 10,000 live births and cleft palate only: 1.3 per 10,000 live births all are lower than the global birth prevalence (Alamoudi NM et al, 2015, Sabbagh HJ et al., 2015a, AlSalloum A. et al., 2015).

Current research indicates that the etiology of $\mathrm{CP}$ involves several genetic and environmental factors, and suggests that there is a correlation between orofacial birth defects and race, ethnicity, country, economical status, chromosome aberration, genetic disorders and teratogenic factors (smoking and alcohol consumption) (Coubourne, 2004; Lidral et al., 2008; Little et al., 2004; Meng et al., 2009; Scapoli et al., 2008; Vieira, 2008; Zhu et al., 2009). 


\subsection{The origin of cells in the palate}

The cells forming the palatal structures are formed of cranial neural crest derived ectomesenchymal cells, pharyngeal ectoderm derived epithelial cells, and mesoderm derived cells (Ito et al., 2003; Shuler et al., 1992; Ferguson, 1984). The palatal shelves are covered by epithelial cells divided into oral epithelia, nasal epithelia and medial edge epithelia. Furthermore, the nasal epithelial cells differentiate into pseudostratified ciliated columnar epithelial cells and the oral epithelial cells differentiate into stratified squamous keratinized epithelium, whereas the (MEE) cells are eliminated from the midline seam by either Cell Migration, Epithelial-Mesenchymal Transdifferentiation (EMT) or Apoptosis (Programed cell death) (Fitchett and Hay, 1989; Martinez-Alvarez et al., 2000; Shuler, 1995; Shuler et al. 1992).

The use of transgenic animal models has helped to understand the cell fate during palatogenesis. The development of the Wnt1-Cre; R26R mouse model showed that more than 90\% of the mesenchymal cells are derived from cranial neural crest cells (CNCC) (Chai et al., 2000; Ito et al., 2003; Iwata et al., 2010). Neural crest cells (NCC) are intermediate cells that originate at the dorsal-most region of the neural tube the embryonic ectoderm cell layer and only found in vertebrates. The (NCC) migrate extensively to generate a number of differentiated cell types including smooth muscle cells, neurons and glial cells, epinephrine-producing cells, melanocytes, and many of the skeletal and connective tissue of the head (Chai et al., 2000; Jiang et al., 2000; Kirby and Waldo, 1995; Nichols, 1981; Sela-Donenfeld and Klacheim, 1999; Snider et al., 2007; Gilbert, 2000). The neural crest can be divided into four main domains: The cranial (cephalic) neural crest, trunk neural crest, vagal and sacral neural crest and cardiac neural crest (Gilbert, 2000). 
The cranial (cephalic) neural crest cells migrate dorsolaterally, which happens before the closure of the neural tube, to create the craniofacial mesenchyme. These CNCC differentiate into cranial neurons, glia, cartilage, bone, and connective tissues of the face. They also give rise to odontoblasts, thymic cells, and bones of the middle ear. Only the cells of the cranial neural crest are able to produce cartilage and bone (Gilbert, 2000). The face is the product of cranial (cephalic) neural crest cells.

\subsection{The process of palatogenesis}

The mammalian palate, a structure that separates the oral cavity from the nasal cavity, facilitates breathing and swallowing functions. It is bordered anteriorly and laterally by the

maxillary teeth and superiorly covered by the respiratory epithelium of the nasal cavity and inferiorly by the masticatory epithelium of the oral cavity. It is divided into two divisions; The primary palate derived from the frontonasal process and the secondary palate originating from the maxillary process of the first branchial arch (Ferguson, 1988). The development of the full palate as one fused structure requires the interaction of complex and dynamic morphogenic events and cellular differentiation (Ferguson, 1988).

\subsubsection{Human palatal development}

The facial prominences surrounding the primitive mouth give rise to the development of the face (Bush \& Jiang, 2011). In humans, these prominences appear during the fourth week of human embryogenesis as ectodermal thickenings or nasal placodes on either side of the inferior aspect of the frontonasal process (Schoenwolf \& Larsen, 2009). As the lateral and medial rims expand to form a pit, the mesenchyme starts to condense and proliferate at the borders of the 
thickened ectoderm (Kernahan, \& Rosenstein, 1990). By the end of the fourth week of embryogenesis, the frontonasal process and lateral and medial nasal process start to bulge, the nasal cavities start to form by deepening of the nasal pits, and the neural crest cells start to migrate from the first branchial arch (Kernahan, \& Rosenstein, 1990). The frontonasal process and the medial nasal processes on both sides form the nose, anterior maxilla, primary palate and the upper lip. At the bottom of the nasal pit, the medial surface of the maxillary process meets with the lateral surface of the medial nasal process forming the primary palate (Kernahan, \& Rosenstein, 1990).

The formation of the secondary palate, which gives separation between oral and nasal cavities, begins between the seventh and eighth week of human embryogenesis. The nasal septum begins growing downwards from the frontonasal process along the midline. The two palatine shelves, extending from the maxillary process, begin to reorient towards the midline (Kernahan, \& Rosenstein, 1990). At the beginning, the two palatine shelves are positioned vertically on each side of the developing tongue. In the seventh week the palatal shelves start to reorient to a horizontal position as the mandible grows and the tongue lowers (Ferguson, 1988). By the eighth week, the opposing palatal shelves start to approximate and begin to fuse anteriorly. As they approximate, the epithelial layers covering the two shelves adhere creating the medial epithelial seam (MES). The MES, which consists of two layers of basal epithelial cells, must then disappear in order to allow for the subsequent mesenchymal confluence and fusion which then occurs between the opposing palatal shelves (Bush \& Jiang, 2011). As the palatal shelves fuse to each other they also fuse to the nasal septum. Fusion of the palatal shelves with the globular process results in the premaxillary area: the primary palate, the maxillary incisors area and the philtrum of the upper lip (Bush \& Jiang, 2011). The fusion of the palate is completed by the 17th week (Bush \& Jiang, 2011). 
Disturbances that occur during the process of palatal development include failure of palatal shelf formation, failure of palatal shelf elevation, failure of palatal shelf growth and failure of palatal shelf adhesion. All of these abnormal patterns of development result in clefting of the palate (Figure 2, Figure 3) (Ferguson, 1988). 

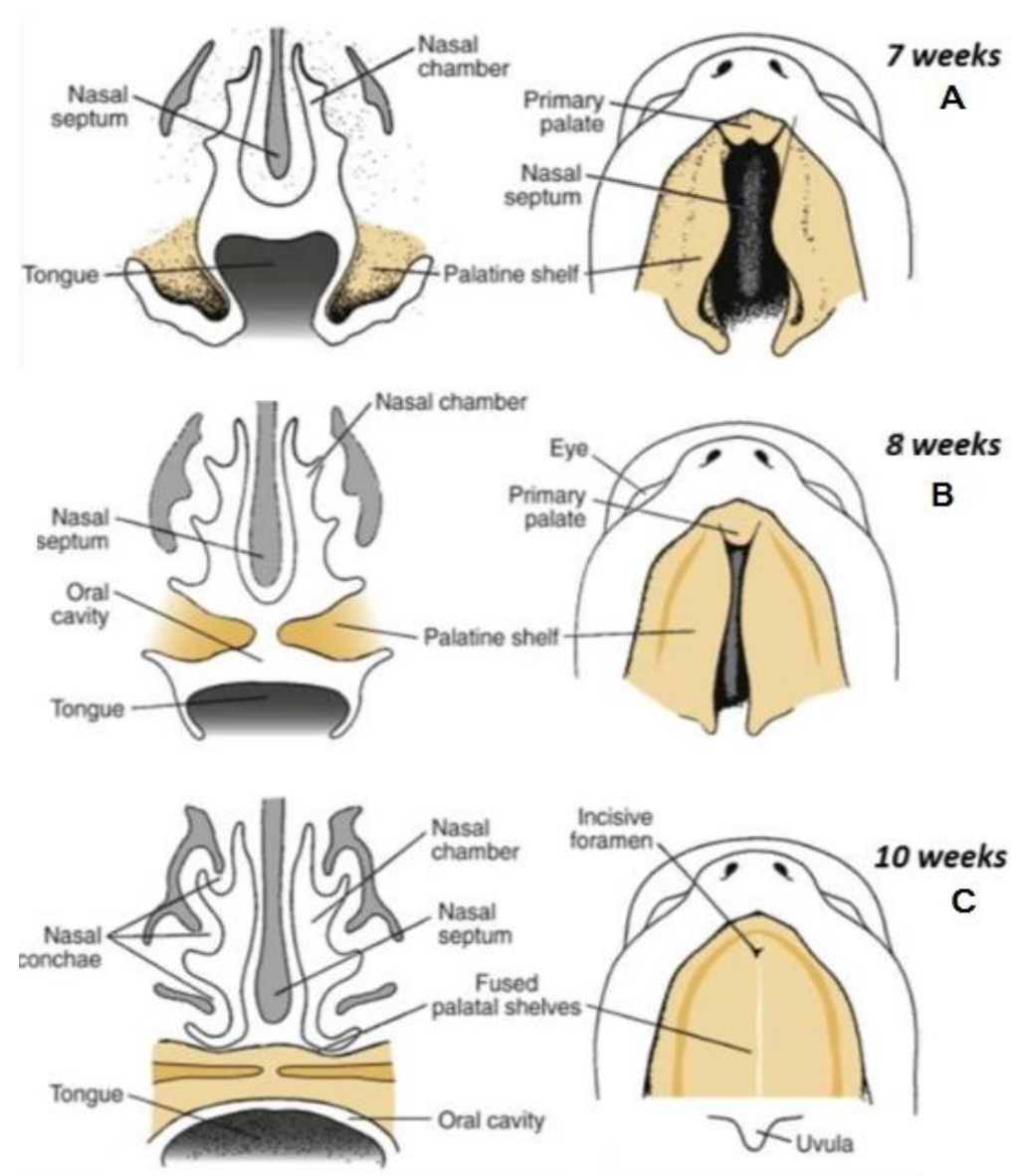

Figure 2 Human palatal Development

A. Frontal section through the head of a 7th-week-old embryo. The palatine shelves are in the vertical position on each side of the tongue. The ventral view of the palatine shelves after removal of the lower jaw and the tongue shows the palatine shelves are still vertical. B. Frontal section through the head of an 8th-week embryo. The tongue has moved downward, and the palatine shelves have reached a horizontal position. The Ventral view of the palatine shelves after removal of the lower jaw and tongue. The shelves are horizontal. Note the nasal septum. C. Frontal section through the head of a 10th-week embryo. The two palatine shelves have fused with each other and with the nasal septum. In the ventral view of the palate. The incisive foramen forms the midline between the primary and secondary palate. Reprinted from Sadler, T., \& Langman (Sadler, T., \& Langman, J., 2010). 


\subsubsection{Mouse palatal development}

The development of the mouse secondary palate has a similar course to the human palate. At embryonic day E11.5 the secondary palate starts to form. The medial aspects of the palatal shelf, which emerge from the inner aspect of the maxillary process and extend antero-posteriorly along the lateral side of the oropharynx, elevate and become parallel to one another (Gritli-Linde, 2007). The anteromedial borders of the palatal shelves then start to fuse with the primary palate. At the same time, the superior aspects of the palatal shelves begin to fuse with the inferior border of the nasal septum in the midline (Kaufman, 1992).

The vertical growth of the palatal shelves continues until day 13 of embryonic development (E13) (Chai and Maxson, 2006). During active growth embryonic days E12 to E14, the vertical palatal shelves become engulfed between the cheeks and the lateral sides of the tongue (Krauss, 2008). Depending on the mouse strain, from embryonic day E14.5 to E15, the palatal shelves begin to reorient horizontally above the dorsum of the tongue (Krauss, 2008). Subsequently, the opposing palatal shelves continue to grow horizontally allowing them to approximate in the midline and adhere between the opposing medial edge epithelia (MEE). This ultimately creates the MES (Gritli-Linde, 2007). Progressive disintegration of the MES allows for a successful mesenchymal confluence between the opposing palatal shelves along the midline, anteriorly with the primary palate and dorsally with the nasal septum, ultimately dividing the cavity into oral and nasal cavities (Gritli-Linde, 2007; Krauss, 2008). Similar to human development, any failure in the process of palatal development, formation, reorientation, or adhesion will result in a cleft in the palate (Figure 3, 4) (Ferguson, 1988). 


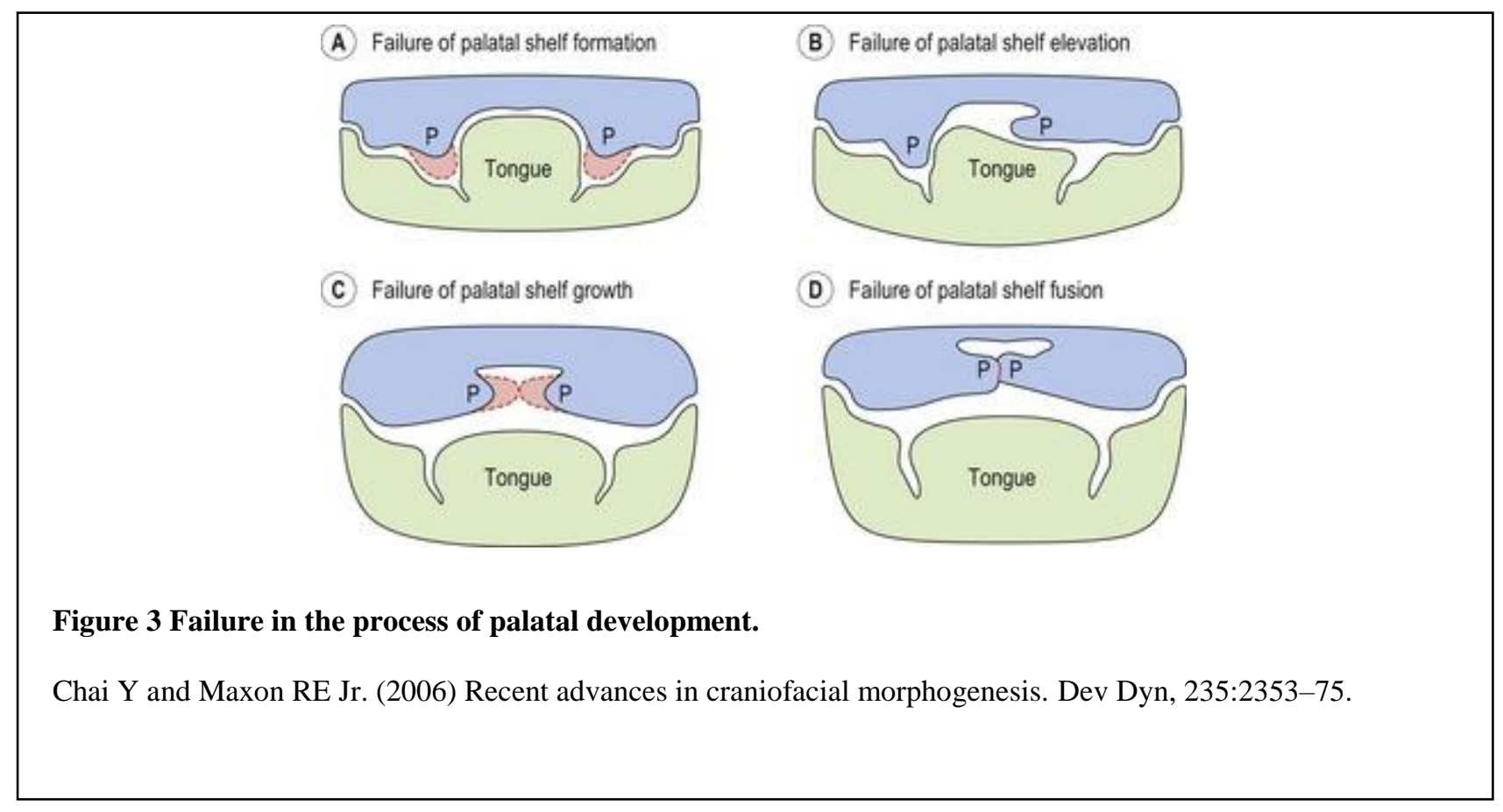




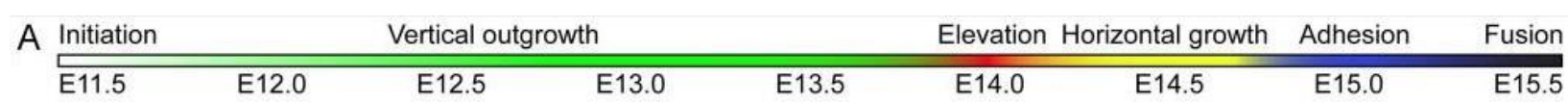
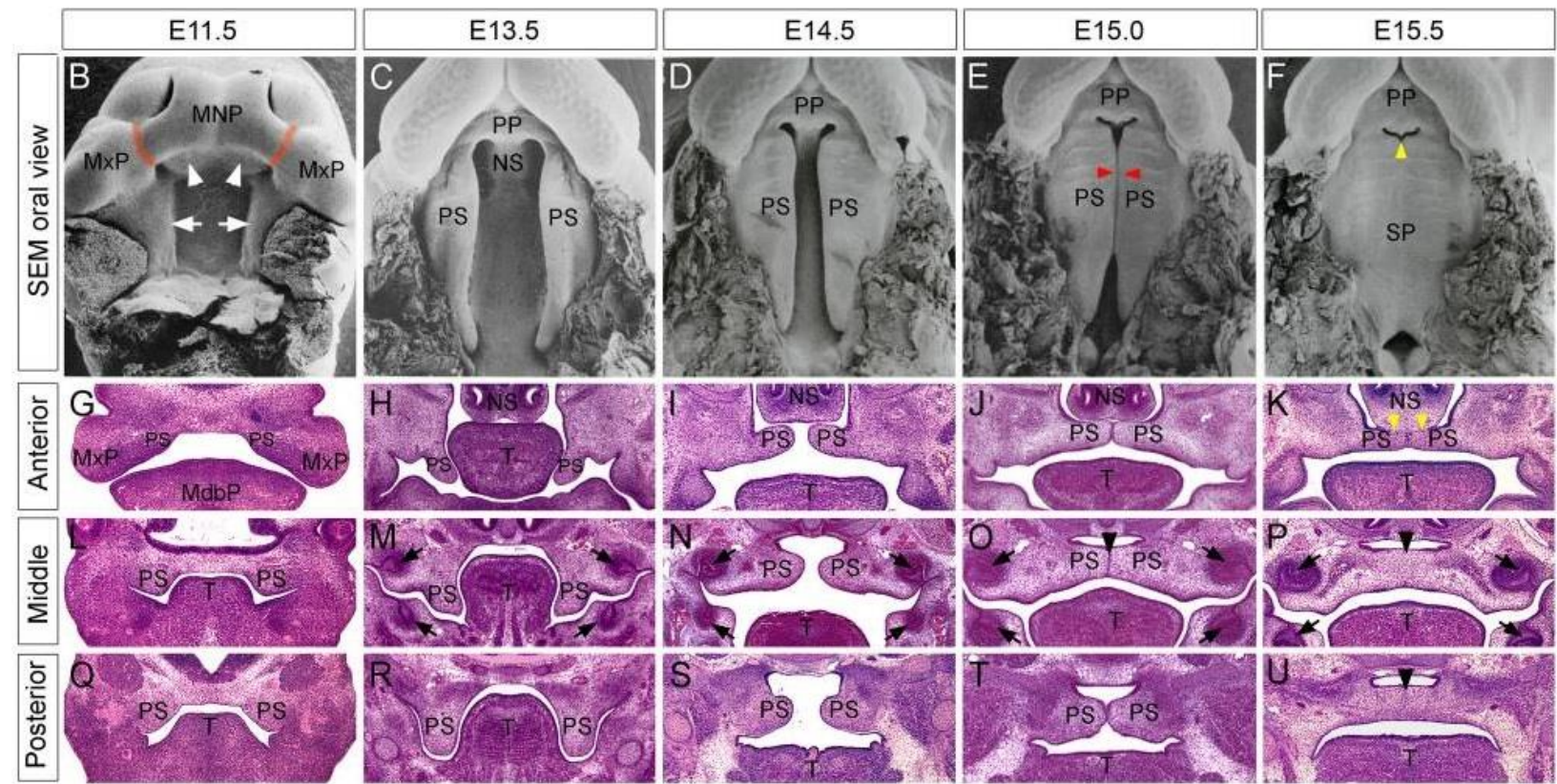

Figure 4 Palatal development in the mouse.

(A) Time course of palate development in mice. (B-F) Scanning electron micrographs showing oral views of the secondary palate at representative developmental stages (Kaufman, 1992). Orange lines mark sites of fusion between the medial nasal processes and maxillary processes, white arrowheads point to initial outgrowths of the primary palate, white arrows point to the initial outgrowth of the secondary palatal shelves, red arrowheads mark the initial site of palatal adhesion and fusion, and the yellow arrowhead points to the gap between the primary and secondary palates that will disappear following fusion between these tissues. (G-U) Representative histological frontal sections from anterior (G-K), middle (L-P), and posterior (Q-U) regions of the developing palate at each indicated stage. Reprinted from Kaufman (Kaufman, 1992). 


\subsubsection{Disparities between mouse and human anatomical development}

Some anatomical differences in lip and palate development exist between mice and humans (Katebi, Kolpakova-Hart, Lin \& Olsen, 2012). In humans, the airway begins in the oronasal cavity which extends posteriorly and then curves as it connects to the trachea inferiorly at a 90-degree angle. The result is a horizontal hard palate, angled soft palate and an inferiorly extended uvula. On the other hand, the mouse hard palate, soft palate and other airway structures remain horizontal due to the fact that mice are quadrupedal (Kaufman, 1992).

Proportionally, the mouse palate is very large when compared to the full body size. On the other hand, the human palate is much smaller in comparison to the total body (Jeong, 2009). The rugae in the mouse spans the entire palate while in the human body rugae are only located in the anterior region. The human hard palate is composed of intact bone from the anterior teeth up to the horizontal plate of the palatine bone, while in mice, a cavity spans from the anterior teeth to the first molar (Jeong, 2009). This cavity is also found in rats and is anatomically called anterior palatine foramen (Greene, 1963). Moreover, in mice a large cavity is found between the nasal cavity and conchae and the hard palate, the function of which is still unknown (Kaufman, 1992), while in humans the only cavities are the nasal cavity and the maxillary sinuses. In humans, orofacial clefts can occur as cleft of the lip, cleft of the alveolus, cleft of the palate or combination of any of these types. They can occur bilaterally either in the lip or palate. While in mice, the clefting can occur bilaterally in the lip but only in the midline in the palate (Jeong, 2009). Despite these differences, the mouse resembles human palate development and is an accessible mammalian model for research on CL/P. 


\subsection{Syndromic cleft lip, with or without cleft palate}

The classification of syndromic CL, with or without a $\mathrm{CP}$, requires the presence of additional physical or cognitive abnormalities. More than 275 syndromes have CL with or without a $\mathrm{CP}$ as a defining feature. The cause of more than $75 \%$ of these syndromes has been identified genetically (Leslie and Marazita, 2013).

Specifically, several syndromes have been linked to certain genetic mutations associated with CL. Van der Woude syndrome, the most common syndrome with clefting has a prevalence of 1 per 34,000, and is caused by a mutation in the IRF6 gene (Kondo et al., 2002). Loeys-Dietz syndrome is associated with mutation in TGF- $\beta$ R1 or TGF- $\beta$ R2 (Loeys et al., 2005). A mutation of the gene PHF8 has been linked to Siderius X-linked mental retardation (Laumonnier et al., 2005), while other syndromes with clefting features include Smith-Lemli-Opitz syndrome (Porter, 2000), Desmosterolosis (Waterham et al., 2001), and X-linked dominanta chondiodysplasia punctata (Dempsey, Tan and Herman, 2011).

The transforming growth factor beta (TGF- $\beta$ ) signaling pathway, an important regulator of many cellular processes including cell growth, cell differentiation, apoptosis, and cellular homeostasis during embryonic development, is another example of a mutation that causes syndromes associated with CP (Hosokawa et al., 2010; Ito et al., 2003; Iwata et al., 2010; Oka et al., 2007; Sasaki et al., 2006). Mutations in TGF- $\beta$ R1 or TGF- $\beta$ R2 have been linked with LoeysDietz syndrome, a syndrome that can show craniofacial malformations including cleft palate and craniosynostosis (Loeys and De PaePe, 2008; Loeys et al., 2005; Mizuguchi et al., 2004). Overexpression of TGF- $\beta$ signaling associated with Fibrillin-1 (FBN-1) gene mutation can cause Marfan syndrome that has the same clinical phenotype as Loeys-Dietz syndrome (Brooke et al., 2008; Habashi et al., 2006; Kalluri and Han, 2008). Another syndrome that exhibit the same 
phenotype as TGF- $\beta$ R2 mutation is $22 \mathrm{q} 11.2$ deletion syndrome or DiGeorge syndrome, the most common microdeletion syndrome with a prevalence estimated at 1:4000, which results from a small deletion on chromosome 22 which causes altered TGF- $\beta$ signaling (Lindsay, 2000; Lindsay et al., 1999; Lindsay et al., 2001; Portmoi, 2009; Vietlli and Baldini 2003; Wurdak et al., 2005; Oskarsdottir, 2004). 


\subsection{Non-syndromic cleft lip, with or without cleft palate}

The etiology of non-syndromic cleft lip with or without palate (NSCL/P) is multifactorial and can be related to any change in numerous genes secondary to epigenetic factors such as smoking during pregnancy, alcohol consumption during pregnancy, or any exposure to drugs such as anticonvulsant drugs that might alter the normal palatal development (Yu, Serrano, Miguel, Ruest, \& Svoboda, 2009; Hanson, Myrianthopoulos, Harvey, \& Smith, 1976). Several studies have associated mutations in TGF-B3, IRF6, CYP, MSX1 and TBX10 with NSCL/P (Yu, Serrano, Miguel, Ruest, \& Svoboda, 2009; Carinci, Scapoli, Palmieri, Zollino, \& Pezzetti, 2007; Vieira et al., 2007).

\subsubsection{Epidemiology of non-syndromic cleft lip, with or without cleft palate}

Approximately $70 \%$ of all cleft lip with or without cleft palate cases (CL/P) and $50 \%$ of cleft palate only cases (CPO); are classified as non-syndromic (NSCL/P) (Jugessur, Farlie, \& Kilpatrick, 2009). In non-syndromic orofacial clefts, the frequency of CL/P is doubled in males, while (CPO) is doubled in females (Mossey et al., 2009). According to Gundalsch and Maus (2006) around $75 \%$ of clefts that involves the lip are unilateral and among them, clefts affecting the left side are twice as common as the right side.

Data have shown that the incidence of non-syndromic NSCL/P also tends to vary by geographic and ethnic origin (Leslie and Marazita, 2013). Asians or Amerindians are most commonly affected by NSCL/P while people of African origin are less affected (Dixon, Marazita, Beaty, \& Murray, 2011). Several environmental factors might explain the difference in prevalence such as general nutrition, level of available medical care, lack of vitamins, and maternal smoking prevalence (Leslie, \& Marazita, 2013). 


\subsubsection{Genetic etiology}

The genetic complexity of NSCL/P comes from the interaction of multiple genes and environmental risk factors. Linking NSCL/P to genetic factors only began in 1942 after recording an increased incidence of orofacial clefts among relatives of a patient with a cleft were observed and noted (Fogh-Anderson, 1942). Furthermore, the segregation analysis done by Marazita, Spence \& Melnick (1984) and later the twin studies done by Mitchel (2002) both confirmed the genetic deteminants of NSCL/P. It is estimated that CL/P and CPO have more than $90 \%$ heritability (Grosen et al., 2010). Families with CL/P and CPO-affected first-degree relatives have 30-40 times higher risk of recurrence compared to the general population (Sivertsen et al., 2008; Grosen et al., 2010).

\subsubsection{Environmental risk factors}

The role of environmental factors in the development of NSCL/P is supported by epidemiological data. Several risk factors including twin births, maternal antibiotic use, antiemetic medication, severe morning sickness, common cold/flu, maternal smoking and passive smoking (Sabbagh et al., 2015a), pesticide exposure (Xu et al., 2015) history of maternal abortion, and parental age at time of childbirth (Lin et al., 2014) have been associated with incidence of NSCL/P.

Alcohol consumption during pregnancy for instance, has been linked to a significantly increased risk of clefting. This link arose from the association between orofacial clefts and a variation in the alcohol dehydrogenase $1 \mathrm{C}$ gene, ADH1C (Jugessur et al., 2009b). The combination of heavy alcohol consumption during pregnancy with reduced enzymatic activity of the ADH1C variant appears to increase the risk of orofacial clefts (Boyles et al., 2010). 
Nutrition during pregnancy also plays a big role based on studies assessing the use of folic acid supplements as a preventive measure (Wehby and Murray, 2010). However, the benefit of folate use during pregnancy remains controversial (Wehby and Murray, 2010; Wilcox et.al., 2007). Reduced risk of NSCL/P has also been observed in correlation with the use of calcium supplementation and adequate hydration during pregnancy (Sabbagh et al., 2015a).

Several studies have shown that gene-environment interaction may contribute to orofacial clefts (Wyszynski, 2002). Romitti et al. (1999) in a case-control study from Iowa, examined environmental factors smoking and alcohol consumption and candidate gene TGF- $\beta 3$ to understand their combined effect on the severity of orofacial clefts. The study showed an increased risk if the mother was smoking more than 10 cigarettes/day. Furthermore, the risk of $\mathrm{CP}$ among infants was even higher if there was an allelic variant at TGF- $\beta 3$ (Romitti et al., 1999). In another study Maserti et al. (1997) utilized case-parent trios to test gene-environment interaction. Their results showed an evidence of increased transmission of TGF- $\beta 3$ allele 6 among smoking mothers (Maestri et al., 1997).

In summary, it's evident that genetic factors and environmental factors play a great role in the etiology of NSCL/P either independently or jointly. Several genes are involved in the etiology of NSCL/P, however TGF- $\beta 3$ has been associated with NSCL/P, both independently or in the presence of other environmental factors (Romitti et al., 1999; Lidral et al. 1998; Maestri et al., 1997). 


\subsubsection{NSCL/P and genetic studies}

A variety of tests and approaches have been employed to identify the genes that contribute to the development of NSCL/P, including linkage analysis, genomic rearrangement, candidate genes, and genome wide association studies (Leslie and Marazita, 2013).

Linkage analysis studies which are based on the segregation of genetic loci can be performed on pairs of affected relatives or large families. For NSCL/P, only 13 genome-wide linkage scans have been conducted and none had a genomic-wide significant LOD score; a statistical estimate of whether a gene and a disease gene have the tendency to be located close to each other on a chromosome and are likely to be inherited (Marazita et al., 2004). One of the largest linkage studies was done on 388 extended families, and meta-analysis of all published linkage scans revealed that there were likely genetic determinants of NSCL/P on chromosome sections 1q32, 2p13, 3q27-28, 9q21, 14q21-24 and 16q24 (Marazita et al., 2004). Further results showed that the chromosomal region $14 \mathrm{q} 24$ containing TGF- $\beta 3$ was a causative gene for NSCL/P (Marazita et al., 2009).

Genomic rearrangement is a major genomic mutation caused by gross alterations of chromosomes or large chromosomal regions taking the form of deletion, duplication, inversion, insertion or translocation of base pairs. Recent analyses in patients with genetic rearrangement implicated the following genes in NSCL/P: cleft lip and palate transmembrane protein 1 (CLPTM1) (Yoshiura et al., 1998), special AT-rich sequence-binding protein 2 (SATB2) (FitzPatrick et al., 2003), small ubiquitin-related modifier 1 (SUMO1) (Alkuraya et al., 2006), and fibroblast growth factor receptor 1 (FGFR1) (Kim et al., 2005).

Mouse models with induced clefting by either mutagenesis or by gene knockout methods have been used in research for gene discovery in this area. Alternatively, many Mendelian 
syndromes that include clefting as part of their phenotype are often caused by severely damaging mutations in a gene, while less deleterious variants of the gene can cause similar but less severe isolated clefts (Stanier and Moore, 2004).

In summary, genome scan meta-analysis studies have identified a significant link between the TGF- $\beta 3$ locus and the incidence of NSCL/P in infants (Marazita et al., 2004). Observational studies support the link between genomic mutations in TGF- $\beta 3$ and NSCL/P in humans (Lidral et al., 1998). Mouse model studies involving TGF- $\beta 3$ knockout or inactivation mice show that these animals experience significant clefting of the secondary palate (Kaartinen et al., 1995). Given the current findings, TGF- $\beta 3$ appears to play a critical role in the development of the secondary palate and is likely involved in the pathogenesis of palatal clefting in mammals, including humans.

\section{$1.7 \quad$ TGF- $\beta$ signaling}

The transforming growth factor beta (TGF- $\beta$ ) superfamily consist of nearly 30 growth and differentiation factors including activins, bone morphogenic proteins (BMBs), inhibins and TGF$\beta$ (Kitisin et al., 2007). TGF- $\beta$ pathway stimulates multiple signaling networks that control cell fate, growth and differentiation (Massague $\&$ Wotton, 2000). The TGF- $\beta$ signaling is carried out through the TGF- $\beta$ type I (T $\beta R I)$ and TGF- $\beta$ type II receptors (T $\beta$ RII); a transmembrane serinethreonine kinase receptor subunit, to a specific mediator known as the SMAD proteins initiating the SMAD-dependent signaling pathway (Kitisin et al., 2007). Also, TGF- $\beta$ is capable of utilizing another non SMAD signaling pathway through Mitogen-activated protein kinases (MAPK) (Iwata, Parada \& Chai, 2011). 


\subsubsection{SMAD-dependent TGF- $\beta$ signaling pathway}

TGF- $\beta$ signaling begins by assembling a specific receptor complex that activates SMAD transcription factors (Feng \& Derynck, 2005). The receptor is composed of two regions, an extracellular region which is a small and tightly folded globular domain and a cytoplasmic region formed by a juxtamembrane segment and a protein kinase domain (Derynck, Zhang \& Feng, 1998). The isoforms of TGF- $\beta$; TGF- $\beta 1$, TGF- $\beta 2$ and TGF- $\beta 3$, bind to the TGF- $\beta$ type II receptor (T $\beta$ RII) which then phosphorylates and activate the receptor. Both TGF- $\beta 1$ and TGF- $\beta 3$ have a higher affinity to bind to the T $\beta$ RII receptor, while the TGF- $\beta 2$ requires an additional receptor, T $\beta$ RIII (Iwata, Parada \& Chai, 2011). Subsequently, TGF- $\beta$ type I receptor (T $\beta$ RI) is included in the complex and activated by T $\beta$ RII through a T $\beta$ RII-mediated glycine-serine phosphorylation (Iwata, Parada \& Chai, 2011; Kitisin et al., 2007). Specific receptor associated SMADs (R-SMADs), Mothers against decapentaplegic homolog 2 (SMAD2) and SMAD3 are phosphorylated by T $\beta$ I (Iwata, Parada \& Chai, 2011; Attisano \& Wrana, 2002). The phosphorylated R-SMADs are then dissociated from this complex and associated with the co-mediator SMAD (co-SMAD) SMAD4 resulting in nuclear translocation and either gene activation or repression (Iwata, Parada \& Chai, 2011; Massague \& Chen, 2000). Meanwhile, the induction of inhibitory SMAD proteins either SMAD6 or SMAD7 creates an autoregulatory feedback loop that prohibits the activation of receptor activated SMADs (Schuster \& Krieglstein, 2002; Massague, 2000).

\subsubsection{SMAD-independent TGF- $\beta$ signaling pathway}

TGF- $\beta$ is capable of activating non-SMAD signaling pathways, specifically GTPases, phosphatidylinositol 3-kinase and MAPK pathways, which include P38, Jun N-terminal kinase (JNK), and extracellular signal-regulated kinases (ERK) (Mu, Gudey \& Landstrom, 2012; Kang, 
Liu \& Derynck, 2009; Zhang, 2009). The process of SMAD-independent TGF- $\beta$ signaling pathway is still ambiguous and how it functions is still unknown. The balance between both signaling pathways is crucial in defining cellular specific response to TGF- $\beta$ signal (Iwata, Parada \& Chai, 2011).

\subsection{Mouse craniofacial phenotypes and deletion of TGF- $\beta$ signaling genes}

\subsubsection{TGF- $\quad$ 1 null (TGF- $\beta 1^{-/-}$) mice}

The expression of TGF- $\beta 1$ during palatal fusion is strongly elevated in the MEE prior to the adhesion of opposing palatal shelves (Fitzpatrick, Denhez, Kondaiah \& Akhurst, 1990). After adhesion, TGF- $\beta 1$ epithelial expression ceases and is expressed in mesenchymal cells only (Iwata, Parada \& Chai, 2011; Li, Yang, Luo, Dedhar \& Liu, 2007). Around 60\% TGF- $\beta 1$ null mutant mice die in utero while $40 \%$ survive to term, they develop normally in the first two weeks of life and die by the fourth week due to rapid wasting syndrome, all the mice develop a multifocal inflammatory disease in most of the tissues (Kulkarni et al., 1995). Heterozygous TGF- $\beta 1$ null mice are normal developmentally.

\subsubsection{TGF- $\beta 2$ null (TGF- $\beta 2^{-/-}$) mice}

The expression of TGF- $\beta 2$ is mainly localized to palatal mesenchyme during palatal adhesion (Iwata, Parada \& Chai, 2011). TGF- $\beta 2$ null mutant mice die prenatally and develop multiple developmental defects (Sanford et al., 1997). Heterozygous TGF- $\beta 2$ null mice are normal developmentally. 


\subsubsection{TGF- $\beta 3$ null (TGF- $\beta 3^{---}$) mice}

The expression of transforming growth factor beta 3 (TGF- $\beta 3$ ) is strongly expressed in MEE cells prior to adhesion of the palatal shelves and continues throughout the palatal fusion process (Yang \& Kaartinen, 2007; Martinez-Sanz et al., 2008). TGF- $\beta 3$ is an essential player in both cell degradation and palatal adhesion (Kaartinen et al., 1995). TGF- $\beta 3$ knockout mice are born with a cleft in the secondary palate caused by a defect in the degeneration of the medial edge epithelial cells and the process of palatal fusion (Taya, O'Kane \& Ferguson, 1999; Kaartinen et al., 1995). Lack of TGF- $\beta 3$ function in null mutant mice leads to loss of surface filopodia (Taya,

O'Kane \& Ferguson, 1999). The loss of TGF- $\beta 3$ signal was rescued by an overexpression of SMAD2 (Cui et al., 2005). Heterozygous TGF- $\beta 3$ null mice are normal developmentally.

\subsubsection{T TRI, T $\beta R I I$ and T $\beta R I I$ null mice.}

T $\beta$ RI null mutant mice die early during embryonic development due to a defect in vascular development of the yolk sac and also the placenta, and absence of red blood cells (Larsson et al., 2001). Heterozygous T $\beta$ RI null mice are normal developmentally.

T $\beta$ RII null mutant mice have a lethal defect in both vasculogenesis and yolk sac hematopoiesis leading to early embryonic death (Oshima, Oshima \& Taketo, 1996). Heterozygous T $\beta$ RII null mice are normal developmentally.

Mutagenic T $\beta$ RIII null mice die at an early embryonic stage before birth due to a proliferative defect in heart and also an increased cell death in the liver (Stenvers et al., 2003). Heterozygous T $\beta$ RIII null mice are normal developmentally. 


\subsubsection{SMAD2 null mice}

Research has revealed an important biological role of SMAD2 in regulating embryogenesis, SMAD2 null mutant mouse embryos failed to form an organized egg cylinder and also lacked mesoderm (Nomura \& Li, 1998; Waldrip, Bikoff, Hoodless, Wrana \& Robertson, 1998; Weinstein et al., 1998). Almost one fifth (20\%) of Heterozygous SMAD2 knockout mice develop gastrulation defects and also lack mandible or eyes (Nomura \& Li, 1998).

\subsubsection{SMAD3 and SMAD4 null mice}

SMAD3 null mutant mice die afterbirth at age one month to eight months due to a primary defect in immune functions (Yang et al., 1999). Heterozygous SMAD3 null mice are normal developmentally.

SMAD4 null mutant mice die early during embryonic development between embryonic day E6.5 and E8.5 and they are all developmentally delayed at E6. They show little or no elongation in the extraembryonic portion of late egg cylinder stage embryos (Yang, Li, Xu \& Deng, 1998). Heterozygous SMAD4 null mice are normal developmentally. 


\subsection{Experimental mammalian models: mice in the study of cleft lip and palate}

Numerous animal species have been used to study human development. Several mammals mimic the same developmental process as humans. Mice models in particular have been used extensively in deciphering those biological processes. The benefit of studying mice in particular to understand CL and CP comes from anatomical and molecular similarities in palatal development and the fact that mice are susceptible to similar genetic modifications and manipulations. In fact, mice and humans share almost $99 \%$ of their genes (Gritli-Linde, 2008). Different studies have used mice to study normal and abnormal palatal development which have revealed key molecules and complex regulatory pathways regulating each step of the lip and palate development.

Development of the secondary palate in mice happens in concurrence with the growth and development of other craniofacial structures (Gritli-Linde, 2007; 2008). Mouse models can be used to determine if clefting is secondary to altered growth of the lip, failure of reorientation of the palatal shelves or abnormal fusion leading to persistent midline epithelium seam. Human genetic studies have succeeded to some extent to identify key genes involved in syndromic orofacial clefts, however the understanding of non-syndromic orofacial clefts remains unclear due to the complex etiology (Gritli-Linde, 2008). 


\subsubsection{Experimental mammalian models: K14-SMAD2 mouse phenotype}

Cytokeratin 14 (K14) is expressed in mammalian epithelial cells. K14 promoter- driven SMAD2 overexpression in transgenic mice has been shown to result in several phenotypic characteristics in mice: half the size of their litter mates until adulthood, short tail, failure of development of the rudiment of external ear, the paws skin was thick, flaky with a tight surface, hair development disturbances, and hyper-keratinized ventral skin surface (Ito et al., 2001).

The K14-SMAD2 overexpression was found to rescue clefting of the secondary palate in the TGF- $\beta 3$ knockout mice (Cui et al., 2005). The mechanism of palatal fusion in the K14-SMAD2 overexpressed TGF- $\beta 3$ knockout mice and the fate of the MEE was not fully investigated. The K14-SMAD2 overexpression played a significant role in the fate of MEE and restoring the SMAD2 signal pathway was enough to restore the fusion of the secondary palate (Cui et al., 2005).

\subsubsection{TGF- $\beta 3^{(--)}$and K14-SMAD2/TGF- $\beta 3^{(--)}$mice phenotype \\ TGF- $\beta 3^{(+/-)}$heterozygous mice were bred to generate TGF- $\beta 3^{(--)}$homozygous knockout} newborns. All homozygous newborn mice TGF- $\beta 3^{(--)}$showed grossly abnormal development of the airways and terminal air spaces, resulting in a primitive lung with decreased alveolarization at birth and cleft palate (Kaartinen et al., 1995).

Research did not reveal any skeletal abnormalities in the newborn except those pertaining to the palatal bones. All homozygous newborn mice TGF- $\beta 3^{(--)}$suffered from clefting of the secondary palate (Kaartinen et al., 1995; Proetzel et al., 1995). The severity of the clefting varied among mice genetic background (Kaartinen et al., 1995; Proetzel et al., 1995; Koo, Cunningham, Arabshahi, Gruss \& Grant, 2001). The phenotype was most severe in the C57BL/6 mouse line background (Cui et al., 2005). In 50\% of the homozygotes, the palatal cleft extended into the most 
anterior palate, while in the remaining homozygotes the anterior segment was fused (Kaartinen et al., 1995). Serial coronal sections of the palate during the course of palatal fusion showed that vertical growth and elevation of the palatal shelves was normal (Kaartinen et al., 1995). TGF- $\beta 3^{(-}$ ${ }^{1-)}$ newborns die within the first day as they cannot suckle (Kaartinen et al., 1995; Proetzel et al., 1995).

TGF- $\beta 3^{(+-)}$heterozygous mice were mated with K14-SMAD2 mice in order to generate K14-SMAD2/TGF- $\beta 3^{(+-)}$line, and then cross mated to produce K14-SMAD2/TGF- $\beta 3^{(--)}$ newborns (Cui et al., 2005). All K14-SMAD2/TGF- $\beta 3^{(--)}$newborn showed fusion of the secondary palate with mesenchymal confluence with no persistent MES (Cui et al., 2005). Fusion extended through the secondary palate and anterior portion of the soft palate in 50\% of the K14SMAD2/TGF- $\beta 3^{(--)}$(Cui et al., 2005). Clefting was still present between the primary and secondary palate (Cui et al., 2005). The palatal fusion score was correlated with levels of phosphorylated-SMAD2 (P-SMAD2), the higher the fusion score the higher the P-SMAD2 levels which indicate that the rescue of the palatal fusion is attributed to the increase in P-SMAD2 levels (Cui et al., 2005). To conclude, all these results suggests that TGF- $\beta 3$ is necessary for initiating and continuing the phosphorylation of SMAD2 in the palatal MEE that was required to induce gene expression mandatory to complete the fusion. The activation and amount of SMAD2 in the absence of TGF- $\beta 3$ proves to be a key player in determining the fate of MEE cells. 


\section{Chapter 2: Medial edge epithelium}

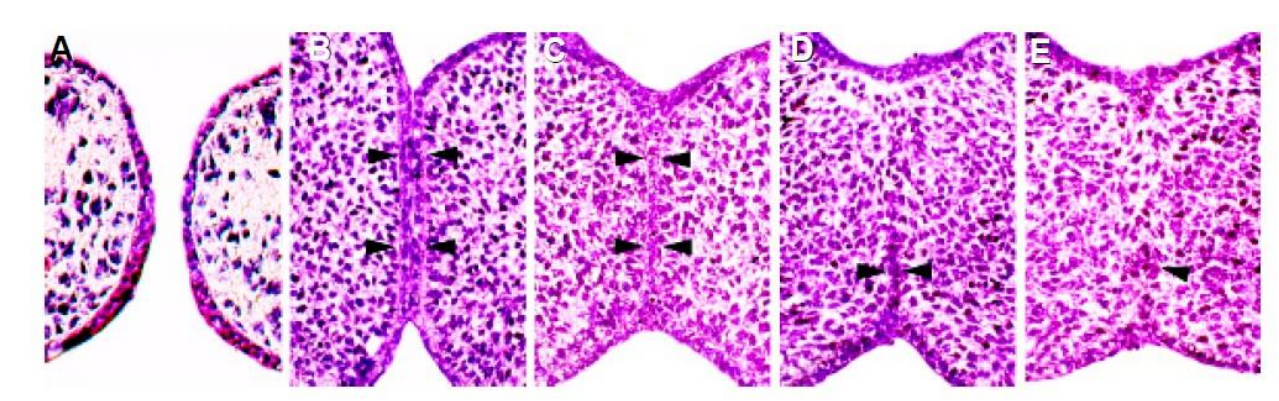

Figure 5 Coronal section of mouse fetus

Process of MEE disappearance in palatal shelves to reach mesenchymal confluence (B-E).

\subsection{Fate of medial edge epithelium}

Throughout the course of palatal development, medial edge epithelium (MEE) disappearance is one of the crucial steps in the process of palatal fusion (Figure 5). However, the fate of these cells is still debated and controversies still remain on this issue. The cellular mechanism behind the disintegration of the midline epithelial seam have been under great focus for decades. No conclusive evidence provides a firm conclusion on the fate of the MEE cells (Iseki, 2011). Different results from research done on both in vitro and in vivo on the fate of MEE suggests that MEE cells select their fate based on the environmental condition (Gurley, Wamsley \& Sandell, 2004). Researchers have proposed three different theories regulating the fate of medial edge epithelium 1) apoptosis, 2) epithelial-mesenchymal transdifferentiation (EMT) and 3) migration (Table 1). 


\subsubsection{Apoptosis (programed cell death)}

Apoptosis was one of the first theories to describe the mechanism regulating MEE cells disappearance. It was based on ultrastructural observation that includes, presence of lysosomes, autophagic vacuoles, macrophages and dense bodies (Farbman, 1968; DeAngelis \& Nalbandian, 1968; Hayward, 1969; Shapiro \& Sweney, 1969; (Shah, Schuing, Benkhaial, Young, \& Burdett, 1991). Later, Martinez-Alvarez et al., (2000), showed in their study the presence of macrophages and phagocytosis of dead cells near the MES and concluded that MEE cells during palatal fusion undergo programmed cell death.

Cuervo \& Covarrubias (2004), used a technique to label MEE cells genetically with an adenovirus that carried a LacZ gene, indicated that apoptosis is the main process for MES disintegration. They also noted that only the periderm cells migrate orally or nasally forming the triangles and this process is crucial for the upcoming MEE cell apoptosis (Cuervo \& Covarrubias, 2004). Furthermore, Cuervo \& Covarrubias (2004) used another labeling technique with carboxydichlorofluorescein diacetate succinimidyl ester (CCFSE), similar to (Griffith \& Hay, 1992) and also concluded that apoptosis is the fate of MEE during palatal fusion. Cuervo \& Covarrubias (2004) argued that there was lack of follow up in previous studies to confirm whether the transforming cells containing the dye were dying cells or were phagocytes containing the dying cells (Cuervo \& Covarrubias, 2004).

Vaziri Sani et al., (2005) utilized conditional knockout mice k14-cre/R26R in order to trace the MEE cells in vivo, and found no labeled cells in the palate mesenchyme. Also, Xu et al., (2006) utilized the same technique and did not find any labeled cells in the palate mesenchyme. Both studies concluded that MEE cells undergo programmed cell death with no evidence of EMT (Vaziri Sani et al., 2005; Xu et al., 2006). Dudas \& others (2006), also emphasized the important 
role of apoptosis during palatal fusion when they added TGF- $\beta 3$ beads to the TGF- $\beta 3^{(-/-)}$MES and demonstrated the occurrence of apoptosis rather than EMT (Dudas et al., 2006).

\subsubsection{Epithelial-mesenchymal transdifferentiation}

Epithelial-mesenchymal transdifferentiation (EMT) is a process allowing an epithelial cell attached to basement membrane to undergo multiple changes enabling it to assume a mesenchymal cell phenotype. Those phenotypes include, enhanced migratory capacity, invasiveness, resistance to apoptosis, and increased production of extracellular matrix (ECM) components. The climax of an EMT process is signaled by the degradation of underlying basement membrane and the formation of a mesenchymal cell that can migrate away from its originating epithelial layer (Kalluri \& Neilson, 2003). The process of EMT plays a fundamental role in wound healing, development and in stem cells (Lamouille, Xu \& Derynck, 2014).

Epithelial and mesenchymal cells differ in functional and phenotypic characteristics. The epithelial layer is composed of cells that are tightly adjoined together by specialized intercellular junctions including tight junctions, adherens junctions, gap junctions and desmosomes (Alberts, Wilson \& Hunt, 2008). Epithelial cells have an apico-basolateral polarization that can be displayed through the distribution of adhesion molecules; cadherins and integrins, the polarized organization of the actin cytoskeleton, the presence of cell-cell junction in lateral belt form and the presence of basal lamina at the basal surface (Thiery \& Sleeman, 2006). On the contrary, forming an organized cell layer is not a characteristic of mesenchymal cells. They don't have the same apical-basolateral organization as epithelial cells, they are not associated with a basal lamina and they contact adjacent mesenchymal cells focally (Thiery \& Sleeman, 2006). 


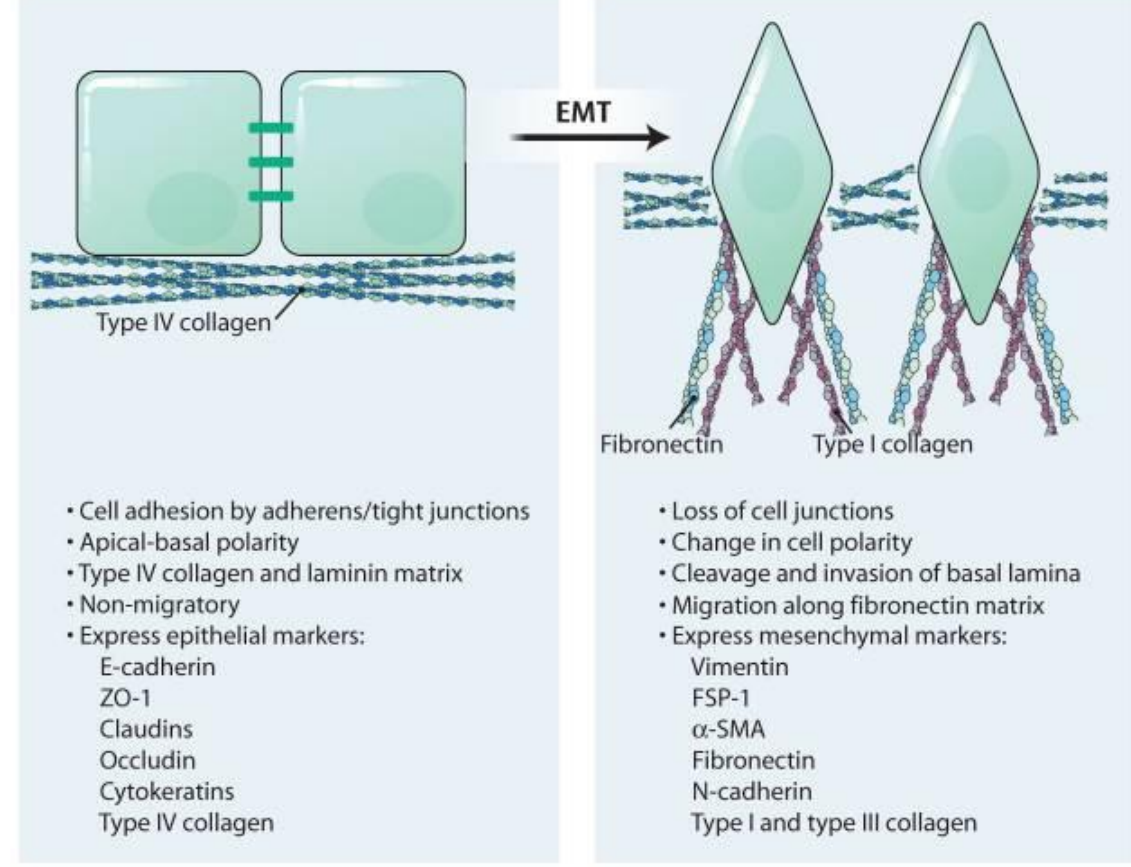

Figure 6 Cellular changes associated with EMT

Epithelial cells demonstrate apical-basal polarity, show strong cell-cell adhesion through adherens junctions and tight junctions, and have a basal matrix consisting primarily of type IV collagen and laminin. Upon induction of EMT, the cells lose their adhesion and change morphology and acquire front end-to-back end polarity (Gonzalez \& Medici, 2014).

Definitive evidence of transformation of the MES cells into mesenchymal cells has been found during examination of palatal fusion in rat embryos utilizing ultra-structural studies and transmission electron microscope (TEM) (Fitchett \& Hay, 1989). The MES before transformation activates vimentin, an intermediate filament expressed by mesenchymal cells (Hay, 1990) and decreases Syndecan, an epithelial determinant, (Fitchett \& Hay, 1989).

Cell linage studies tracing MES cells incorporating dyes was utilized to trace the fate of the MES cells (Shuler, Halpern, Guo \& Sank, 1992; Shuler, Guo, Majumder \& Luo, 1991). By using Dil (1,1'-Dioctadecyl-3,3,3',3'-Tetramethylindocarbocyanine Perchlorate), a florescent dye 
to trace the cell linage, Shuler showed that EMT occurs during MES disappearance and confirmed the ultrastructural findings (Shuler, Halpern, Guo \& Sank, 1992; Shuler, Guo, Majumder \& Luo, 1991). This approach utilizing Dil dye was first used by Serbedzija and colleagues to trace neural crest cells undergoing EMT (Serbedzija, Bronner-Fraser \& Fraser, 1992; Serbedzija, Burgan, Fraser \& Bronner-Fraser, 1991; Serbedzija, Bronner-Fraser \& Fraser, 1989) and was adopted in both the in vitro and in vivo models to determine the fate of the MEE cells during palatal fusion (Shuler, Halpern, Guo \& Sank, 1992; Shuler, Guo, Majumder \& Luo, 1991). Griffith \& Hay, 1992, used another dye to trace MEE transformation during palatal fusion, (CCFSE) which is localized only in the epithelial cells and does not transport into the connective tissue (Griffith \& Hay, 1992). Their findings (Griffith \& Hay, 1992) concur with the findings of Shuler and colleagues (1991, 1992). The concept of EMT during palatal fusion was also supported by the findings of (Kaartinen, Cui, Heisterkamp, Groffen \& Shuler, 1997; Kaartinen et al., 1995) emphasizing the role of TGF$\beta 3$ during MES EMT.

Contrary to Vaziri Sani et al., (2005) and Xu et al., (2006) results, another study was done utilizing the same technique and found labeled epithelial cells present in the palatal mesenchyme (Jin \& Ding, 2006). Although all the studies have used different k14-cre transgenic mice lines, the discrepancy in the result could be due to differences in the time of k14 promoter transgene activation or due to different insertion sites of each k14 promoter transgene (Iseki, 2011). Also Jin \& Ding, (2006) in their study examined the programed cell death fate of MEE cells in the apoptotic protease activating factor 1 (Apaf-1) deficient mice where they lack Caspase 9 and 3 (caspase effectors), and showed that although Caspase 9 and 3 where not activated palatal fusion was normal. 
Opposed to Martinez-Alvarez et al., (2000) findings, Fitchett \& Hay, (1989), observed those phagocytic cells previously discovered and concluded that they were restricted to the midpalatal raphe and posterior palate and are involved in the removal of the peridermal cells caught in the MES. Griffith \& Hay (1992), stained the palate with Gomori stain for acid phosphatase, an enzyme marker for lysosomes, and found that the isolation bodies were not lysosomes.

\subsubsection{Cell migration}

The concept of cell migration was first observed by Carette and Ferguson in 1992, they proposed that medial edge epithelial might migrate to the oral or nasal epithelia during the process of palatal fusion (Carette \& Ferguson, 1992). They used a Dil labeling technique to label the MEE cells and trace them during the process of palatal fusion in organ culture. Their finding revealed that MEE cells migrate nasally or orally forming the nasal and oral triangles on both sides of the palate, and eventually become part of the oral and nasal epithelia. Cell culture studies have demonstrated that MES cells migrate by suppressing E-cadherin, which facilitates cell to cell adhesion and expressing vimentin, fibronectin and $\alpha$-smooth muscle actin in response to TGF- $\beta 3$ (Ahmed et al., 2007).

Jin \& Ding, 2006, utilized a different organ culture method where a Rosa26-originated "blue" palatal shelf was paired with a C57BL/6-derived "white" palatal shelf. In their study they observed the migration of MEE cells to the nasal side only. they also observed an anteroposterior migration of MEE cells, which could have a role in posterior palate fusion. Several studies have shown that peridermal cells that cover the MEE migrate to the edges of the palatal midline prior 
to contact of the palatal shelves and their presence initially is necessary for the first contact between the two shelves (Dudas, Li, Kim, Yang \& Kaartinen, 2007).

To conclude, most studies have emphasized on the fate of the periderm cells indicating that they either die early prior to fusion or migrate toward the nasal or the oral epithelia. Furthermore, current research indicated that migration is one of the fates of MEE during palatal fusion but not the only one.

\subsection{The role of twist1 and collagen IV during palatal development}

The process of EMT is controlled by multiple signaling molecules including growth factor, transcription factors and extracellular matrix activator (Thiery \& Sleeman, 2006). One of the hallmarks of EMT in both development and tumorigenesis is the suppression of epithelial cadherin (E-Cadherin) (Yu, Kamara, \& Svoboda, 2008). The suppression of E-cadherin is associated with loss of intercellular epithelial junctional complexes (Yu, Kamara, \& Svoboda, 2008). E-cadherin is supressed by several EMT transcription factors including Twist1, Snail1 and Snail2 (Slug) (Batlle et al., 2000; Yu, Kamara, \& Svoboda, 2008).

Twist1 protein, a basic-helix-loop-helix (bHLH) transcription factor, is expressed in the palatal shelves in both the MEE cells prior to fusion and mesenchymal cells (Yu, Kamara, \& Svoboda, 2008; Kitase, Yamashiro, Fu, Richman, \& Shuler, 2011). This was also confirmed in organ culture, the expression of Twist 1 was upregulated in chicken palatal shelves treated with TGF- $\beta 3$ and decreased in mouse palatal shelves treated with TGF- $\beta 3$ neutralizing antibodies (Yu, Kamara, \& Svoboda, 2008). The addition of Twist1 siRNA to cultured palatal shelves downregulated Twist1 expression and prevented fusion (Yu, Kamara, \& Svoboda, 2008). 
Twist1 plays a pivotal role in the process of EMT in embryonic development and tumor progression. Twist 1 is essential for the development of mice mesenchyme (Zhu, Ma, Wang, Song, \& Lv, 2016). Twist1 plays a key role in migratin and localizatin during the morphogenisis of cranial neural tube (Soo et al., 2002). Twist1 was also linked to tumor progression and metastasis (Yang et al., 2004). In mammary cell carcinoma, Twist1 levels were correlated with tumor metastasis and invasion (Yang et al., 2004). The Twist1 null mutant mice Twist $1^{(--)}$die early during embryonic development at day E11.5 with failure of neural tube closure (Bourgeois et al., 1998). Heterozygous mice Twist $1^{(+-)}$are born with a craniofacial abnormality similar to SaethreChotzen syndrome in the human (Bourgeois et al., 1998).

The basement membrane (BM) is composed of a network of proteins that include collagens, fibronectins and laminin (McClay \& Ettensohn, 1987). In the palatal shelves, the BM separate the MEE from the surrounding mesenchyme. In epithelial tissues, the basement membrane is mainly composed of Laminin, type IV collagen, and fibronectin (Iamaroon \& Diewert, 1996). Type IV collagen is a member of the collagen superfamily and consist of six distinct $\alpha$-chains (Khoshnoodi, Pedchenko, \& Hudson, 2008). Degradation of the basement membrane is one of the hallmarks of EMT. Epithelial cells cultured on fibrillary collagen type I and type III undergo EMT, acquire motile capability and become invasive (Menke et al., 2001). When the same cells are cultured on collagen type IV (ColIV) and laminin they maintain their epithelial phenotype (Menke et al., 2001). TGF- $\beta 3^{(--)}$mice with cleft of the secondary palate retained their MEE cells basement membrane and when TGF- $\beta 3$ was added to the culture medium it resulted in the loss of the basement membrane and coincided with fusion of the palatal shelves (Kaartinen, Cui, Heisterkamp, Groffen, \& Shuler, 1997). Previous studies have suggested a correlation between loss of ColIV in the MES basement membrane and the ability of MEE cells 
to undergo EMT through the expression of twist1 (Kitase, Yamashiro, Fu, Richman, \& Shuler, 2011).

To sum up, the loss of BM is considered an important step toward EMT. The selective loss of ColIV in the BM and the presence of the mesenchymal marker twist1 in the MEE cells provides evidence for EMT. 
Table 1: Fate of medial edge epithelium (MEE) in literature

\begin{tabular}{|c|c|c|c|}
\hline References & Study type & Fate & Methods \\
\hline $\begin{array}{l}\text { DeAngelis \& Nalbandian (1968), } \\
\text { Farbman (1968),Hayward (1969), } \\
\text { Shapiro \& Sweney (1969) }\end{array}$ & In vivo & Cell death & $\begin{array}{l}\text { Histology } \\
\text { Electron microscopy }\end{array}$ \\
\hline Fitchett \& Hay (1989) & $\begin{array}{l}\text { In vivo } \\
\text { In vitro }\end{array}$ & $\begin{array}{l}\text { EMT, cell death in the } \\
\text { periderm }\end{array}$ & $\begin{array}{l}\text { Electron microscopy } \\
\text { Immunohistochemistry }\end{array}$ \\
\hline Griffith \& Hay (1992) & $\begin{array}{l}\text { In vivo } \\
\text { In vitro }\end{array}$ & EMT & Fluorescent labelling (CCFSE) \\
\hline Shuler et al. $(1991,1992)$ & $\begin{array}{l}\text { In vivo } \\
\text { In vitro }\end{array}$ & EMT & Fluorescent labelling (Dil) \\
\hline Carette \& Ferguson (1992) & In vitro & Migration & Fluorescent labelling (Dil) \\
\hline Kaartinen et al. (1997) & In vitro & EMT & Fluorescent labelling (Dil) \\
\hline Martínez-Álvarez et al. (2000) & In vitro & $\begin{array}{l}\text { Cell death, EMT, } \\
\text { migration was not } \\
\text { excluded }\end{array}$ & $\begin{array}{l}\text { TUNEL staining Retroviral vector } \\
\text { labelling }\end{array}$ \\
\hline Cuervo \& Covarrubias (2004) & In vitro & $\begin{array}{l}\text { Cell death, a few EMT, } \\
\text { migration of periderm } \\
\text { cells }\end{array}$ & $\begin{array}{c}\text { Fluorescent labelling (CCFSE) } \\
\text { Adenoviral vector infection } \\
\text { Cytochalasin D TUNEL staining }\end{array}$ \\
\hline Takigawa \& Shiota (2004) & In vitro & $\begin{array}{l}\text { Cell death, EMT, } \\
\text { migration, migration and } \\
\text { cell death (periderm) }\end{array}$ & $\begin{array}{c}\text { Electron microscopy TUNEL } \\
\text { Immunohistochemistry }\end{array}$ \\
\hline Gurley et al. 2004 & In vitro & $\begin{array}{l}\text { Cell death, EMT, no } \\
\text { migration }\end{array}$ & $\begin{array}{c}\text { Fluorescent labelling (CCFSE) } \\
\text { TUNEL staining }\end{array}$ \\
\hline Jin \& Ding (2006) & $\begin{array}{l}\text { In vivo } \\
\text { In vitro }\end{array}$ & $\begin{array}{l}\text { Cell death, EMT, } \\
\text { migration }\end{array}$ & $K 14$-cre; R26R mouse \\
\hline $\begin{array}{l}\text { Vaziri Sani et al. (2005) Xu et al. } \\
(2006)\end{array}$ & In vivo & Cell death & K14-cre; R26R mouse \\
\hline
\end{tabular}




\subsection{How cells die: apoptosis, autophagy and necrosis}

\subsubsection{Cell death}

During the course of development, cell death plays a role in shaping organs or separating fingers and toes. It also serves a role in eliminating structures that had a function and are no longer needed. The total elimination of the tadpole tail during amphibian metamorphosis is an example. By the end of metamorphosis, all the tissues in the tail are removed by apoptosis (Ishizuya-Oka, Hasebe \& Shi, 2009). Apoptosis is an evolutionarily conserved phenomenon essential for both development and tissue homeostasis in all multi-cellular organisms (Elmore, 2007).

Research has shown that cells can die by several mechanisms (Schulze-Osthoff, 2008). Current research has enumerated in mammals, as many as eleven different pathways of cell death (Kroemer et al., 2005, Melino, Knight \& Nicotera, 2005). According to morphological criteria, cell death can be distinguished in mammals into three distinct types; apoptosis (Type I cell death), autophagic cell death (Type II cell death) and necrosis (Type III cell death), Figure 7 (Alvarez et al., 2010). 


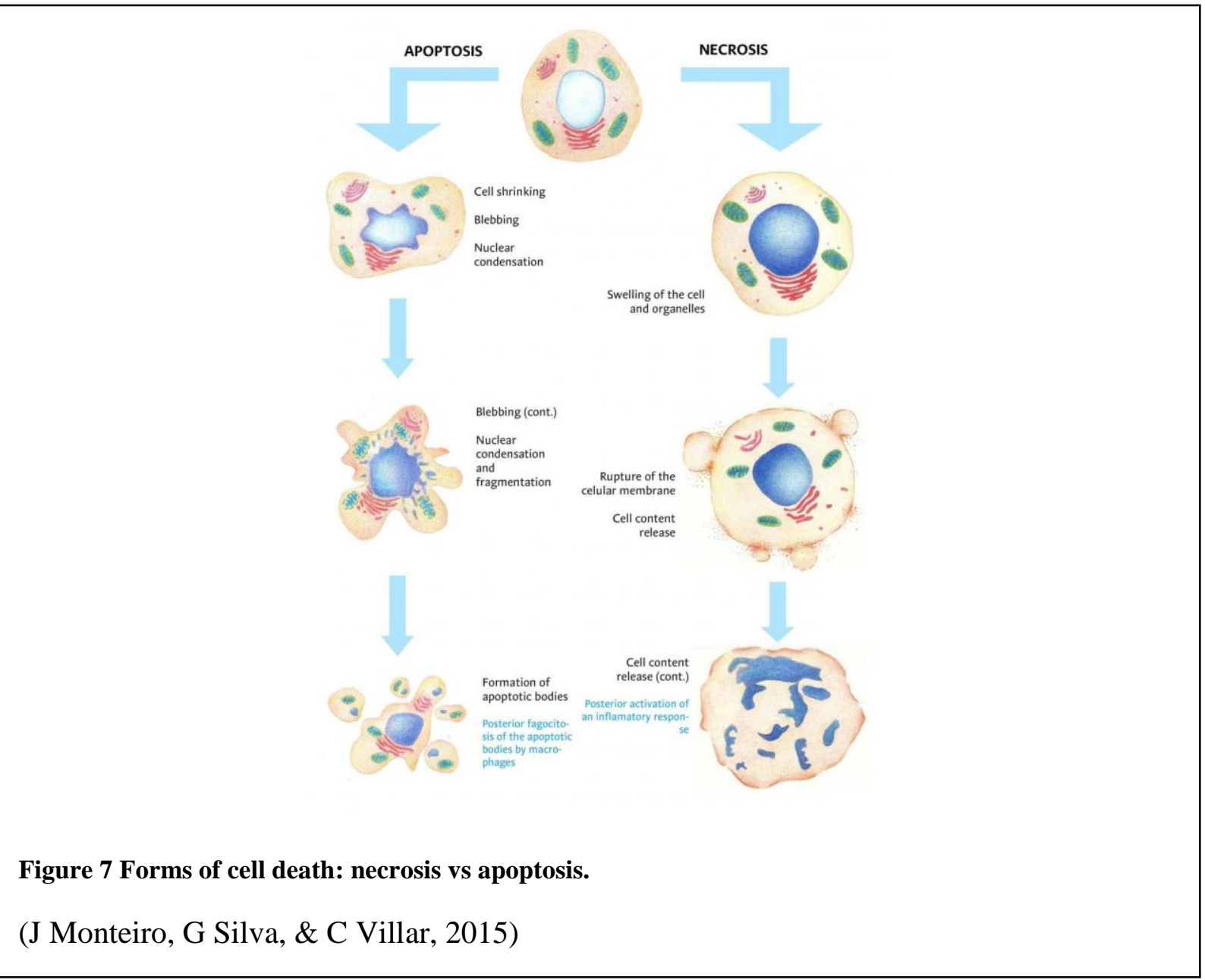

\subsubsection{Differences between mechanism of cell death.}

Many morphological and biochemical differences have been observed between apoptosis, autophagy and necrosis (Vermes \& Haanan, 1994). Cell necrosis occurs due to exposure to extreme physiological conditions; hypothermia and hypoxia; leading to damage in the plasma membrane. Necrosis is a nonspecific cell death that happens when the cell loses its ability to maintain homeostasis, causing rapid influx of extracellular ions $\mathrm{Na}^{+}$and $\mathrm{Ca}^{+}$and water (Barros et al., 2001; Barros, Hermosilla, \& Castro, 2001). This process causes the entire cell to swell including the intracellular organelles that then rupture, releasing the cytoplasmic content with the 
lysosomal enzymes into the extracellular fluid (Barros, Hermosilla, \& Castro, 2001). Necrotic cell death is associated with tissue damage and inflammatory response (Kroemer et al., 2005).

Apoptosis is a type of cell death that occurs in normal physiologic conditions with the cell participating in its own death (Schulze-Osthoff, 2008). Apoptosis occurs during tissue homeostasis, development of the nervous system and embryogenesis (Sgonc \& Gruber, 1998). It is characterized by special changes in the nuclear morphology, chromatin condensation and fragmentation, cell shrinkage, blebbing of the plasma membrane and formation of apoptotic bodies (Bowen, 1993; Carson \& Ribeiro, 1993; Cohen, 1993).

Phagocytosis is a process that was first detected 100 years ago by Metchnikoff (Flannagan, Jaumouille, \& Grinstein, 2012). It is defined as the process of large particle $(>0.5-\mu \mathrm{m})$ ingestion by cells (Flannagan, Jaumouille, \& Grinstein, 2012). This process is a crucial part of the immune system providing innate immunity and it is also crucial for tissue homeostasis and remodeling (Aderem, 2003). phagocytosis utilizes receptors on the cell surface to recognize foreign bodies and bind to them (Flannagan, Jaumouille, \& Grinstein, 2012).

\subsection{TGF- $\beta$ and apoptosis.}

The TGF- $\beta$ through its activated intracellular SMAD proteins has been linked to programmed cell death (apoptosis) in epithelial cells (Schuster \& Krieglstein, 2002). TGF- $\beta$ utilizes SMAD2 inside the cell by means of phosphorylation in order to carry the signal to the nucleus. This activation increases caspase activation specifically; the activation of caspase3, which cleaves proteins in many cell compartments leading to morphological changes of apoptosis (Wyllie, 2010). 
Among other functions of TGF- $\beta$ is its ability to induce programmed cell death in a variety of cells. TGF- $\beta$ was found to induce apoptosis in human and mouse lymphocytes (Chaouchi et al., 1995). Brown and colleagues, (1998) found that a mouse lymphoma cell line responds to TGF- $\beta$ in a dose dependent manner. When TGF- $\beta$ is administrated cell growth is inhibited and with higher dosages of TGF- $\beta$ a large number of cells die by apoptosis (Brown et al., 1998). Further experiments done on the same lymphoma cell line found that interference with SMAD pathways, either overexpression of SMAD7 which inhibits SMAD signaling mediated by TGF- $\beta$ or mutation of SMAD2 and SMAD3, inhibited TGF- $\beta$ mediated apoptosis (Patil et al., 2000). TGF- $\beta$ also was found to induce apoptosis in liver epithelial cells. Liver epithelial cells in rats undergo programmed cell death when treated with TGF- $\beta$ (Teramoto et al., 1998). TGF- $\beta$ was found to induce growth arrest in fetal hepatocytes (Sanchez et al., 1995) and induce apoptosis (Sanchez et al., 1997). Also TGF- $\beta$ was shown to induce apoptosis in both non-tumorigenic rat prostate epithelial cells (Hsing et al., 1996) and prostatic carcinoma cells (LandstrÖm et al., 1996). Another study has revealed the involvement of SMAD proteins in this process and found an increased expression and activation of SMAD2 (Brodin et al., 1999). TGF- $\beta$ was found to be essential in regulating apoptosis in the central retina, the application of TGF- $\beta$ neutralizing antibodies decreased the number of apoptosis positive cells in the central retina (Dünker et al., 2001). Lee et al. (2002) studied the effect of TGF- $\beta$ on human lens epithelial cells in vitro and found that TGF- $\beta$ induced apoptosis through downregulation of B-cell lymphoma 2 (BCl2) (Lee et al., 2002). Moreover, TGF- $\beta$ was found to induce apoptosis in human gastric carcinoma cells and the process was found to be inhibited by SMAD3 knockdown (Kim et al., 2004). A recent study found that TGF- $\beta$ induced apoptosis in human gingival epithelium through a SMAD2 and caspase 9/3 cascade (Yoshimoto et al., 2015). 
Studies have reported a critical role of SMAD2 in TGF- $\beta$ induced apoptosis in a variety of cells and in tumors. In murine gingival junctional epithelium, SMAD2 overexpression in K14SMAD2 mice was found to induce apoptosis and the levels of apoptotic cells were correlated to levels of phosphorylated-SMAD2 (Fujita et al., 2012). TGF- $\beta$ through SMAD2 signaling was found to be involved in human brain glioma and current research showed that SMAD2 induced apoptosis by upregulating caspase 3 and downregulating BCL-2 (Zhao et al., 2015). Additionally, decreased levels of phosphorylated-SMAD2 was correlated to cancer invasion and poor prognosis in gastric cancer (Wu et al., 2012). In summary, evidence from in vitro and in vivo studies support the role of TGF- $\beta$ as a death inducing factor in epithelial cells. TGF- $\beta$ was found to induce apoptosis through its SMAD signaling pathway. Most significantly, current studies have found a correlation between levels of phosphorylated-SMAD2 and programmed cell death in epithelial cells.

\subsection{Mechanism of apoptosis}

The mechanism of apoptosis is a cascade of multiple events (Cohen, 1997). There are two main pathways of apoptosis, extrinsic (death receptor pathway) and intrinsic (mitochondrial pathway) (Elmore, 2007). Caspases, major players in the event of programmed cell death, are categorized into initiators (caspase 2, 8, 9, and 10), executioners (caspase 3, 6, and 7) and inflammatory caspases (caspase 1, 4, and 5) (Hancock, 2010; Marks, Klingmüller \& MüllerDecker, 2009).

The extrinsic signaling pathway involves a receptor mediated interaction, the receptors are members of the tumor necrosis factor (TNF) superfamily (Elmore, 2007). The common ligand and corresponding death receptor include Fas ligand / Fas receptor (FasL/FasR) and TNF $\alpha /$ TNFR1 
(Elmore, 2007). Upon binding to the receptor, cytoplasmic adaptor proteins are recruited. Fas ligand bind to Fas receptor and causes adaptor protein FADD to bind, TNF ligand binds to TNF receptor and causes adaptor proteins TRADD, FADD and Rip to bind together (Hancock, 2010; Marks, Klingmüller \& Müller-Decker, 2009). Then, FADD associates with procaspase-8 and an auto-catalytic activation of procaspase- 8 occurs. Once caspase 8 is activated the executioner caspases have been activated (Elmore, 2007).

The intrinsic pathway involves no receptor mediated stimuli, mitochondrial initiated events occur (Elmore, 2007). Stimuli include, absence of growth factors or cytokines or the presence of radiation, toxins, hypoxia or viral infections (Hancock, 2010; Marks, Klingmüller \& MüllerDecker, 2009). These stimuli alter the inner mitochondrial membrane and result in an opening of the transition pores (Saelens et al., 2004). This releases pro-apoptotic proteins, mainly cytochrome c, Smac/DIABLO and serine protease HtrA2/Omi from the intermembrane space into the cytosol (Hancock, 2010; Marks, Klingmüller \& Müller-Decker, 2009). These proteins are involved in the activation of the mitochondrial pathway, cytochrome c binds to Apaf-1 and procaspase-9. This leads to the activation of caspase 9 (Elmore, 2007). Caspase-9 then binds to and activates procaspase-3, procaspase-6 and procaspase-7 as well (Budihardjo, Oliver, Lutter, Luo, \& Wang, 1999). After that caspase-3, an executioner caspase, causes activation of the endonuclease caspaseactivated DNase (CAD), which is responsible for the apoptotic DNA fragmentation, and chromatin degradation (Sakahira, Enari, \& Nagata, 1998).

In conclusion, both the intrinsic and extrinsic pathways will lead eventually to the activation of the executioner caspases. The presence of activated caspase- 3 in a cell will indicate that it is undergoing programmed cell death. 


\subsection{Apoptosis detection methods}

Apoptosis is a major player in multiple cellular events (Sgonc \& Gruber, 1998). Cell death that occurs during embryonic development, metamorphosis and endocrine tissue atrophy (Nagata, 1997). Apoptosis can occur in pathological conditions including cardiovascular and neurodegenerative diseases (Wang, 1997). Apoptosis targets individual cells instead of all the cells in a specific tissue (Carson \& Ribeiro, 1993). In contrast, necrosis is a massive synchronized loss of cells from tissues (Wang, 1997). Once apoptosis is initiated the cascade proceeds quickly and cell death happens within hours (Nagata, 1997; Carson \& Ribeiro, 1993).

Programmed cell death, apoptosis, is a process that involves a sequence of events from cell shrinkage, increased density of the cytoplasm, chromatin condensation, DNA fragmentation, degradation of nuclear proteins, formation of apoptotic bodies and finally phagocytosis by neighboring cells and macrophages (Bowen, 1993; Carson \& Ribeiro, 1993; Cohen, 1993). The analysis of apoptosis depends on those characteristics and is very important in various clinical and basic investigations (Sgonc \& Gruber, 1998). Several methods have been utilized in order to differentiate between necrotic, apoptotic and viable cells (Elmore, 2007; Sgonc \& Gruber, 1998).

\subsubsection{TUNEL technique}

A common method to detect apoptosis is based on DNA fragmentation. Terminal deoxynucleotidyl transferase (Tdt) mediated dUTP nick-end labeling (TUNEL) detects DNA fragments by labeling the ends. The method was developed by Gavrieli to study apoptosis on different types of cells (Gavrieli, Sherman, \& Ben-Sasson, 1992). This method uses terminal transferase to add a labeled UTP to the 3'-hydroxyl ends of DNA fragments. The labeled dUTP 
can be detected by fluorescence microscopy (Sgonc \& Gruber, 1998). The advantages of this technique is the ability to detect initial DNA fragmentation in cells undergoing apoptosis, the high sensitivity, and the ability to detect a single cell using fluorescence microscopy. This method requires careful controls because it is prone to false positive either are possible from necrotic cells or cells undergoing DNA repair (Elmore, 2007).

\subsubsection{Immunohistochemistry detection of apoptosis related caspase-3}

Immunohistochemical detection of apoptotic cells using antibodies against a variety of apoptotic markers, specifically caspase-3 is a productive approach (Archana, Yogesh, \& Kumaraswamy, 2013). Caspase-3 is a cysteine protease that cleaves target proteins at aspartic acid residues. Caspase-3 is an executioner enzyme and it is responsible for the proteolytic cleavage of many important proteins (Sakahira, Enari, \& Nagata, 1998). Caspase-3 is considered the main player in the cascade of apoptosis. Cleavage of caspase- 3 at the P1 position activates caspase- 3 and is involved in the activation of other caspases (Elmore, 2007). This enzymatic activation of caspase-3 generates neo-epitopes which are used as antigens to generate antibodies specific to immunodetect activated caspase-3. The detection of cleaved caspase-3 (Ccaspase-3) is a direct and very sensitive method to detect apoptosis (Archana, Yogesh, \& Kumaraswamy, 2013). 


\subsection{Hypothesis}

Smad2 overexpression rescues cleft palate in the TGF-ß3 null mutant mice by increased apoptosis of MEE.

\subsection{Aims and objectives}

Aim:

To identify the mechanism of MEE disappearance as a result of K14-SMAD2 overexpression in the TGF- $\beta 3$ null mutant mice.

Objective 1 To investigate in vivo the effect of Smad2 overexpression in MEE cells on the mechanism of fusion of palatal shelves for K14-Smad2 mice and K14-Smad2/TGF$\beta 3$ null mice by detecting basement membrane loss and Twist1 positive cells.

Objective 2 To detect and quantify the medial edge epithelial cell apoptosis rate that results from Smad2 overexpression by detecting Cleaved caspase 3 positive cells and TUNEL positive cells in K14-Smad2 mice and K14-Smad2/TGF- $\beta 3$ null mice and compare them with WT and TGF- $\beta 3$ null mutant mice. 


\section{Chapter 3: Materials and methods}

\subsection{Animal breeding}

We thank Dr. Yang Chai for providing the K14-SMAD2 mice (Ito et al., 2001). Methods within this study followed the guidelines of the Animal Care Committee of the University of British Columbia. To identify the K14-Smad2 transgene a polymerase chain reaction (PCR) primer set was used to detect the cytokeratin 14 promoter region. To detect the TGF- $\beta 3$ knockout gene another PCR primer set was used to detect the mutated allele (discussed in detail in section 3.2). Mice heterozygous with respect to the TGF- $\beta 3^{(+/-)}$gene were mated to produce TGF- $\beta 3^{(--)}$null embryos, as well as TGF- $\beta 3^{(+/-)}$heterozygous and TGF- $\beta 3^{(+/+)}$homozygous embryos. TGF- $\beta 3^{(+/-)}$ heterozygous mice were then mated with K14-SMAD2 mice to generate a TGF- $\beta 3^{(+/-)} / \mathrm{K} 14-$ SMAD2 line, which was then cross mated to produce TGF- $\beta 3^{(--)} / \mathrm{K} 14-\mathrm{SMAD} 2$ newborns (rescue mouse line).

\subsection{Animal genotyping}

The day of finding a vaginal plug was designated day 0.5. Pregnant mice were killed on embryonic day (E14.5) and the fetuses were recovered. Fetuses were individually labelled and decapitated for further study and the bodies used for genotyping by polymerase chain reaction (PCR). DNA was isolated from the mouse embryo using REDExtract-N-Amp ${ }^{\text {TM }}$ Tissue PCR Kit (Sigma-Aldrich, St. Louis, MO, USA). Each mouse tissue sample was added to $56.25 \mu 1$ tissue extract solution $(45 \mu \mathrm{l}$ extraction solution mixed with $11.25 \mu$ l tissue prep solution) in a $1.5 \mathrm{ml}$ microtube. The sample was mixed thoroughly by vortexing and incubated for 10 minutes at room temperature. Next, the sample was incubated for 3 minutes at $95^{\circ} \mathrm{C}$. After that, $45 \mu 1$ neutralization 
solution B was added to the sample and mixed by vortixing. The sample tissue extract was stored at $4^{\circ} \mathrm{C}$. A $13 \mu \mathrm{l}$ master PCR mix was made by mixing: $4.36 \mu 1 \mathrm{H} 2 \mathrm{O}, 8 \mathrm{ul}$ REDExtract-N-Amp PCR reaction mix, $0.32 \mu \mathrm{l}(1: 100)$ forward primer and $0.32 \mu 1(1: 100)$ reverse primer in a $1.5 \mathrm{ml}$ microtube. Then, $2 \mu 1$ of the sample tissue extract was added to $13 \mu 1$ master PCR mix.

PCR analysis was carried out using two sets of primers, one for TGF- $\beta 3$ and one for K14SMAD2 (Table 2). First primer set for TGF- $\beta 3$ was forward sequence: $5^{\prime}$ TGGGA GTCAT GGCTG TAACT 3' and reverse sequences: 5' CACTC ACACT GGCAA GTAGT 3'. PCR products were a $400 \mathrm{bp}$ fragment for the wildtype TGF- $\beta 3$ allele and a 1,300 bp fragment for the mutated allele. PCR conditions were 31 cycles of $95^{\circ} \mathrm{C}$ for 20 seconds, $56^{\circ} \mathrm{C}$ for 25 seconds, $72^{\circ} \mathrm{C}$ for 1 minute, followed by a final cycle of $72^{\circ} \mathrm{C}$ for 10 minutes. Second Primer set was forward sequence: 5' ACACC TCCAA AGCAG GACCA AGTGG 3' and reverse sequences: 5'ATTTA CGCCT CTGTG ACCCA GGGCT TC 3'. PCR product size was 487 bp fragment for the K14SMAD2 allele. PCR conditions were 35 cycles of $94^{\circ} \mathrm{C}$ for $1 \mathrm{~min}, 62^{\circ} \mathrm{C}$ for $1 \mathrm{~min}, 72^{\circ} \mathrm{C}$ for $1 \mathrm{~min}$. PCR products were analyzed by gel electrophoresis using a SYBR® Green (Thermo Fisher Scientific, Waltham, USA) stained 2\% agarose gel (UltraPure ${ }^{\mathrm{TM}}$ Agarose, Fisher Scientific, Waltham, Massachusetts, USA). After the PCR cycles had finished, $15 \mu 1$ from each PCR mix were loaded to individual lanes on the agarose gel. The results were analyzed by visualizing the gel with UV light and a digital photograph is taken of the stained DNA separation pattern. Careful labelling of all samples enabled the genotype to be assigned to individual embryonic heads in various experimental conditions.

The total sample size was 40 mice divided in 4 groups, with 10 mice in each of the groups analyzed. G*power software (Heinrich-Heine-University, Düsseldorf, Germany) was used to calculate the sample size as it gave a power of 0.9 for all groups in each methodology. 
Table 2 : Primers used for mouse genotyping

Bold characters indicate forward sequence. Reverse sequences are placed underneath.

\begin{tabular}{|c|c|c|c|}
\hline Primer & Sequence $\left(5^{\prime}-3^{\prime}\right)$ & Product (bp) & Reference \\
\hline TGF- $\beta 3$ & $\begin{array}{l}\text { 5'TGGGAGTCATGGCTGTAACT 3' } \\
\text { 5' САСТСАСАСТGGCAAGTAGT 3' }\end{array}$ & $\begin{array}{c}\text { WT } 400 \mathrm{bp} \\
\text { Mutated } 1300 \mathrm{bp}\end{array}$ & Taya et. al, 1999 \\
\hline K14-SMAD2 & $\begin{array}{l}\text { 5'ACACCTCCAAAGCAGGACCAAGTGG 3' } \\
\text { 5'ATTTACGCCTCTGTGACCCAGGGCTTC 3' }\end{array}$ & $487 \mathrm{bp}$ & Ito et. al, 2001 \\
\hline
\end{tabular}

\subsection{Histology and immunohistochemistry}

Immunohistochemistry was used to identify the location and distribution of target antigens in MEE cells by staining with specific antibodies. ColIV (1:100, ab19808, Abcam), degradation of type IV collagen is a fundamental event in EMT. Twist1 (1:50, ab50887, Abcam) plays an important role in the EMT, Ccaspase3 (1:100, \#96645, Cell Signaling Technology, USA) a critical activator of apoptosis, Psmad2 (1:20, \#31012, Cell Signaling Technology, USA) a critical mediator of TGF- $\beta$ signaling were examined in palatal tissue. Ecadherin $(1: 100,3165622$, Transduction Laboratories) an epithelial cell marker, loss of E-cadherin is considered to be an important step in EMT. Histology and immunohistochemistry were conducted as follows:

\subsubsection{Fixation and paraffin embedding of the samples}

C57BL/6 mice heads were dissected on the indicated gestational day (E14.5). Samples were fixed in 4\% Paraformaldehyde (PFA)/Phosphate-buffered saline (PBS) with pH 7.4 at $4{ }^{\circ} \mathrm{C}$ on a shaker overnight (12 hours). Samples were then washed in PBS for 30 minutes twice at $4^{\circ} \mathrm{C}$ 
on a shaker. Samples were then dehydrated through a series of graded ethanol (EtOH) (Fisher Scientific, Waltham, Massachusetts, USA) at room temperature with shaking in the following sequence: washed in $50 \% \mathrm{EtOH}$ for 15 minutes twice, then $70 \% \mathrm{EtOH}$ for 30 minutes twice, then $85 \% \mathrm{EtOH}$ for 60 minutes once, then $95 \% \mathrm{EtOH}$ for 60 minutes once, then $100 \% \mathrm{EtOH}$ for 30 minutes three times. Following ethanol dehydration, the samples were washed in xylene (Fisher Scientific, Waltham, Massachusetts, USA) for 45 minutes twice with shaking at room temperature. Samples were then immersed in a xylene: paraffin mixture at $1: 1$ ratio in the oven at $58^{\circ} \mathrm{C}$ for 45 minutes. Then, samples were immersed in paraffin for 20 minutes and placed in a vacuum chamber and repeated three times. Finally, fixed mouse heads were embedded in an embedding block with paraffin wax.

Serial frontal sections $7 \mu \mathrm{m}$ thick were prepared using a microtome $(820$ microtome, American optical spencer, Buffalo, NY) along the anterior-posterior axis perpendicular to the secondary palate midline for immunofluorescence and confocal microscopic analysis.

\subsubsection{Hematoxylin and eosin}

Prior to immunofluorescence, slides were appropriately stained for microscopic evaluation using Harris's hematoxylin solution. Samples were first deparaffinized in the oven at $58^{\circ} \mathrm{C}$ for 10 min. after that, the samples were then rehydrated through xylene (Fisher Scientific, Waltham, Massachusetts, USA) and a graded ethanol series (EtOH) (Fisher Scientific, Waltham, Massachusetts, USA) at room temperature in the following sequence: immerse the slides in xylene for 10 minutes twice, then $100 \% \mathrm{EtOH}$ for 3 minutes twice, then $95 \% \mathrm{EtOH}$ for 1 minute once, then $70 \% \mathrm{EtOH}$ for 1 minutes once, then $50 \% \mathrm{EtOH}$ for 1 minute, and finally in PBS for 1 minute twice. Next, slides were immersed in hematoxylin stain (Modified Harris Hematoxylin, Sigma- 
Aldrich, St. Louis, MO, USA) for 1 minute. Then, the slides were immersed in a water container, stained water was discarded, and the container was refilled again with water. After that, the slides were placed under running water for 10 minutes. Next, the slides were stained with eosin (EosinY Saturated, Richard-Allan Scientific, Kalamazoo, MI, USA) for 40 seconds. Slides were dehydrated through graded ethanol $(\mathrm{EtOH})$ series and xylene at room temperature in a fume hood in the following sequence: $70 \% \mathrm{EtOH}$ for 1 minute, then $95 \% \mathrm{EtOH}$ for 1 minute, then $100 \%$ $\mathrm{EtOH}$ for 10 minutes, then Xylene for 10 minutes and then in a new xylene for 30 minutes. after that, 230ul of mounting medium were placed on each slide, and a coverslip were mounted. The slides were viewed by light microscopy

\subsubsection{Deparaffinization of tissue sections and rehydration}

Prior to staining the tissue sections with specific antibodies, samples were first deparaffinized in the oven at $58^{\circ} \mathrm{C}$ for $10 \mathrm{~min}$. after that, the samples were then rehydrated through xylene (Fisher Scientific, Waltham, Massachusetts, USA) and a graded series of ethanol (EtOH) (Fisher Scientific, Waltham, Massachusetts, USA) at room temperature in the following sequence: immerse the slides in xylene for 10 minutes twice, then 100\% EtOH for 3 minutes twice, then $95 \%$ EtOH for 1 minute once, then $70 \% \mathrm{EtOH}$ for 1 minutes once, then $50 \% \mathrm{EtOH}$ for 1 minute, and finally in PBS for 1 minute twice.

\subsubsection{Antigen retrieval and background stain blocking}

Slides were then placed in a pressure cooker (containing 2-liter water and $4 \mathrm{ml}$ EDTA) for antigen retrieval for 2.5 minutes. Then the pressure valve was relieved and the pressure cooker was placed under running water for 10 minutes to cool down. Then, samples were rinsed in PBS 
once and washed in PBS in a Coplin jar on a shaker for 5 minutes twice. Slides were then placed in a humidified chamber and $100 \mu 1$ blocking solution (3\% bovine serum albumin (BSA)/ $0.1 \%$ Triton X-100 / PBS) per slide were applied to cover the entire sample for 30 minutes to reduce background staining.The blocking solution was drained from the slides (but not dry).

\subsubsection{Analysis of MEE apoptosis rate TUNEL technique}

Apoptotic cells were detected in paraffin sections by the TUNEL technique using an In Situ Cell Death Detection Kit (Roche Applied Science, Basel, Switzerland). Slides were first deparaffinized and then rehydrated (see section 3.3.3). Slides were then placed in a humidified chamber and $100 \mu 1$ blocking solution (3\% bovine serum albumin(BSA)/ $0.1 \%$ Triton X-100 / PBS) per slide were applied to cover the entire sample for 30 minutes to reduce background staining. After that, the blocking solution was drained from the slides (but not dry) and $100 \mu 1$ of the TUNEL mix $(10 \mu 1$ of the enzyme solutions were mixed with $90 \mu$ l of the label solution) were applied on each slide. Slides were placed in an incubator at $37^{\circ} \mathrm{C}$ for 60 minutes. Samples were rinsed in PBS once and washed in PBS in a Coplin jar on a shaker for 5 minutes three times (slides were covered during washing to protect them from light). Next, slides were placed in the humidified chamber, coverslips were mounted with mounting medium including 4',6-diamidino-2-phenylindole (DAPI; Vector Labs) for labeling nuclear DNA. To confirm the specificity of antibodies, additional slides were incubated with the labeling solution only. No fluorescence staining was found in these negative control sections. FFPE mouse spleen sections were stained for TUNEL and used as a positive control.

Total (DAPI) and apoptotic (TUNEL positive) cells were counted in MEE. The percentage of apoptotic MEE cells was calculated as follows: apoptotic MEE cells $(\%)=$ number of TUNEL 
positive staining cells/number of total DAPI positive cells $\times 100$. Nine sections obtained from each sample for each secondary palate location (Anterior, Middle and Posterior) were analyzed, and average values were calculated for ten samples in each group. These mean values and the standard deviations were used for one-way ANOVA that compared TUNEL positive cells in the wild type, K14- SMAD2/ TGF- $\beta 3^{(+-)}$and K14- SMAD2/TGF- $\beta 3^{(--)}$mice groups.

\subsubsection{Analysis of MEE apoptosis rate ccaspase 3 technique}

Apoptotic cells were detected in paraffin sections by using cleaved caspase3 (Ccaspase3) antibody (1:100, Cell Signaling Technology, USA). Slides were first deparaffinized and then rehydrated (see section 3.3.3). After that, Antigen retrieval was done in a pressure cocker and a blocking solution was applied (see section 3.3.4). Then, primary antibodies were diluted with blocking solution, Ccaspase3 (1:100, Cell Signaling Technology, USA) and Ecadherin (1:100, Transduction Laboratories) and $100 \mu \mathrm{l}$ applied on each slide. Slides were incubated with the primary antibodies overnight in a humidified chamber at $4^{\circ} \mathrm{C}$. Next, samples were rinsed in PBS once and washed in PBS in a Coplin jar on a shaker for 5 minutes three times. Fluorescein labeled secondary antibodies Donkey anti-Mouse IgG, Alexa Fluor® 488 (1:100, Invitrogen, CA, USA) and Goat anti-Rabbit IgG, Alexa Fluor® 568 (1:100, Invitrogen, CA, USA), were diluted with blocking solution and $100 \mu \mathrm{l}$ were applied on each slide. Slides were placed in a humidified chamber for 60 minutes at room temperature. Samples were rinsed in PBS once and washed in PBS in a Coplin jar on a shaker for 5 minutes three times. Next, slides were placed in the humidified chamber, coverslips were mounted with mounting medium including 4',6-diamidino2-phenylindole (DAPI; Vector Labs). To confirm the specificity of antibodies, additional slides 
were incubated without the primary antibodies. No fluorescence staining was found in these sections. Mouse spleen sections were stained for Ccaspase3 and used as a positive control.

Total (DAPI) and apoptotic (Ccaspase3 positive) cell counts were counted in MEE. The percentage of apoptotic MEE cells was calculated as follows: apoptotic MEE cells $(\%)=$ number of Ccaspase 3 positive staining cells/number of total DAPI positive cells $\times 100$. Nine sections obtained from each sample for each secondary palate location (Anterior, Middle and Posterior) were analyzed, and average values were calculated for ten samples in each group. These mean values and the standard deviations were used for one-way ANOVA that compared Ccaspase3 positive cells in the wild type, K14- SMAD2/ TGF- $\beta 3^{(+/-)}$and K14- SMAD2/TGF- $\beta 3^{(-/-)}$mice groups.

\subsubsection{Analysis of MEE phosphorylated-SMAD2 rate}

Cells containing phosphorylated-SMAD2 were detected in paraffin sections by using Psmad2 antibody (1:20, Cell Signaling Technology, USA) (Fujita et al., 2012). Slides were first deparaffinized and then rehydrated (see section 3.3.3). Antigen retrieval was done in a pressure cocker and a blocking solution was applied (see section 3.3.4). Then primary antibodies were diluted with blocking solution, Psmad2 (1:20, Cell Signaling Technology, USA) and Ecadherin

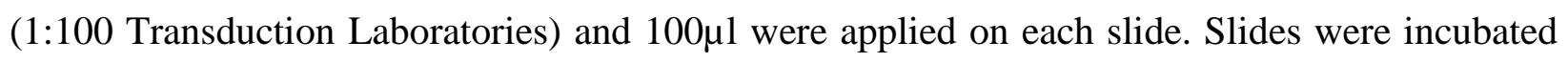
with the primary antibodies overnight in a humidified chamber at $4^{\circ} \mathrm{C}$. Next, samples were rinsed in PBS once and washed in PBS in a Coplin jar on a shaker for 5 minutes three times. Fluorescein labeled secondary antibodies Donkey anti-Mouse IgG, Alexa Fluor® 488 (1:100, Invitrogen, CA, USA) and Goat anti-Rabbit IgG, Alexa Fluor® 568 (1:100, Invitrogen, CA, USA), were diluted with blocking solution and $100 \mu 1$ were applied on each slide. Slides were placed in a humidified 
chamber for 60 minutes at room temperature. Samples were rinsed in PBS once and washed in PBS in a Coplin jar on a shaker for 5 minutes three times. Next, slides were placed in the humidified chamber, coverslips were mounted with mounting medium including 4',6-diamidino2-phenylindole (DAPI; Vector Labs). To confirm the specificity of antibodies, additional slides

were incubated without the primary antibodies. No fluorescence staining was found in these sections. Mouse colon tissue sections were stained for Psmad2 and used as a positive control.

Total (DAPI) and Psmad2 positive cells were counted in MEE. The percentage of Phosphorylated-SMAD2 MEE cells was calculated as follows: Phosphorylated-SMAD2 MEE cells $(\%)=$ number of Psmad2 positive staining cells/number of total DAPI positive cells $\times 100$. Nine sections obtained from each sample for each secondary palate location (Anterior, Middle and Posterior) were analyzed, and average values were calculated for ten samples in each group. These mean values and the standard deviations were used for one-way ANOVA that compared Psmad2 positive cells in the wild type, K14- SMAD2/ TGF- $\beta 3^{(+/-)}$and K14- SMAD2/TGF- $\beta 3^{(-/-)}$mice groups.

\subsubsection{Analysis of MEE twist1 and collagen IV expression}

During EMT, the climax of this process is signaled by the loss of the basement membrane and the creation of a mesenchymal cell capable of migrating away from the original epithelial layer. Type IV collagen is a component of basement membrane. In order to detect loss of basement membrane during palatal fusion in MEE, ColIV (1:100, Abcam) antibody was used. Also, MEE cells expressing twist1 protein, a marker of a cell undergoing EMT, were detected using Twist1 (1:50, Abcam) antibody. 
Slides were first deparaffinized and then rehydrated (see section 0). After that, antigen retrieval was done in a pressure cocker and a blocking solution was applied (see section 3.3.4). Then primary antibodies were diluted with blocking solution, Twist1 (1:50, Abcam) and ColIV (1:100, Abcam) and $100 \mu 1$ were applied on each slide. Slides were incubated with the primary antibodies overnight in a humidified chamber at $4{ }^{\circ} \mathrm{C}$. Next, samples were rinsed in PBS once and washed in PBS in a Coplin jar on a shaker for 5 minutes three times. Fluorescein labeled secondary antibodies Donkey anti-Mouse IgG, Alexa Fluor® 488 (1:100, Invitrogen, CA, USA) and Goat anti-Rabbit IgG, Alexa Fluor ${ }^{\circledR} 568$ (1:100, Invitrogen, CA, USA), were diluted with blocking solution and $100 \mu 1$ were applied on each slide. Slides were placed in a humidified chamber for 60 minutes at room temperature. Samples were rinsed in PBS once and washed in PBS in a Coplin jar on a shaker for 5 minutes three times. Next, slides were placed in the humidified chamber, coverslips were mounted with mounting medium including 4',6-diamidino-2-phenylindole (DAPI; Vector Labs). To confirm the specificity of antibodies, additional slides were incubated without the primary antibodies. No fluorescence staining was found in these sections. Basement membrane in blood vessels served as an internal positive control for ColIV.

\subsection{Confocal laser microscopy}

Sections were examined with a Nikon D-Eclipse C1 Laser Scanning Confocal Microscope (Nikon Instruments Inc., Melville, NY, USA) equipped with 3 laser diode modules (405/488/543 nm). Each section was scanned with a Plan Fluor 40X (aperture 0.75) lens and a Plan Apo VC 60X (aperture 1.4) oil lens. Fluorescent images were captured with a Qimaging Retiga-2000R digital camera installed on the Nikon D-Eclipse C1 Laser Scanning Confocal Microscope (image 
resolution: 1600x1200 pixels). Z stack of images were analyzed using ImageJ (U. S. National Institutes of Health, Bethesda, Maryland, USA).

\subsection{Statistical analysis}

All data were interpreted using IBM SPSS Statistics for Windows, Version 20.0. Armonk, NY: IBM Corp. Shapiro-Wilk test was used to test data normal distribution. Values are expressed as the mean \pm SEM. Differences between groups were determined using a one-way ANOVA. Differences were considered statistically significant at $\mathrm{P}<0.05$. 


\section{Chapter 4: Results and conclusion}

\subsection{Increased MEE cell apoptotic rate.}

TUNEL assay was conducted to examine whether overexpression of Smad2 can induce apoptosis in MEE cells. Spleen sections were used as positive control of apoptosis. No TUNEL positive nuclei were observed in negative control sections. DNA defragmentation was detected and localized in the palatal MEE cells in the anterior, middle and posterior regions of the secondary palate at day E14.5 (figure 10). K14-SMAD2/TGF- $\beta 3^{(+/-)}$mice exhibited an increase in TUNEL positive MEE cells (19.8\% anterior, $12.12 \%$ middle and $10.77 \%$ posterior) compared to the wild type $(0 \%$ anterior, $0 \%$ middle and $0 \%$ posterior) (Figure 11$)$. Also, K14-SMAD2/TGF- $\beta 3^{(-/-)}$ rescue mice exhibited an increase in TUNEL positive MEE cells (12.3\% anterior, 30.5\% middle and $29.4 \%$ posterior) compared to the wild type (Figure 11). There was a significant difference of amount of apoptotic cell ratio at the $p<.05$ level for the three groups $[\mathrm{F}(2,6)=10.30, p=0.011]$. Post hoc comparisons using the Tukey HSD test indicated that the mean score for the K14$\mathrm{SMAD} 2 / \mathrm{TGF}-\beta 3^{(--)}$rescue mice apoptotic cell ratio $(\mathrm{M}=24.07, \mathrm{SD}=10.20)$ was significantly different than the wild type mice.

Cleaved caspase3 (Ccaspase3) antibody, an apoptosis marker, was also used to detect apoptotic cells associated with Smad2 overexpression in the palatal MEE cells. Ccaspase-3 protein was localized in the palatal MEE cells, in the anterior, middle and posterior regions of the secondary palate at day E14.5 (figure 8). Our results showed that Ccaspase-3 positive cells were detected in the nasal and oral MES triangles. The K14-SMAD2/TGF- $\beta 3^{(+/-)}$mice also had a much higher ratio of Ccaspase 3 apoptosis positive MEE (13.7\% anterior, $10.1 \%$ middle and $17.6 \%$ posterior) when compared to the wild-type mice $(0.0 \%$ anterior, $5.31 \%$ middle and $0.0 \%$ posterior $)$ (Figure 9). K14-SMAD2/TGF- $\beta 3^{(-/)}$rescue mice had higher ratio of Ccaspase3 positive MEE cells 
(31.7\% anterior, $33 \%$ middle and $35.6 \%$ posterior) when compared to the wild-type mice and K14SMAD2/TGF- $\beta 3^{(+/)}$(Figure 9). There was a significant difference of Ccaspase 3 positive cell ratio at the $p<.05$ level for the three groups $[\mathrm{F}(2,6)=83.87, p=0.000041]$. Post hoc comparisons using the Tukey HSD test indicated that the mean score for the K14-SMAD2/TGF- $\beta 3^{(-/)}$rescue mice Ccaspase3 positive cell ratio $(\mathrm{M}=33.43, \mathrm{SD}=1.98)$ was significantly different than the wild type mice. Also, the mean score for the K14-SMAD2/TGF- $\beta 3^{(+/-)}$mice Ccaspase 3 positive cell ratio $(\mathrm{M}=13.8, \mathrm{SD}=3.75)$ was significantly different than the wild type mice. 


\section{Ccaspase3 expression in coronal E14.5 palatal sections}

E-cad/Ccaspase3/DAPI

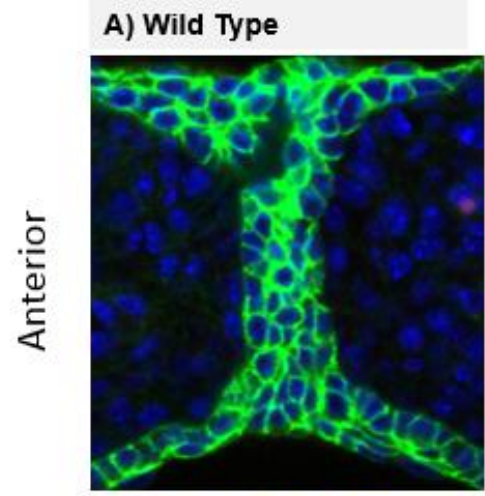

B) TGF- $\beta 33^{+/-/ K 14 S m a d 2}$
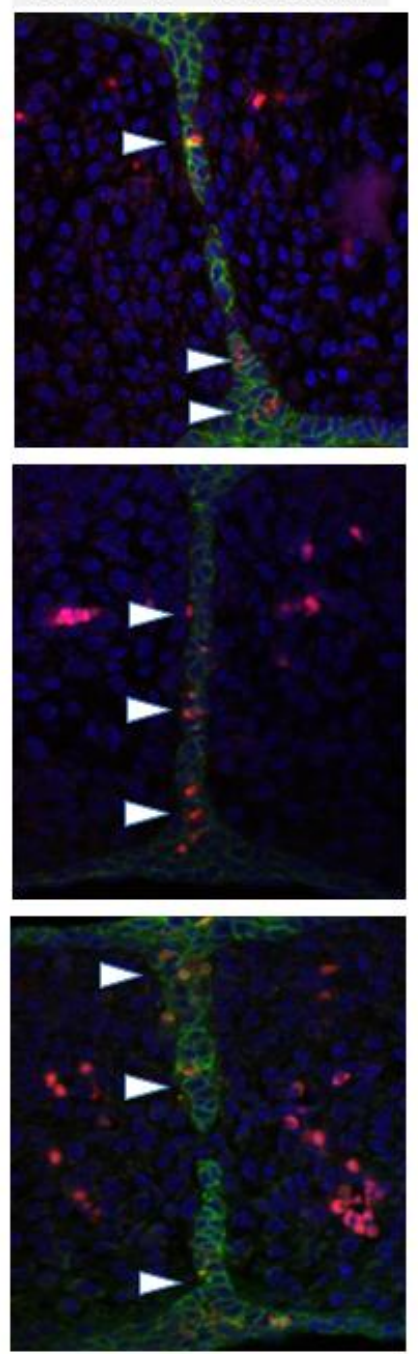

C) TGF- $\beta 3-/-/$ K14Smad2
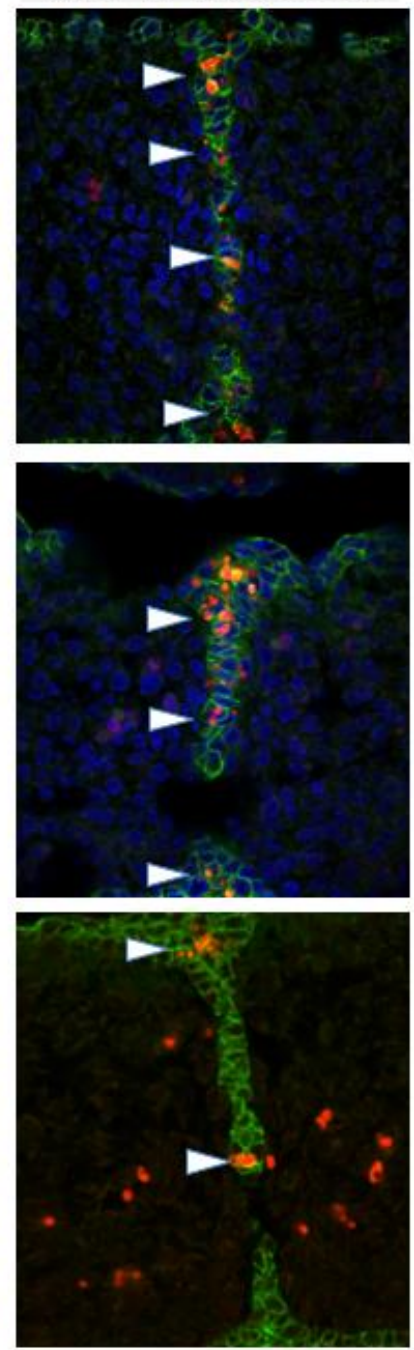

Figure 8 Ccaspase3 expression in coronal E14.5 palatal sections

Fluorescent images of Ccaspase3 during palate development at E14.5. A) Wild-Type mice shows fewer apoptotic cells in the MEE. B) K-14Smad2 overexpression mice have a higher ratio of apoptotic activity in the MEE, C) TGF- $\beta 3$-/- K-14Smad2 Rescue shows higher ratio of apoptosis in the MEE, indicating that $\operatorname{Smad} 2$ overexpression may have rescued the cleft palate by increased MEE apoptosis. Arrowheads indicate Ccaspase3 positive cells in MEE. 


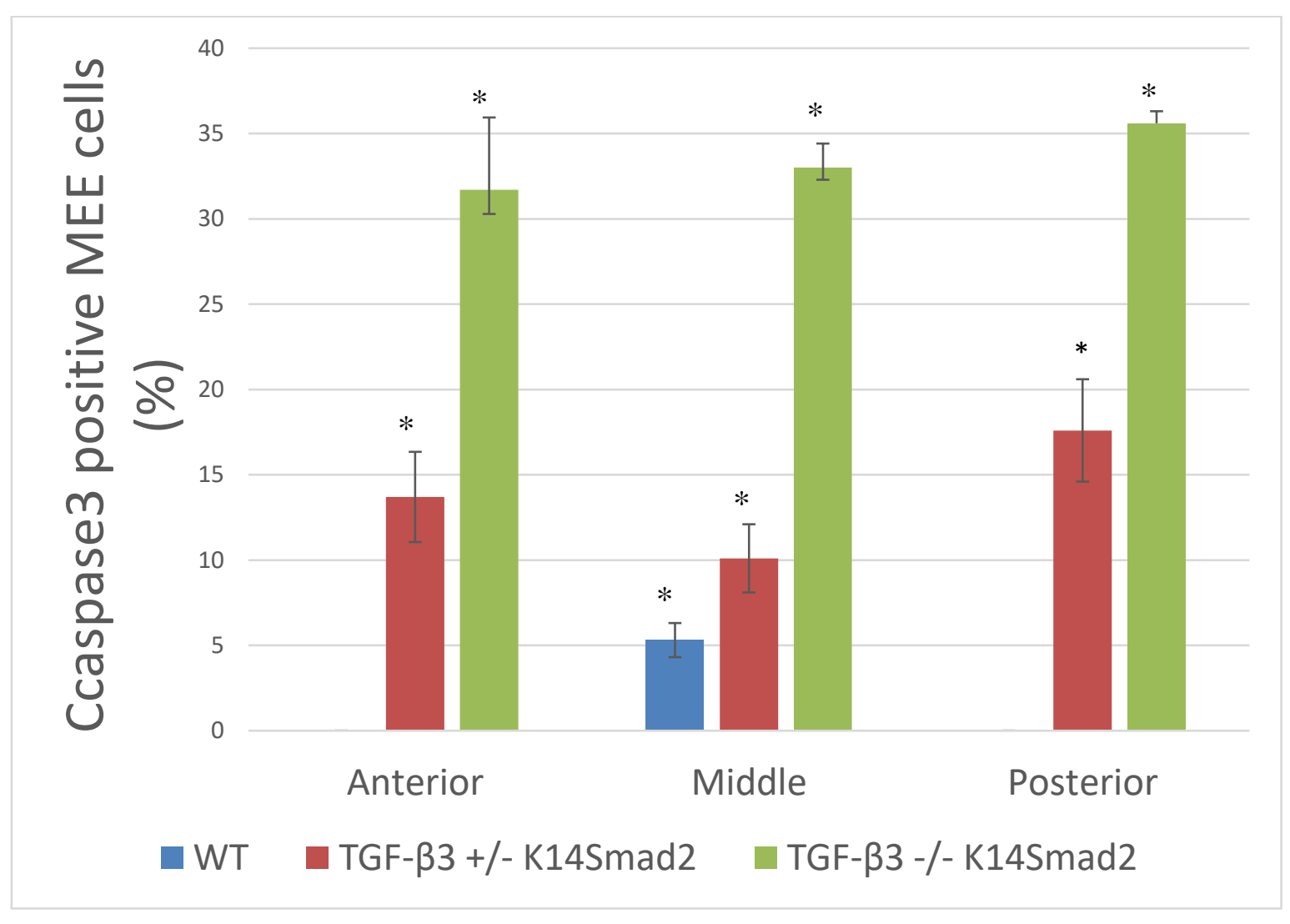

Figure 9 Apoptosis ratio in MEE of wild type mice, K14-Smad2 mice and TGF-B3 ${ }^{(--)} /$K14Smad2 $^{2}$

Quantification of Ccaspase3 positive cells expressed as percent of total nuclei in the MEE. In the anterior middle and posterior there were statistical significance between the groups $[\mathrm{F}(2,6)=$ 83.87, $p=0.000041, n=10](* P<.01)$. 


\section{Apoptosis detection in coronal E14.5 palatal sections by TUNEL assay.}
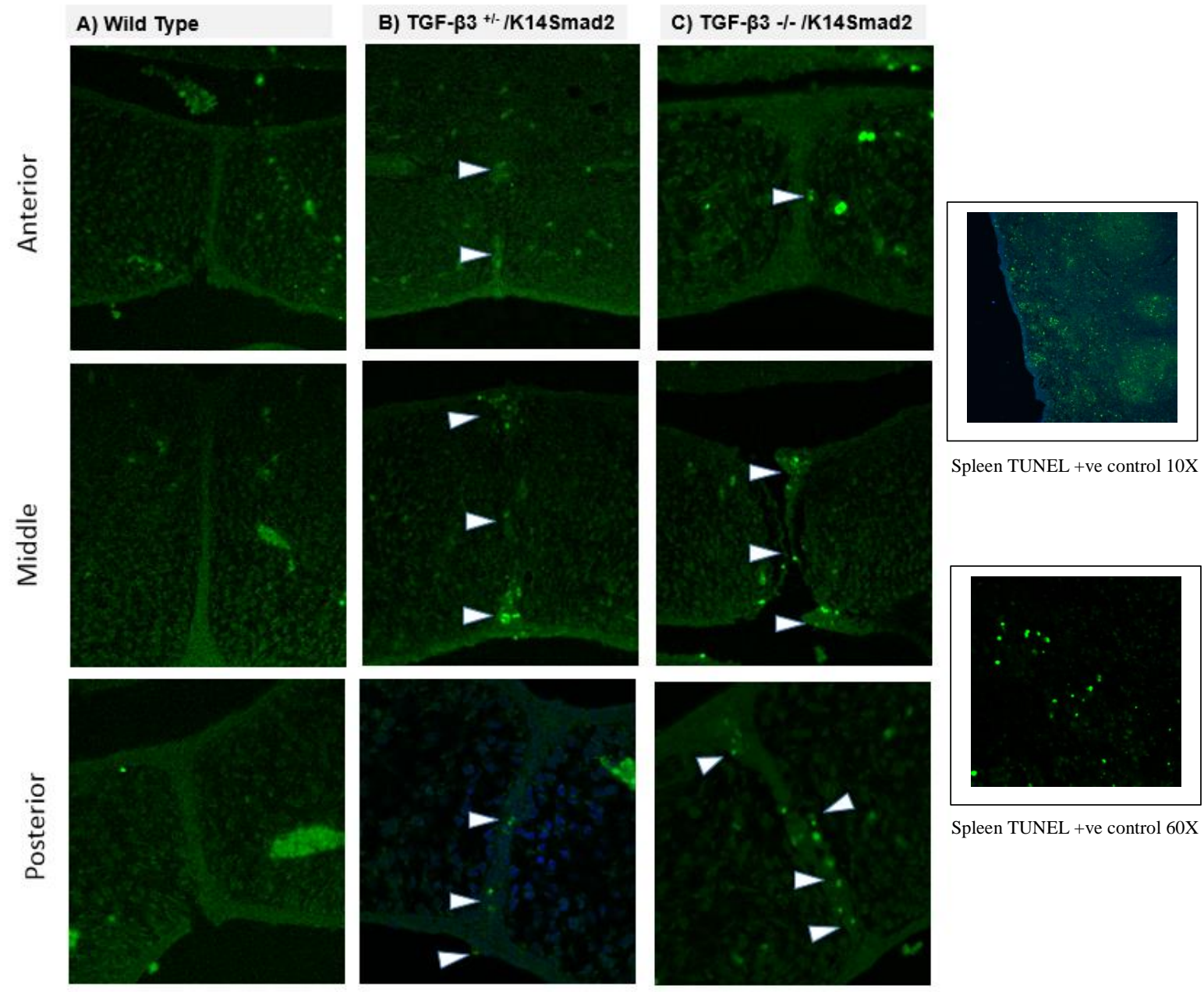

Spleen TUNEL + ve control 10X

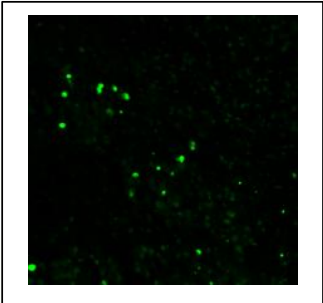

Spleen TUNEL + ve control 60X

Figure 10 Apoptosis detection in coronal E14.5 palatal sections by TUNEL assay.

Fluorescent images during palate development at E14.5 of Terminal deoxynucleotidyl transferase (TdT) dUTP Nick-End Labeling (TUNEL) technique which detects apoptotic cells that undergo extensive DNA degradation during the late stages of apoptosis. A) Wild-Type mice coronal sections shows no TUNEL positive cells. B) K14-Smad2 over-expression mice have a higher ratio of apoptotic activity in the MEE. C) TGF- $\beta 3$-/- /K-14Smad2 rescue mice shows higher ratio of apoptosis in the MEE. Arrowheads indicate TUNEL positive cells in MEE. 


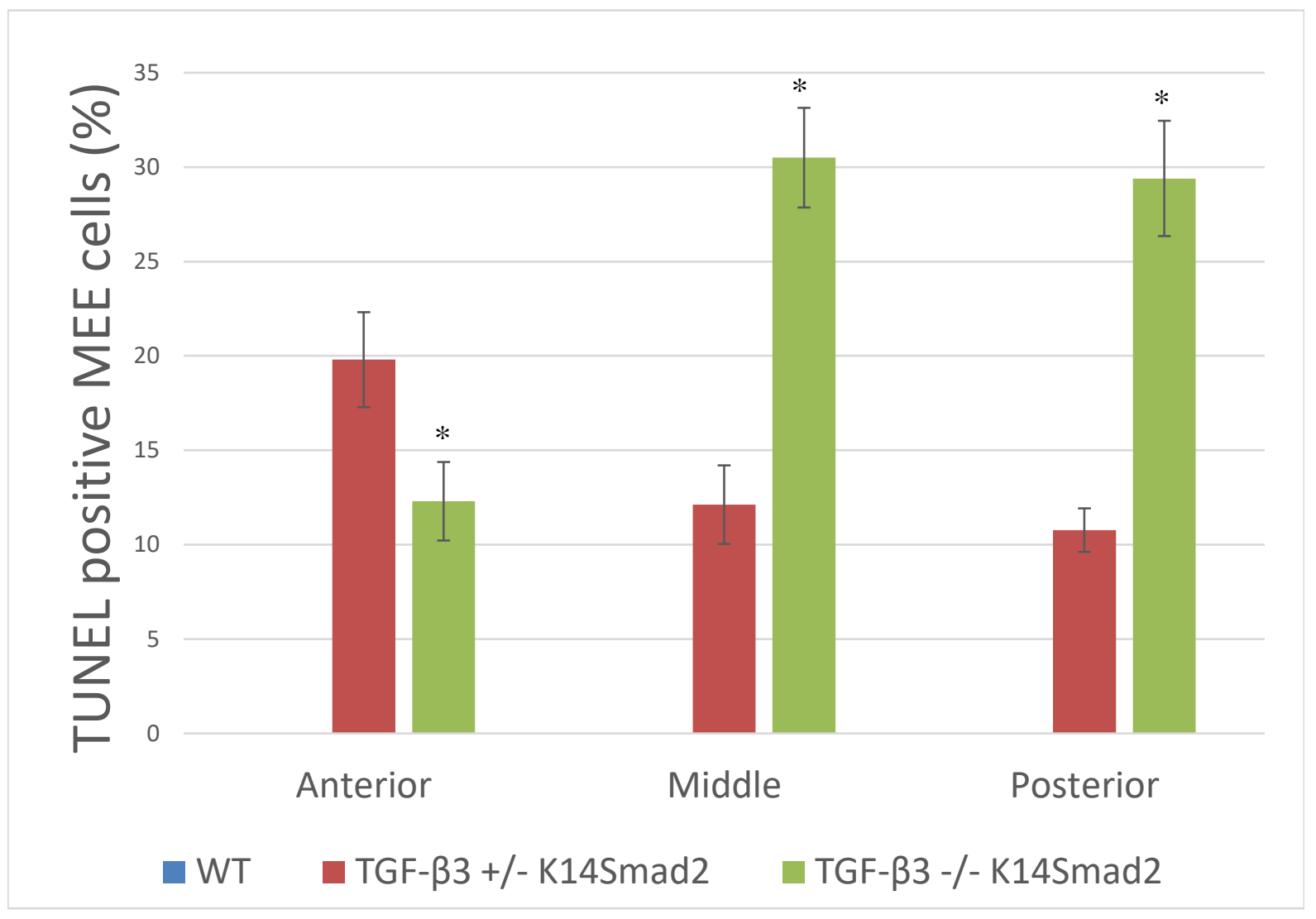

Figure 11 Apoptosis ratio in MEE of wild type mice, K14-Smad2 mice and TGF-B3 ${ }^{(-/)} /$K14Smad2 $^{-14}$

Quantification of TUNEL positive cells expressed as percent of total nuclei in the MEE $* P<0.5$. In the anterior middle and posterior there were statistical significance between the WT and TGFB3 (-/-) /K14Smad2 groups $[\mathrm{F}(2,6)=10.30, p=0.011, n=10](* P<.01)$. 


\subsection{Increased levels of activated "phosphorylated" SMAD2 in the MEE}

We performed immunofluorescence to determine the level of Phospho-SMAD2 protein in wild type, K14-Smad2 and K14-Smad2/ TGF- $\beta 3^{(-/-)}$transgenic mice. High magnification images showed that Phospho-SMAD2 protein was present in the MEE cells during the process of palatal fusion at day E14.5 in wild type, K14-Smad2/ TGF- $\beta 3^{(+/-)}$and K14-Smad2/ TGF- $\beta 3^{(-/-)}$mice (figure 12). Strong Phospho-SMAD2 protein signal was detect across the secondary palate in the anterior, middle and posterior regions.

High levels of phospho-SMAD2 were observed in MEE cells in K14-Smad2/ TGF- $\beta 3^{(-/-}$

) mice $\left(43.12 \%\right.$ anterior, $61.6 \%$ middle and $56.1 \%$ posterior) and K14-Smad2/ TGF- $\beta 3^{(+/-)}$which had strong phospho-SMAD2 protein signal (26.9\% anterior, $41.05 \%$ middle and $38.7 \%$ posterior). Wild type mice had lower levels of phospho-SMAD2 when compared to both K14-Smad2/ TGF$\beta 3^{(+/-)}$and K14-Smad2/ TGF- $\beta 3^{(-/-)}$. A significant difference in the amount of phospho-Smad2 at the $\mathrm{p}<.05$ level for the three groups was also identified $[\mathrm{F}(2,6)=26.97, p=0.001002]$.

Immunofluorescence double staining revealed TUNEL positive MEE cells were immunoreactive for phospho-SMAD2 (figure 12E) indicating a correlation between cell death and phosphorylation of SMAD2. A Pearson product-moment correlation coefficient was computed to assess the relationship between the ratio of apoptotic MEE and levels of phospho-Smad2. There was a positive correlation between the two variables in both $\mathrm{K} 14-\mathrm{Smad} 2 / \mathrm{TGF}-\beta 3^{(-/)}$mice, $\mathrm{r}=$ 0.9901, $\mathrm{n}=9, p=0.00001$, and K14-Smad2/ TGF- $\beta 3^{(+/)}$mice, $\mathrm{r}=0.8767, \mathrm{n}=9, p=0.001954$ Overall, there was a strong, positive correlation between levels of phospho-Smad2 and cell death. Increases in SMAD2 phosphorylation were correlated with increases in the ratio of cell death in the MEE during palatal fusion. 


\section{Phospho-Smad2 expression in coronal palatal sections}

E-cad/Phospho-SMAD2IDAPI

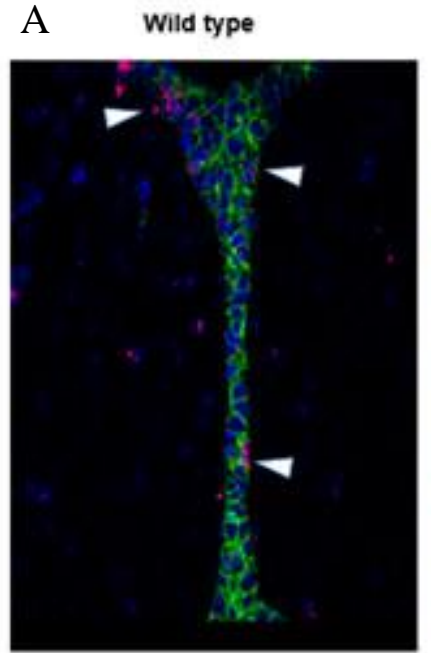

$\mathrm{D}$

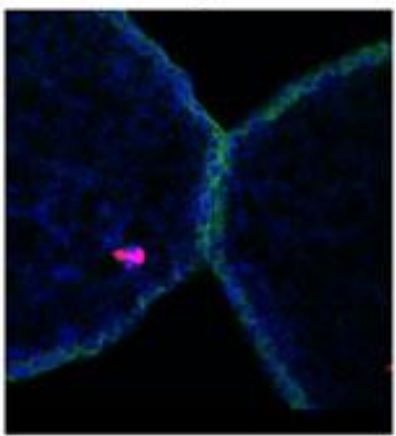

B TGF- $33 * / K 14$ Smad2

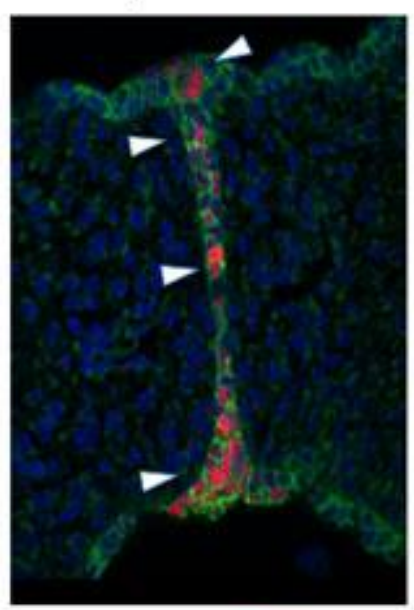

PSMAD

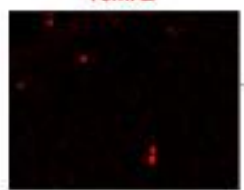

TUNEL

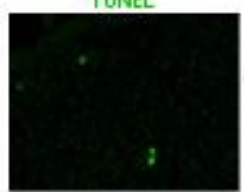

C TGF- $\beta 3+/ K 14$ Smad2

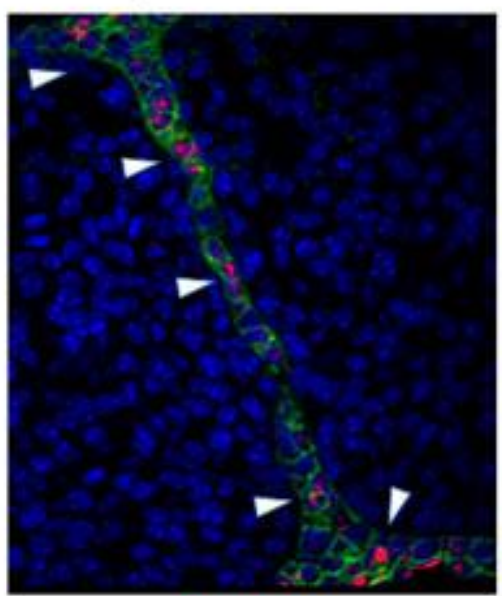

PSMAD + TUNEL

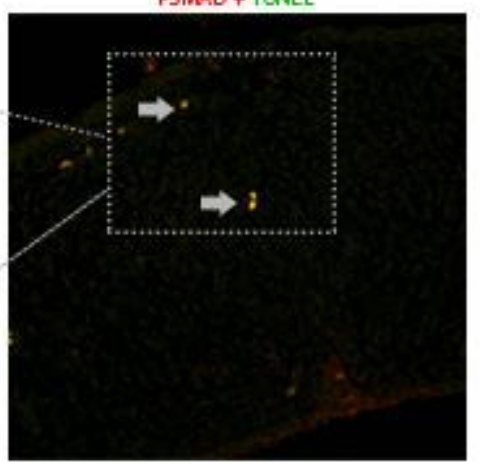

E

Figure 12 Phospho-Smad2 expression in coronal palatal sections

Fluorescent images of Phospho-Smad2 (Red) at E14.5 and its localization in the MEE from Wildtype, TGF- $\beta 3$ +/- K14Smad2 and TGF- $\beta 3$-/- K14Smad2 (A-D). Coronal section of TGF- $\beta 3$ +/K14Smad2 and TGF- $\beta 3$-/- K14Smad2 mice palates showed higher expression of Phospho-Smad2 in the MEE. Arrowheads indicate Phospho-Smad2 positive cells in MEE. Immunofluorescence double staining revealed TUNEL positive MEE cells showing immunoreactivity to phosphoSMAD2 (E). 


\subsection{Loss of basement membrane in the MEE cell and twist1 positive cells.}

To investigate whether MEE associated with SMAD2 overexpression were undergoing EMT during palatal fusion we performed confocal microscopic analysis using an EMT marker Twist1 and a basement membrane marker collagen IV. Twist1 is a protein that induces EMT by downregulating epithelial gene expression and activating mesenchymal gene expression (Lamouille, Xu \& Derynck, 2014). Twist1 also, causes loss of cell-cell adhesion mediated by Ecadherin. To distinguish MEE cells undergoing EMT from mesenchymal cells, Collagen type IV was used as a marker of basement membrane. The loss of basement membrane is considered one of the hallmarks of EMT.

At earlier stages of palatal fusion, microscopic analysis showed that the basement membrane was retained in the palatal MES, this finding coincides with presence of higher levels of apoptosis. As the degradation of MES occurred on day E14.5, fewer numbers of Twist positive cells were detected in the MEE of wild type, K14-Smad2/TGF- $\beta 3^{(+-)}$and K14-Smad2/TGF- $\beta 3^{(--)}$ mice (figure 13). Those cells indicated by arrowheads (figure 13) were associated with loss of basement membrane. Thinning and degradation of basement membrane was also detected in the K14-Smad2/TGF- $\beta 3^{(+/-)}$and K14-Smad2/TGF- $\beta 3^{(--)}$mice at day E14.5. These results further indicate that the process of EMT occurs at a later stage than programmed cell death.

To trace epithelial cells undergoing EMT originating from MEE we used immunofluorescence double staining using twist1 and phospho-Smad2 antibodies. Confocal microscopic analysis revealed cells positive to twist 1 and phospho-Smad2 in the palatal mesenchyme adjacent to the MES in the K14-Smad2/TGF- $\beta 3^{(+/)}$and K14-Smad2/TGF- $\beta 3^{(--)}$mice (figure 14). This finding coincided, with high levels of phospho-Smad2 detected at the protein level with immunofluorescence in both experimental groups. 


\section{Twist1 expression in coronal palatal sections}

TWIST/Collagen IVIDAPI

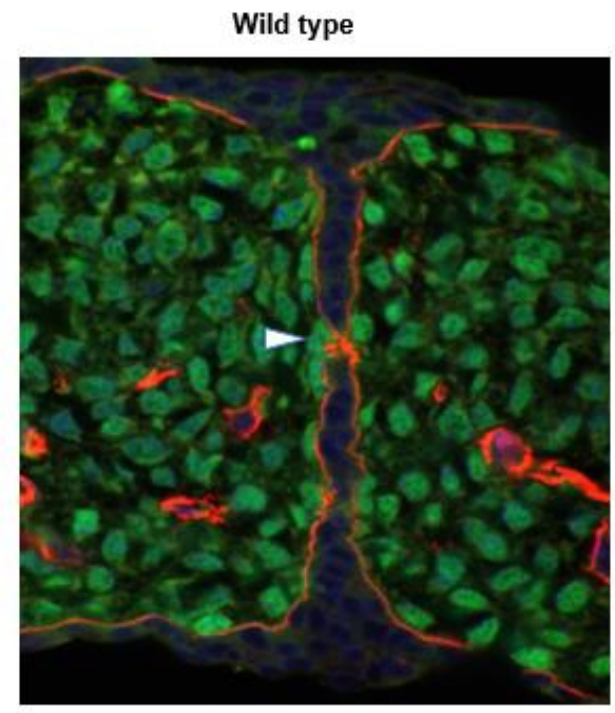

TGF- $\beta 3$ \%/K14Smad2

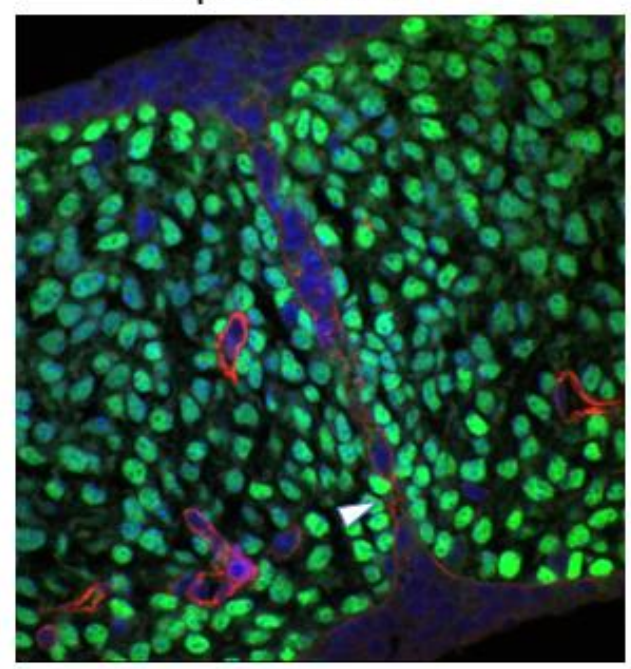

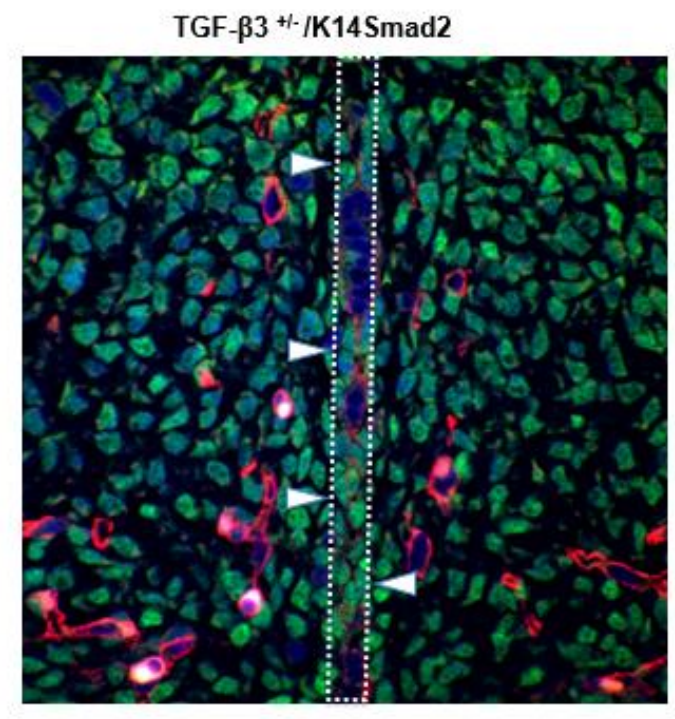

TGF $-\beta 3 \%$

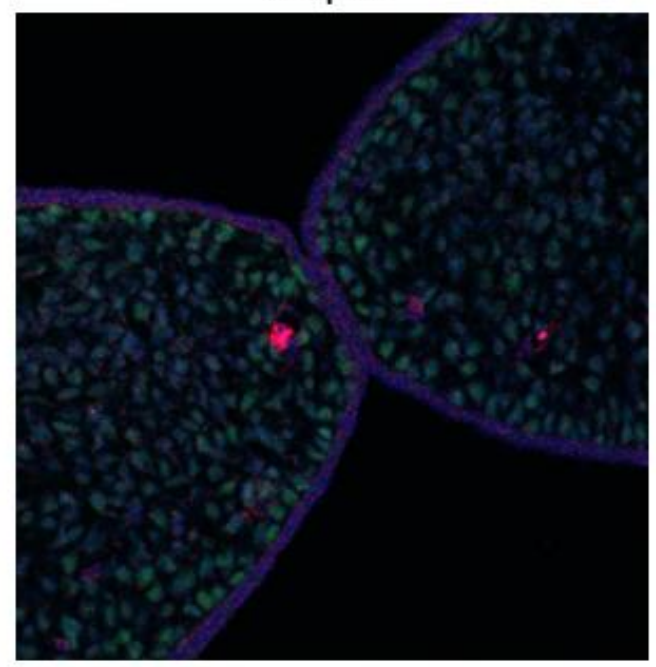

Figure 13 Twist1 expression in coronal palatal sections

Fluorescent images of TWIST1 (green) an EMT Marker, Collagen IV (red) basement membrane marker and DAPI at E14.5 in the MEE from Wild-type, TGF- $\beta 3^{(+/-)}$K14Smad2, TGF- $\beta 3^{(-/)}$ K14Smad2 and TGF- $\beta 3^{(--)}$. Arrowheads indicate Twist positive cells in MEE. No Twist positive cells were observed in the TGF- $\beta 3$ null mice MES. 


\section{Twist1 and Phospho-Smad2 expression in coronal palatal sections}

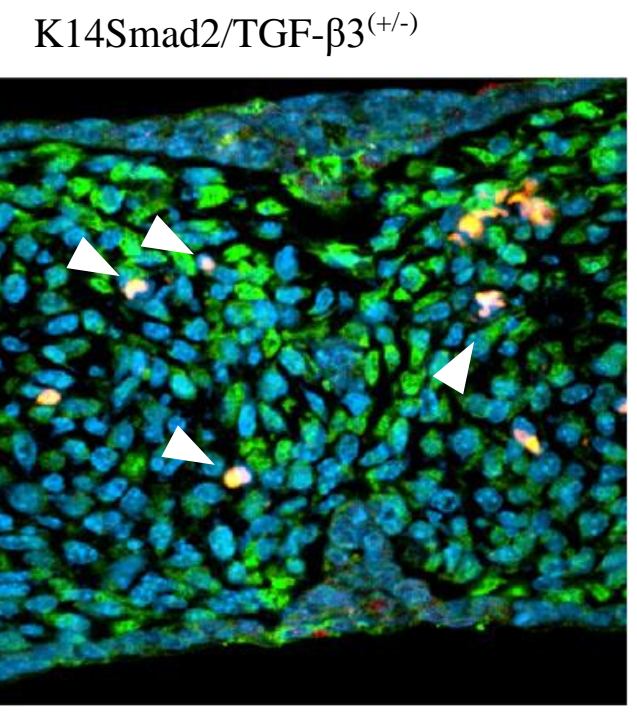

$\mathrm{K} 14 \mathrm{Smad} 2 / \mathrm{TGF}-\beta 3^{(+/-)}$
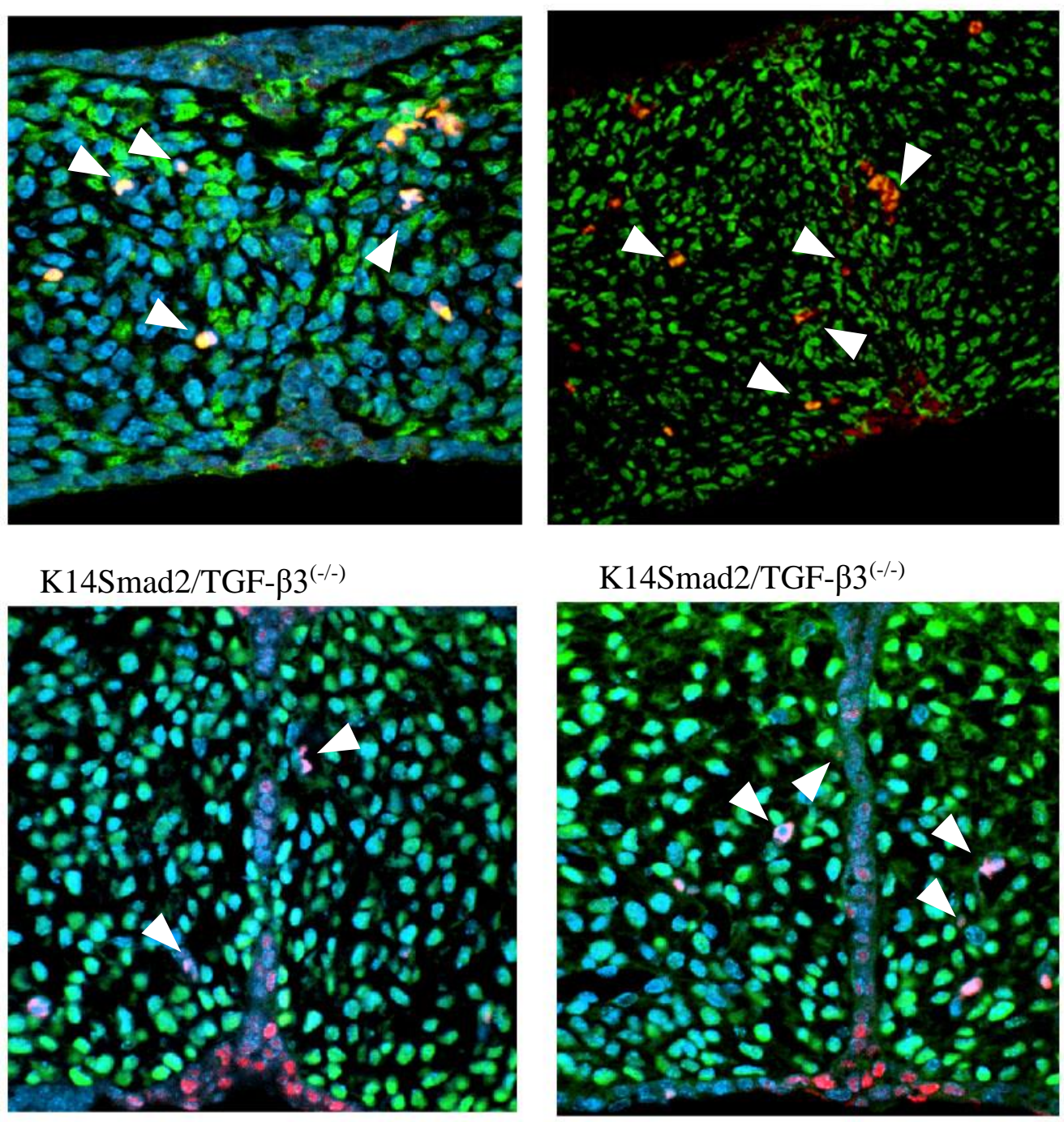

Figure 14 Twist1 and Phospho-Smad2 expression in coronal palatal sections

Fluorescent images of TWIST1 (green), Phospho-Smad2 (red) and DAPI (blue) at E14.5 in the MEE from K14Smad2/TGF- $\beta 3^{(+/-)}$and K14Smad2/TGF- $\beta 3^{(-/-)}$mice. Arrowheads indicate Twist positive cells with immunoreactivity to Phospho-Smad2. 


\subsection{Discussion}

TGF- $\beta 3$ has been known to play a role in the fate of MEE cells during palatal fusion (Kaartinen et al., 1995). TGF- $\beta 3$ null mutant mice are born with a clefting of the secondary palate due to failure in MEE adhesion (Taya, O'Kane \& Ferguson, 1999; Kaartinen et al., 1995). SMAD2 over expression in TGF- $\beta 3$ null mutant mice rescued the cleft palatal fusion and mesenchymal confluence was established (Cui et al., 2005). Little is known about the precise MEE fate induced by SMAD2 overexpression in this mouse model. Here we have shown that SMAD2 activation in TGF- $\beta 3$ null mutant mice rescues the palatal clefting by increasing apoptosis in MEE cells.

The fate of the MEE cells during palatal fusion in the K14-Smad2/TGF- $\beta 3^{(-/-)}$rescue model was not studied previously. K14-Smad2/TGF- $\beta 3^{(-/)}$and K14-Smad2/TGF- $\beta 3^{(+/-)}$mice were used in our study in order to understand the molecular mechanism of MES disintegration induced by SMAD2 overexpression. Overexpression of SMAD2 was localized in the MEE cells in both K14Smad2/TGF- $\beta 3^{(-/-)}$and K14-Smad2/TGF- $\beta 3^{(+/-)}$and higher levels of phosphorylated SMAD2 was detected in both K14-Smad2/TGF- $\beta 3^{(+/-)}$and K14-Smad2/TGF- $\beta 3^{(-/-)}$. Ito et al., (2001) reported that SMAD2 expression is critical for regulating TGF- $\beta$ signaling. Additionally, the results of Cui et al., (2005), stated that the higher the fusion score was correlated with higher phospho-SMAD2 levels. These mouse models K14-Smad2/TGF- $\beta 3^{(+/-)}$and K14-Smad2/TGF- $\beta 3^{(-/)}$have proven to be a valuable tool to evaluate the effects of the TGF- $\beta$ /SMAD pathway on MEE and the fate of MES. 


\subsubsection{SMAD2 overexpression rescues palatal fusion by inducing apoptosis}

In order to attribute the fate of MEE cells during palatal fusion to the overexpression of SMAD2, we first examined the apoptotic rate. We used two different methods to detect apoptosis in MEE during palatal fusion; TUNEL technique and Ccaspase3 localization. Our result showed a higher ratio of apoptosis in both mouse models, K14-Smad2/TGF- $\beta 3^{(+/-)}$and K14-Smad2/TGF$\beta 3^{(--)}$compared to the Wild type model. Second, we examined the levels and the localization of phospho-SMAD2. Higher levels of phospho-SMAD2 were detected in all experimental models and were localized to the MEE. A positive correlation was found between apoptotic rate and levels of phospho-SMAD2. These findings indicate that SMAD2 was activated to initiate a TGF- $\beta$ mediated response. These results also indicate that SMAD2 signaling pathways had a role in inducing TGF- $\beta$ dependent apoptosis in the MEE during palatal fusion. Colocalization of phosphoSMAD2 and TUNEL signals presents strong evidence linking them to the induction of apoptosis in MEE. Apoptosis or programmed cell death has been strongly supported as a mechanism of palatal fusion by many researchers (Xu et al., 2006; Vaziri Sani et al., 2005; Dudas et al., 2006; and Cuervo \& Covarrubias, 2004). SMAD2 overexpression has been found to induce apoptosis in various epithelial cells (Zhao et al., 2015; Wu et al., 2012; Fujita et al., 2012). These results provide evidence that the mechanism of disappearance of MES in K14-Smad2/TGF- $\beta 3^{(-/)}$is through apoptosis and induced by SMAD2 overexpression. 


\subsubsection{Evidence of EMT mechanism and basement membrane degradation.}

Epithelial-Mesenchymal Transdifferentiation (EMT) is one of the mechanisms involved in the fate of MEE and degradation of MES (Fitchett \& Hay, 1989; Shuler, Guo, Majumder \& Luo, 1991). EMT involves basal lamina degradation, acquisition of cell motility and loss of intercellular junctions (Kalluri \& Neilson, 2003). TGF- $\beta$ is involved in many models of EMT. TGF- $\beta 3^{(--)}$null mutant mice retained laminin containing basement membrane, which was correlated to inability of MEE to undergo EMT (Kaartinen, Cui, Heisterkamp, Groffen \& Shuler, 1997). We have found fewer Twist1 positive cells associated with basement membrane degradation in the K14Smad2/TGF- $\beta 3^{(+-)}$and K14-Smad2/TGF- $\beta 3^{(--)}$transgenic mice models. These findings indicate that the process of EMT does occur in the rescue mouse model but at a lower rate. Contact of the MEE during palatal fusion with mesenchymal extracellular matrix is necessary. Colocalization of both phospho-SMAD2 and twist1 positive cells in the palatal mesenchymal support the process of EMT. TGF- $\beta 3$ mutant mice with cleft palate retained basement membrane and no signs of Twist positive cells in the MEE, confirming with results of (Kaartinen, Cui, Heisterkamp, Groffen \& Shuler, 1997). Further investigation of protein and mRNA levels of EMT markers during palatal fusion in this mouse model is indicated to shed more light on the molecular mechanism of EMT. 


\subsection{Conclusion}

The present study has focused on the effect of SMAD2 over expression on medial edge epithelial cells during palatal fusion. The mechanism of MEE disappearance during palatal fusion was examined. This study is the first to have studied specifically the fate of MEE during palatal fusion in the k14-SMAD2/TGF- $\beta 3^{\left(-\rho^{-}\right)}$mouse model. The available data indicate that the SMAD2 overexpression and activation may have rescued the palatal fusion in the TGF- $\beta 3^{(-/-)}$mice by increased MEE apoptosis. The same effect was seen in the k14-SMAD2/TGF- $\beta 3^{(+/-)}$mouse model which indicate that SMAD2 is involved in the apoptosis mechanism. 


\section{Bibliography}

Abu-Issa, R., Smyth, G., Smoak, I., Yamamura, K., \& Meyers, E. (2002). Fgf8 is required for pharyngeal arch and cardiovascular development in the mouse. Development, 129(19), 4613--4625.

Aderem, A. (2003). Phagocytosis and the inflammatory response. Journal Of Infectious Diseases, 187(Supplement 2), 340--5.

Ahmed, S., Liu, C., \& Nawshad, A. (2007). Mechanisms of palatal epithelial seam disintegration by transforming growth factor (TGF) beta3. Dev. Biol., 309(2), 193--207.

Alamoudi, N., Sabbagh, H., Innes, N., El Derwi, D., Hanno, A., \& Al-Aama, J. et al. (2014). Prevalence and Characteristics of Non-Syndromic Orofacial Clefts and the Influence of Consanguinity. Journal Of Clinical Pediatric Dentistry, 38(3), 241-246. http://dx.doi.org/10.17796/jcpd.38.3.bm4m2158v17p2535

Alappat, S., Zhang, Z., Suzuki, K., Zhang, X., Liu, H., \& Jiang, R. et al. (2005). The cellular and molecular etiology of the cleft secondary palate in Fgf10 mutant mice. Dev. Biol., 277(1), 102--113.

Alberts, B., Wilson, J., \& Hunt, T. (2008). Molecular biology of the cell. New York: Garland Science.

Alkuraya, F., Saadi, I., Lund, J., Turbe-Doan, A., Morton, C., \& Maas, R. (2006). SUMO1 Haploinsufficiency Leads to Cleft Lip and Palate. Science, 313(5794), 1751-1751. http://dx.doi.org/10.1126/science.1128406

Alotaibi, M., Kitase, Y., \& Shuler, C. (2014). Smad2 overexpression reduces the proliferation of the junctional epithelium. J. Dent. Res., 93(9), 898--903.

AlSalloum, A., ElMouzan, M., AlHerbish, A., AlOmer, A., \& Qurashi, M. (2015). Prevalence of selected congenital anomalies in Saudi children: a community-based study. Ann Saudi Med, 35(2), 107--110. 
Alvarez, A., Lacalle, J., CaÃ \pm avate, M., Alonso-Alconada, D., Lara-Celador, I., Alvarez, F., \& Hilario, E. (2010). Cell death. A comprehensive approximation. Necrosis. In Microscopy: Science, Technology, Application And Education, 3, 1017â€“1024.

Archana, M., Yogesh, T., \& Kumaraswamy, K. (2013). Various methods available for detection of apoptotic cells--a review. Indian J Cancer, 50(3), 274--283.

Attisano, L. \& Wrana, J. (2002). Signal transduction by the TGF-beta superfamily. Science, 296(5573), 1646--1647.

Bader, B., Rayburn, H., Crowley, D., \& Hynes, R. (1998). Extensive vasculogenesis, angiogenesis, and organogenesis precede lethality in mice lacking all alpha $\mathrm{v}$ integrins. Cell, 95(4), 507--519.

Bamforth, J., Hughes, I., Lazarus, J., Weaver, C., \& Harper, P. (1989). Congenital hypothyroidism, spiky hair, and cleft palate. J. Med. Genet., 26(1), 49--51.

Barros, L., Hermosilla, T., \& Castro, J. (2001). Necrotic volume increase and the early physiology of necrosis. Comp. Biochem. Physiol., Part A Mol. Integr. Physiol., 130(3), 401$-409$.

Barros, L., Stutzin, A., Calixto, A., Catalan, M., Castro, J., Hetz, C., \& Hermosilla, T. (2001). Nonselective cation channels as effectors of free radical-induced rat liver cell necrosis. Hepatology, 33(1), 114--122.

Batlle, E., Sancho, E., Franci, C., Dominguez, D., Monfar, M., Baulida, J., \& Garcia De Herreros, A. (2000). The transcription factor snail is a repressor of E-cadherin gene expression in epithelial tumour cells. Nat. Cell Biol., 2(2), 84--89.

Benko, S., Fantes, J., Amiel, J., Kleinjan, D., Thomas, S., \& Ramsay, J. et al. (2009). Highly conserved non-coding elements on either side of SOX9 associated with Pierre Robin sequence. Nat. Genet., 41(3), 359--364.

Birth Defects. (2014). Centers for Disease Control and Prevention.. Retrieved 3 February 2016, from http://www.cdc.gov/ncbddd/birthdefects/index.html 
Bourgeois, P., Bolcato-Bellemin, A., Danse, J., Bloch-Zupan, A., Yoshiba, K., Stoetzel, C., \& Perrin-Schmitt, F. (1998). The variable expressivity and incomplete penetrance of the twistnull heterozygous mouse phenotype resemble those of human Saethre-Chotzen syndrome. Hum. Mol. Genet., 7(6), 945--957.

Bowen, I. (1993). Apoptosis or programmed cell death?. Cell Biology International, 17(4), 365380. http://dx.doi.org/10.1006/cbir.1993.1075

Boyles, A., DeRoo, L., Lie, R., Taylor, J., Jugessur, A., Murray, J., \& Wilcox, A. (2010). Maternal Alcohol Consumption, Alcohol Metabolism Genes, and the Risk of Oral Clefts: A Population-based Case-Control Study in Norway, 1996-2001. American Journal Of Epidemiology, 172(8), 924-931. http://dx.doi.org/10.1093/aje/kwq226

Braybrook, C., Doudney, K., Marcano, A., Arnason, A., Bjornsson, A., \& Patton, M. et al. (2001). The T-box transcription factor gene TBX22 is mutated in X-linked cleft palate and ankyloglossia. Nat. Genet., 29(2), 179--183.

Brinkley, L. \& Morris-Wiman, J. (1984). Chapter 2. Role of Extracellular Matrices in Palatal Shelf Closure. Current Topics In Developmental Biology, 17-36. http://dx.doi.org/10.1016/s0070-2153(08)60393-2

Budihardjo, I., Oliver, H., Lutter, M., Luo, X., \& Wang, X. (1999). Biochemical pathways of caspase activation during apoptosis. Annu. Rev. Cell Dev. Biol., 15, 269--290.

Bush, J. \& Jiang, R. (2011). Palatogenesis: morphogenetic and molecular mechanisms of secondary palate development. Development, 139(2), 231-243. http://dx.doi.org/10.1242/dev.067082

Bush, J. \& Jiang, R. (2012). Palatogenesis: morphogenetic and molecular mechanisms of secondary palate development. Development, 139(2), 231--243.

Canfield, M., Honein, M., Yuskiv, N., Xing, J., Mai, C., \& Collins, J. et al. (2006). National estimates and race/ethnic-specific variation of selected birth defects in the United States, 1999-2001. Birth Defects Res. Part A Clin. Mol. Teratol., 76(11), 747--756. 
Carette, M. \& Ferguson, M. (1992). The fate of medial edge epithelial cells during palatal fusion in vitro: an analysis by DiI labelling and confocal microscopy. Development, 114(2), 379-388.

Carinci, F., Scapoli, L., Palmieri, A., Zollino, I., \& Pezzetti, F. (2007). Human genetic factors in nonsyndromic cleft lip and palate: an update. Int. J. Pediatr. Otorhinolaryngol., 71(10), 1509--1519.

Carroll, T., Park, J., Hayashi, S., Majumdar, A., \& McMahon, A. (2005). Wnt9b plays a central role in the regulation of mesenchymal to epithelial transitions underlying organogenesis of the mammalian urogenital system. Dev. Cell, 9(2), 283--292.

Carson, D. \& Ribeiro, J. (1993). Apoptosis and disease. Lancet, 341(8855), 1251--1254.

Casey, L., Lan, Y., Cho, E., Maltby, K., Gridley, T., \& Jiang, R. (2006). Jag2-Notch1 signaling regulates oral epithelial differentiation and palate development. Dev. Dyn., 235(7), 1830-1844.

Celli, J., Duijf, P., Hamel, B., Bamshad, M., Kramer, B., \& Smits, A. et al. (1999). Heterozygous germline mutations in the p53 homolog p63 are the cause of EEC syndrome. Cell, 99(2), $143--153$.

Chai, Y. \& Maxson, R. (2006). Recent advances in craniofacial morphogenesis. Dev. Dyn., 235(9), 2353--2375.

Chai, Y., Jiang, X., Ito, Y., Bringas, P., Han, J., \& Rowitch, D. et al. (2000). Fate of the mammalian cranial neural crest during tooth and mandibular morphogenesis. Development, 127(8), 1671--1679.

Cohen, G. (1997). Caspases: the executioners of apoptosis. Biochem. J., 326 ( Pt 1), 1--16.

Cohen, J. (1993). Apoptosis. Immunology Today, 14(3), 126-130.

http://dx.doi.org/10.1016/0167-5699(93)90214-6

Colvin, J., White, A., Pratt, S., \& Ornitz, D. (2001). Lung hypoplasia and neonatal death in Fgf9- 
null mice identify this gene as an essential regulator of lung mesenchyme. Development, 128(11), 2095--2106.

Cooper, M., Ratay, J., \& Marazita, M. (2006). Asian oral-facial cleft birth prevalence. Cleft Palate Craniofac. J., 43(5), 580--589.

Cuervo, R. \& Covarrubias, L. (2004). Death is the major fate of medial edge epithelial cells and the cause of basal lamina degradation during palatogenesis. Development, 131(1), 15--24.

Cui, X., Chai, Y., Chen, J., Yamamoto, T., Ito, Y., Bringas, P., \& Shuler, C. (2003). TGF-beta3dependent SMAD2 phosphorylation and inhibition of MEE proliferation during palatal fusion. Dev. Dyn., 227(3), 387--394.

Cui, X., Shiomi, N., Chen, J., Saito, T., Yamamoto, T., \& Ito, Y. et al. (2005). Overexpression of Smad2 in Tgf-beta3-null mutant mice rescues cleft palate. Dev. Biol., 278(1), 193--202.

Culiat, C., Stubbs, L., Nicholls, R., Montgomery, C., Russell, L., Johnson, D., \& Rinchik, E. (1993). Concordance between isolated cleft palate in mice and alterations within a region including the gene encoding the beta 3 subunit of the type A gamma-aminobutyric acid receptor. Proc. Natl. Acad. Sci. U.S.A., 90(11), 5105--5109.

Culiat, C., Stubbs, L., Woychik, R., Russell, L., Johnson, D., \& Rinchik, E. (1995). Deficiency of the beta 3 subunit of the type A gamma-aminobutyric acid receptor causes cleft palate in mice. Nat. Genet., 11(3), 344--346.

Dai, L., Zhu, J., Mao, M., Li, Y., Deng, Y., \& Wang, Y. et al. (2010). Time trends in oral clefts in Chinese newborns: data from the Chinese National Birth Defects Monitoring Network. Birth Defects Res. Part A Clin. Mol. Teratol., 88(1), 41--47.

De Moerlooze, L., Spencer-Dene, B., Revest, J., Hajihosseini, M., Rosewell, I., \& Dickson, C. (2000). An important role for the IIIb isoform of fibroblast growth factor receptor 2 (FGFR2) in mesenchymal-epithelial signalling during mouse organogenesis. Development, 127(3), 483--492.

DeAngelis, V. \& Nalbandian, J. (1968). Ultrastructure of mouse and rat palatal processes prior to 
and during secondary palate formation. Arch. Oral Biol., 13(6), 601--608.

Dempsey, M., Tan, C., \& Herman, G. (2011). Chondrodysplasia punctata 2, X-linked.

Derynck, R., Zhang, Y., \& Feng, X. (1998). Smads: transcriptional activators of TGF-beta responses. Cell, 95(6), 737--740.

Ding, H., Wu, X., Bostrom, H., Kim, I., Wong, N., \& Tsoi, B. et al. (2004). A specific requirement for PDGF-C in palate formation and PDGFR-alpha signaling. Nat. Genet., 36(10), 1111--1116.

Dixon, M., Marazita, M., Beaty, T., \& Murray, J. (2011). Cleft lip and palate: understanding genetic and environmental influences. Nat Rev Genet, 12(3), 167-178. http://dx.doi.org/10.1038/nrg2933

Dode, C., Levilliers, J., Dupont, J., De Paepe, A., Le Du, N., \& Soussi-Yanicostas, N. et al. (2003). Loss-of-function mutations in FGFR1 cause autosomal dominant Kallmann syndrome. Nat. Genet., 33(4), 463--465.

Dudas, M., Kim, J., Li, W., Nagy, A., Larsson, J., \& Karlsson, S. et al. (2006). Epithelial and ectomesenchymal role of the type I TGF-beta receptor ALK5 during facial morphogenesis and palatal fusion. Dev. Biol., 296(2), 298--314.

Dudas, M., Li, W., Kim, J., Yang, A., \& Kaartinen, V. (2007). Palatal fusion - where do the midline cells go? A review on cleft palate, a major human birth defect. Acta Histochem., 109(1), 1--14.

Dudas, M., Sridurongrit, S., Nagy, A., Okazaki, K., \& Kaartinen, V. (2004). Craniofacial defects in mice lacking BMP type I receptor Alk2 in neural crest cells. Mech. Dev., 121(2), 173-182.

el Ghouzzi, V., Le Merrer, M., Perrin-Schmitt, F., Lajeunie, E., Benit, P., \& Renier, D. et al. (1997). Mutations of the TWIST gene in the Saethre-Chotzen syndrome. Nat. Genet., 15(1), 42--46. 
Elmore, S. (2007). Apoptosis: a review of programmed cell death. Toxicol Pathol, 35(4), 495-516.

Eswarakumar, V., Horowitz, M., Locklin, R., Morriss-Kay, G., \& Lonai, P. (2004). A gain-offunction mutation of Fgfr2c demonstrates the roles of this receptor variant in osteogenesis. Proc. Natl. Acad. Sci. U.S.A., 101(34), 12555--12560.

Farbman, A. (1968). Electron microscope study of palate fusion in mouse embryos. Dev. Biol., $18(2), 93--116$.

Farbman, A. (1968). Electron microscope study of palate fusion in mouse embryos. Dev. Biol., 18(2), 93--116.

Feng, X. \& Derynck, R. (2005). Specificity and versatility in tgf-beta signaling through Smads. Annu. Rev. Cell Dev. Biol., 21, 659--693.

Ferguson, M. (1988). Palate development. Development, 103(Suppl), 41-60.

Ferrante, M., Giorgio, G., Feather, S., Bulfone, A., Wright, V., \& Ghiani, M. et al. (2001). Identification of the gene for oral-facial-digital type I syndrome. Am. J. Hum. Genet., 68(3), 569--576.

Fitchett, J. \& Hay, E. (1989). Medial edge epithelium transforms to mesenchyme after embryonic palatal shelves fuse. Dev. Biol., 131(2), 455--474.

FitzPatrick, D., Carr, I., McLaren, L., Leek, J., Wightman, P., \& Williamson, K. et al. (2003). Identification of SATB2 as the cleft palate gene on 2q32-q33. Hum. Mol. Genet., 12(19), 2491--2501.

Fitzpatrick, D., Denhez, F., Kondaiah, P., \& Akhurst, R. (1990). Differential expression of TGF beta isoforms in murine palatogenesis. Development, 109(3), 585--595.

Flannagan, R., Jaumouille, V., \& Grinstein, S. (2012). The cell biology of phagocytosis. Annu Rev Pathol, 7, 61--98.

Fogh-Andersen, P. \& Aagesen, E. (1942). Inheritance of Harelip and Cleft Palate: Contribution 
to the Elucidation of the Etiology of the Congenital Clefts of the Face. Munksgaard.

Foster, J., Dominguez-Steglich, M., Guioli, S., Kwok, C., Weller, P., \& Stevanovi?, M. et al. (1994). Campomelic dysplasia and autosomal sex reversal caused by mutations in an SRYrelated gene. Nature, 372(6506), 525--530.

Frank, D., Fotheringham, L., Brewer, J., Muglia, L., Tristani-Firouzi, M., Capecchi, M., \& Moon, A. (2002). An Fgf8 mouse mutant phenocopies human 22q11 deletion syndrome. Development, 129(19), 4591--4603.

Frebourg, T., Oliveira, C., Hochain, P., Karam, R., Manouvrier, S., \& Graziadio, C. et al. (2006). Cleft lip/palate and CDH1/E-cadherin mutations in families with hereditary diffuse gastric cancer. J. Med. Genet., 43(2), 138--142.

Fujita, T., Alotaibi, M., Kitase, Y., Kota, Y., Ouhara, K., Kurihara, H., \& Shuler, C. (2012). Smad2 is involved in the apoptosis of murine gingival junctional epithelium associated with inhibition of Bcl-2. Arch. Oral Biol., 57(11), 1567--1573.

Gavrieli, Y., Sherman, Y., \& Ben-Sasson, S. (1992). Identification of programmed cell death in situ via specific labeling of nuclear DNA fragmentation. J. Cell Biol., 119(3), 493--501.

Genisca, A., Frias, J., Broussard, C., Honein, M., Lammer, E., \& Moore, C. et al. (2009). Orofacial clefts in the National Birth Defects Prevention Study, 1997-2004. Am. J. Med. Genet. A, 149A(6), 1149--1158.

Greene, E. (1963). anatomy of the rat. New York: Hafner Publishing Company.

Griffith, C. \& Hay, E. (1992). Epithelial-mesenchymal transformation during palatal fusion: carboxyfluorescein traces cells at light and electron microscopic levels. Development, 116(4), 1087--1099.

Gripp, K., Wotton, D., Edwards, M., Roessler, E., Ades, L., \& Meinecke, P. et al. (2000). Mutations in TGIF cause holoprosencephaly and link NODAL signalling to human neural axis determination. Nat. Genet., 25(2), 205--208. 
Gritli-Linde, A. (2007). Molecular control of secondary palate development. Developmental Biology, 301(2), 309-326. http://dx.doi.org/10.1016/j.ydbio.2006.07.042

Gritli-Linde, A. (2008). The etiopathogenesis of cleft lip and cleft palate: usefulness and caveats of mouse models. Curr. Top. Dev. Biol., 84, 37--138.

Gundlach, K. \& Maus, C. (2006). Epidemiological studies on the frequency of clefts in Europe and world-wide. J Craniomaxillofac Surg, 34 Suppl 2, 1--2.

Gurley, J., Wamsley, M., \& Sandell, L. (2004). Alterations in apoptosis and epithelialmesenchymal transformation in an in vitro cleft palate model. Plast. Reconstr. Surg., 113(3), 907--914.

Hagiwara, N., Katarova, Z., Siracusa, L., \& Brilliant, M. (2003). Nonneuronal expression of the GABA(A) beta3 subunit gene is required for normal palate development in mice. Dev. Biol., 254(1), 93--101.

Hahn, H., Wicking, C., Zaphiropoulous, P., Gailani, M., Shanley, S., \& Chidambaram, A. et al. (1996). Mutations of the human homolog of Drosophila patched in the nevoid basal cell carcinoma syndrome. Cell, 85(6), 841--851.

Halford, M., Armes, J., Buchert, M., Meskenaite, V., Grail, D., \& Hibbs, M. et al. (2000). Rykdeficient mice exhibit craniofacial defects associated with perturbed Eph receptor crosstalk. Nat. Genet., 25(4), 414--418.

Hancock, J. (2010). Cell signalling. Oxford: Oxford University Press.

Hanson, J., Myrianthopoulos, N., Harvey, M., \& Smith, D. (1976). Risks to the offspring of women treated with hydantoin anticonvulsants, with emphasis on the fetal hydantoin syndrome. J. Pediatr., 89(4), 662--668.

Hay, E. (1990). Role of cell-matrix contacts in cell migration and epithelial-mesenchymal transformation. Cell Differ. Dev., 32(3), 367--375.

Hayward, A. (1969). Ultrastructural changes in the epithelium during fusion of the palatal 
processes in rats. Arch. Oral Biol., 14(6), 661--678.

Homanics, G., DeLorey, T., Firestone, L., Quinlan, J., Handforth, A., \& Harrison, N. et al. (1997). Mice devoid of gamma-aminobutyrate type A receptor beta3 subunit have epilepsy, cleft palate, and hypersensitive behavior. Proc. Natl. Acad. Sci. U.S.A., 94(8), 4143--4148.

Hosokawa, R., Oka, K., Yamaza, T., Iwata, J., Urata, M., \& Xu, X. et al. (2010). TGF-beta mediated FGF10 signaling in cranial neural crest cells controls development of myogenic progenitor cells through tissue-tissue interactions during tongue morphogenesis. Dev. Biol., 341(1), 186--195.

Howard, T., Paznekas, W., Green, E., Chiang, L., Ma, N., \& Ortiz de Luna, R. et al. (1997). Mutations in TWIST, a basic helix-loop-helix transcription factor, in Saethre-Chotzen syndrome. Nat. Genet., 15(1), 36--41.

Iamaroon, A. \& Diewert, V. (1996). Distribution of basement membrane components in the mouse primary palate. J. Craniofac. Genet. Dev. Biol., 16(1), 48--51.

Iseki, S. (2011). Disintegration of the medial epithelial seam: is cell death important in palatogenesis?. Dev. Growth Differ., 53(2), 259--268.

Ishizuya-Oka, A., Hasebe, T., \& Shi, Y. (2009). Apoptosis in amphibian organs during metamorphosis. Apoptosis, 15(3), 350-364. http://dx.doi.org/10.1007/s10495-009-0422-y

Ito, Y., Sarkar, P., Mi, Q., Wu, N., Bringas, P., \& Liu, Y. et al. (2001). Overexpression of Smad2 reveals its concerted action with Smad4 in regulating TGF-beta-mediated epidermal homeostasis. Dev. Biol., 236(1), 181--194.

Ito, Y., Yeo, J., Chytil, A., Han, J., Bringas, P., \& Nakajima, A. et al. (2003). Conditional inactivation of Tgfbr2 in cranial neural crest causes cleft palate and calvaria defects. Development, 130(21), 5269--5280.

Iwata, J., Hosokawa, R., Sanchez-Lara, P., Urata, M., Slavkin, H., \& Chai, Y. (2010). Transforming growth factor-beta regulates basal transcriptional regulatory machinery to control cell proliferation and differentiation in cranial neural crest-derived osteoprogenitor 
cells. J. Biol. Chem., 285(7), 4975--4982.

Iwata, J., Parada, C., \& Chai, Y. (2011). The mechanism of TGF-Ã $Z \hat{A}^{2}$ signaling during palate development. Oral Dis, 17(8), 733--744.

Jeong, L. (2009). Genetic review of mouse and human cleft lip and palate (Msc). university of southern california.

Jiang, R., Lan, Y., Chapman, H., Shawber, C., Norton, C., \& Serreze, D. et al. (1998). Defects in limb, craniofacial, and thymic development in Jagged2 mutant mice. Genes Dev., 12(7), 1046--1057.

Jin, J. \& Ding, J. (2006). Analysis of cell migration, transdifferentiation and apoptosis during mouse secondary palate fusion. Development, 133(17), 3341--3347.

Johnson, R., Rothman, A., Xie, J., Goodrich, L., Bare, J., \& Bonifas, J. et al. (1996). Human homolog of patched, a candidate gene for the basal cell nevus syndrome. Science, 272(5268), 1668--1671.

Johnston, J., Sapp, J., Turner, J., Amor, D., Aftimos, S., \& Aleck, K. et al. (2010). Molecular analysis expands the spectrum of phenotypes associated with GLI3 mutations. Hum. Mutat., 31(10), 1142--1154.

Jugessur, A., Farlie, P., \& Kilpatrick, N. (2009). The genetics of isolated orofacial clefts: from genotypes to subphenotypes. Oral Diseases, 15(7), 437-453.

http://dx.doi.org/10.1111/j.1601-0825.2009.01577.x

Jugessur, A., Shi, M., Gjessing, H., Lie, R., Wilcox, A., \& Weinberg, C. et al. (2009). Genetic Determinants of Facial Clefting: Analysis of 357 Candidate Genes Using Two National Cleft Studies from Scandinavia. Plos ONE, 4(4), e5385.

http://dx.doi.org/10.1371/journal.pone.0005385

Juriloff, D., Harris, M., McMahon, A., Carroll, T., \& Lidral, A. (2006). Wnt9b is the mutated gene involved in multifactorial nonsyndromic cleft lip with or without cleft palate in A/WySn mice, as confirmed by a genetic complementation test. Birth Defects Res. Part A 
Clin. Mol. Teratol., 76(8), 574--579.

Kaartinen, V., Cui, X., Heisterkamp, N., Groffen, J., \& Shuler, C. (1997). Transforming growth factor-beta3 regulates transdifferentiation of medial edge epithelium during palatal fusion and associated degradation of the basement membrane. Dev. Dyn., 209(3), 255--260.

Kaartinen, V., Voncken, J., Shuler, C., Warburton, D., Bu, D., Heisterkamp, N., \& Groffen, J. (1995). Abnormal lung development and cleft palate in mice lacking TGF-beta 3 indicates defects of epithelial-mesenchymal interaction. Nat. Genet., 11(4), 415--421.

Kalay, E., Sezgin, O., Chellappa, V., Mutlu, M., Morsy, H., \& Kayserili, H. et al. (2012). Mutations in RIPK4 cause the autosomal-recessive form of popliteal pterygium syndrome. Am. J. Hum. Genet., 90(1), 76--85.

Kalluri, R. \& Neilson, E. (2003). Epithelial-mesenchymal transition and its implications for fibrosis. J. Clin. Invest., 112(12), 1776--1784.

Kang, J., Liu, C., \& Derynck, R. (2009). New regulatory mechanisms of TGF-beta receptor function. Trends Cell Biol., 19(8), 385--394.

Kang, P. \& Svoboda, K. (2005). Epithelial-mesenchymal transformation during craniofacial development. J. Dent. Res., 84(8), 678--690.

Katebi, N., Kolpakova-Hart, E., Lin, C., \& Olsen, B. (2012). The mouse palate and its cellular responses to midpalatal suture expansion forces. Orthod Craniofac Res, 15(3), 148--158.

Kaufman, M. (1992). The atlas of mouse development. London: Academic Press.

Kernahan, D. \& Rosenstein, S. (1990). Cleft lip and palate. Baltimore: Williams \& Wilkins.

Khoshnoodi, J., Pedchenko, V., \& Hudson, B. (2008). Mammalian collagen IV. Microsc. Res. Tech., 71(5), 357--370.

Kim, H., Herrick, S., Lemyre, E., Kishikawa, S., Salisz, J., \& Seminara, S. et al. (2005). Hypogonadotropic hypogonadism and cleft lip and palate caused by a balanced translocation producing haploinsufficiency for FGFR1. Journal Of Medical Genetics, 42(8), 
666-672. http://dx.doi.org/10.1136/jmg.2004.026989

Kitase, Y., Yamashiro, K., Fu, K., Richman, J., \& Shuler, C. (2011). Spatiotemporal localization of periostin and its potential role in epithelial-mesenchymal transition during palatal fusion. Cells Tissues Organs (Print), 193(1-2), 53--63.

Kitisin, K., Saha, T., Blake, T., Golestaneh, N., Deng, M., \& Kim, C. et al. (2007). Tgf-Beta signaling in development. Sci. STKE, 2007(399), 1.

Klinghoffer, R., Hamilton, T., Hoch, R., \& Soriano, P. (2002). An Allelic Series at the PDGFÎ \pm R Locus Indicates Unequal Contributions of Distinct Signaling Pathways During Development. Developmental Cell, 2(1), 103-113. http://dx.doi.org/10.1016/s15345807(01)00103-4

Kondo, S., Schutte, B., Richardson, R., Bjork, B., Knight, A., \& Watanabe, Y. et al. (2002). Mutations in IRF6 cause Van der Woude and popliteal pterygium syndromes. Nat. Genet., 32(2), 285--289.

Koo, S., Cunningham, M., Arabshahi, B., Gruss, J., \& Grant, J. (2001). The transforming growth factor-beta 3 knock-out mouse: an animal model for cleft palate. Plast. Reconstr. Surg., 108(4), 938--948.

Krantz, I., McCallum, J., DeScipio, C., Kaur, M., Gillis, L., \& Yaeger, D. et al. (2004). Cornelia de Lange syndrome is caused by mutations in NIPBL, the human homolog of Drosophila melanogaster Nipped-B. Nat. Genet., 36(6), 631--635.

Krauss, R. (2008). Mouse models of developmental genetic disease. San Diego, Calif.: Academic.

Kroemer, G., El-Deiry, W., Golstein, P., Peter, M., Vaux, D., \& Vandenabeele, P. et al. (2005). Classification of cell death: recommendations of the Nomenclature Committee on Cell Death. Cell Death Differ, 12, 1463-1467. http://dx.doi.org/10.1038/sj.cdd.4401724

Kulkarni, A., Ward, J., Yaswen, L., Mackall, C., Bauer, S., \& Huh, C. et al. (1995). Transforming growth factor-beta 1 null mice. An animal model for inflammatory disorders. 
Am. J. Pathol., 146(1), 264--275.

Kurihara, Y., Kurihara, H., Suzuki, H., Kodama, T., Maemura, K., \& Nagai, R. et al. (1994). Elevated blood pressure and craniofacial abnormalities in mice deficient in endothelin-1. Nature, 368(6473), 703--710.

Lamouille, S., Xu, J., \& Derynck, R. (2014). Molecular mechanisms of epithelial-mesenchymal transition. Nat. Rev. Mol. Cell Biol., 15(3), 178--196.

Lamouille, S., Xu, J., \& Derynck, R. (2014). Molecular mechanisms of epithelial-mesenchymal transition. Nat. Rev. Mol. Cell Biol., 15(3), 178--196.

Larsson, J., Goumans, M., Sjostrand, L., van Rooijen, M., Ward, D., \& Leveen, P. et al. (2001). Abnormal angiogenesis but intact hematopoietic potential in TGF-beta type I receptordeficient mice. EMBO J., 20(7), 1663--1673.

Laumonnier, F., Holbert, S., Ronce, N., Faravelli, F., Lenzner, S., \& Schwartz, C. et al. (2005). Mutations in PHF8 are associated with X linked mental retardation and cleft lip/cleft palate. J. Med. Genet., 42(10), 780--786.

Lederer, D., Grisart, B., Digilio, M., Benoit, V., Crespin, M., \& Ghariani, S. et al. (2012). Deletion of KDM6A, a histone demethylase interacting with MLL2, in three patients with Kabuki syndrome. Am. J. Hum. Genet., 90(1), 119--124.

Lee, C., Hwang, S., Lee, Y., Kim, M., \& Seo, K. (2015). Prevalence of orofacial clefts in Korean live births. Obstet Gynecol Sci, 58(3), 196--202.

Lee, J., Wan, X., Song, J., Kang, J., Chung, W., Lee, E., \& Kim, E. (2002). TGF-beta-induced apoptosis and reduction of Bcl-2 in human lens epithelial cells in vitro. Curr. Eye Res., 25(3), 147--153.

Leslie, E. \& Marazita, M. (2013). Genetics of cleft lip and cleft palate. Am. J. Med. Genet., 163(4), 246-258. http://dx.doi.org/10.1002/ajmg.c.31381

Li, Y., Yang, J., Luo, J., Dedhar, S., \& Liu, Y. (2007). Tubular epithelial cell dedifferentiation is 
driven by the helix-loop-helix transcriptional inhibitor Id1. J. Am. Soc. Nephrol., 18(2), 449--460.

Lidral, A., Romitti, P., Basart, A., Doetschman, T., Leysens, N., \& Daack-Hirsch, S. et al. (1998). Association of MSX1 and TGFB3 with nonsyndromic clefting in humans. Am. J. Hum. Genet., 63(2), 557--568.

Lin, Y., Shu, S., \& Tang, S. (2014). A case-control study of environmental exposures for nonsyndromic cleft of the lip and/or palate in eastern Guangdong, China. International Journal Of Pediatric Otorhinolaryngology, 78(3), 545-551.

http://dx.doi.org/10.1016/j.ijporl.2014.01.002

listed, N. (1996). Positional cloning of a gene involved in the pathogenesis of Treacher Collins syndrome. The Treacher Collins Syndrome Collaborative Group. Nat. Genet., 12(2), 130-136.

Liu, L., Liu, X., Ren, X., Tian, Y., Chen, Z., \& Xu, X. et al. (2016). Smad2 and Smad3 have differential sensitivity in relaying TGFÃŽ $\hat{A}^{2}$ signaling and inversely regulate early lineage specification. Sci Rep, 6, 21602.

Liu, W., Sun, X., Braut, A., Mishina, Y., Behringer, R., Mina, M., \& Martin, J. (2005). Distinct functions for Bmp signaling in lip and palate fusion in mice. Development, 132(6), 1453-1461.

Liu, Z., Xu, J., Colvin, J., \& Ornitz, D. (2002). Coordination of chondrogenesis and osteogenesis by fibroblast growth factor 18. Genes Dev., 16(7), 859--869.

Loeys, B., Chen, J., Neptune, E., Judge, D., Podowski, M., \& Holm, T. et al. (2005). A syndrome of altered cardiovascular, craniofacial, neurocognitive and skeletal development caused by mutations in TGFBR1 or TGFBR2. Nat. Genet., 37(3), 275--281.

Lohnes, D., Mark, M., Mendelsohn, C., Dolle, P., Dierich, A., \& Gorry, P. et al. (1994). Function of the retinoic acid receptors (RARs) during development (I). Craniofacial and skeletal abnormalities in RAR double mutants. Development, 120(10), 2723--2748. 
Lv, Z., Yang, Z., Wang, H., Li, J., Kong, B., \& Wang, X. et al. (2012). The cytotoxic effect of TGF-Ã $̌ \hat{A}^{2} 1$ on mesothelial cells via apoptosis in early peritoneal carcinomatosis. Oncol. Rep., 27(6), 1753--1758.

Machida, J., FÃ@lix, T., Murray, J., Yoshiura, K., Tanemura, M., \& Kamamoto, M. et al. (2009). Searching for Genes for Cleft Lip and/or Palate Based on Breakpoint Analysis of a Balanced Translocation t(9;17)(q32;q12). The Cleft Palate-Craniofacial Journal, 46(5), 532-540. http://dx.doi.org/10.1597/08-047.1

Maestri, N., Beaty, T., Hetmanski, J., Smith, E., McIntosh, I., \& Wyszynski, D. et al. (1997). Application of transmission disequilibrium tests to nonsyndromic oral clefts: including candidate genes and environmental exposures in the models. Am. J. Med. Genet., 73(3), 337--344.

Marazita, M., Lidral, A., Murray, J., Field, L., Maher, B., \& Goldstein McHenry, T. et al. (2009). Genome Scan, Fine-Mapping, and Candidate Gene Analysis of Non-Syndromic Cleft Lip with or without Cleft Palate Reveals Phenotype-Specific Differences in Linkage and Association Results. Human Heredity, 68(3), 151-170. http://dx.doi.org/10.1159/000224636

Marazita, M., Murray, J., Lidral, A., Arcos-Burgos, M., Cooper, M., \& Goldstein, T. et al. (2004). Meta-Analysis of 13 Genome Scans Reveals Multiple Cleft Lip/Palate Genes with Novel Loci on 9q21 and 2q32-35. The American Journal Of Human Genetics, 75(2), 161173. http://dx.doi.org/10.1086/422475

Marazita, M., Spence, M., \& Melnick, M. (1984). Genetic analysis of cleft lip with or without cleft palate in Danish kindreds. American Journal Of Medical Genetics, 19(1), 9-18. http://dx.doi.org/10.1002/ajmg.1320190104

Marks, F., KlingmuÌ̀ller, U., \& Muì̀ller-Decker, K. (2009). Cellular signal processing. New York: Garland Science.

Martinez-Alvarez, C., Tudela, C., Perez-Miguelsanz, J., O'Kane, S., Puerta, J., \& Ferguson, M. (2000). Medial edge epithelial cell fate during palatal fusion. Dev. Biol., 220(2), 343--357. 
Martinez-Sanz, E., Del Rio, A., Barrio, C., Murillo, J., Maldonado, E., \& Garcillan, B. et al. (2008). Alteration of medial-edge epithelium cell adhesion in two Tgf-beta3 null mouse strains. Differentiation, 76(4), 417--430.

Massague, J. (2000). How cells read TGF-beta signals. Nat. Rev. Mol. Cell Biol., 1(3), 169--178.

Massague, J. \& Chen, Y. (2000). Controlling TGF-beta signaling. Genes Dev., 14(6), 627--644.

Massague, J. \& Wotton, D. (2000). Transcriptional control by the TGF-beta/Smad signaling system. EMBO J., 19(8), 1745--1754.

Mastroiacovo, P., Maraschini, A., Leoncini, E., Mossey, P., Bower, C., \& Castilla, E. et al. (2011). Prevalence at birth of cleft lip with or without cleft palate: data from the International Perinatal Database of Typical Oral Clefts (IPDTOC). Cleft Palate Craniofac. J., 48(1), 66--81.

Matzuk, M., Kumar, T., \& Bradley, A. (1995). Different phenotypes for mice deficient in either activins or activin receptor type II. Nature, 374(6520), 356--360.

Matzuk, M., Kumar, T., Vassalli, A., Bickenbach, J., Roop, D., Jaenisch, R., \& Bradley, A. (1995). Functional analysis of activins during mammalian development. Nature, 374(6520), 354--356.

Matzuk, M., Lu, N., Vogel, H., Sellheyer, K., Roop, D., \& Bradley, A. (1995). Multiple defects and perinatal death in mice deficient in follistatin. Nature, 374(6520), 360--363.

McClay, D. \& Ettensohn, C. (1987). Cell adhesion in morphogenesis. Annu. Rev. Cell Biol., 3, 319--345.

McGrath, J., Duijf, P., Doetsch, V., Irvine, A., de Waal, R., \& Vanmolkot, K. et al. (2001). HayWells syndrome is caused by heterozygous missense mutations in the SAM domain of p63. Hum. Mol. Genet., 10(3), 221--229.

Melino, G., Knight, R., \& Nicotera, P. (2005). How many ways to die? How many different models of cell death?. Cell Death Differ, 12, 1457-1462. 
http://dx.doi.org/10.1038/sj.cdd.4401781

Menke, A., Philippi, C., Vogelmann, R., Seidel, B., Lutz, M., Adler, G., \& Wedlich, D. (2001). Down-regulation of E-cadherin gene expression by collagen type I and type III in pancreatic cancer cell lines. Cancer Res., 61(8), 3508--3517.

Miettinen, P., Chin, J., Shum, L., Slavkin, H., Shuler, C., Derynck, R., \& Werb, Z. (1999). Epidermal growth factor receptor function is necessary for normal craniofacial development and palate closure. Nat. Genet., 22(1), 69--73.

Milunsky, J., Maher, T., Zhao, G., Roberts, A., Stalker, H., \& Zori, R. et al. (2008). TFAP2A mutations result in branchio-oculo-facial syndrome. Am. J. Hum. Genet., 82(5), 1171-1177.

Mitchell, K., O'Sullivan, J., Missero, C., Blair, E., Richardson, R., \& Anderson, B. et al. (2012). Exome sequence identifies RIPK4 as the Bartsocas-Papas syndrome locus. Am. J. Hum. Genet., 90(1), 69--75.

Morgan, N., Brueton, L., Cox, P., Greally, M., Tolmie, J., \& Pasha, S. et al. (2006). Mutations in the embryonal subunit of the acetylcholine receptor (CHRNG) cause lethal and Escobar variants of multiple pterygium syndrome. Am. J. Hum. Genet., 79(2), 390--395.

Mossey, P. \& Modell, B. (2012). Epidemiology of Oral Clefts 2012: An International Perspective, 1-18. http://dx.doi.org/10.1159/000337464

Mossey, P., Little, J., Munger, R., Dixon, M., \& Shaw, W. (2009). Cleft lip and palate. The Lancet, 374(9703), 1773-1785. http://dx.doi.org/10.1016/s0140-6736(09)60695-4

Mu, Y., Gudey, S., \& Landstrom, M. (2012). Non-Smad signaling pathways. Cell Tissue Res., $347(1), 11--20$.

Nagata, S. (1997). Apoptosis by death factor. Cell, 88(3), 355--365.

Nam, J., Park, E., Turcotte, T., Palencia, S., Zhan, X., \& Lee, J. et al. (2007). Mouse R-spondin2 is required for apical ectodermal ridge maintenance in the hindlimb. Dev. Biol., 311(1), 
124--135.

Nawshad, A. (2008). Palatal seam disintegration: to die or not to die? that is no longer the question. Dev. Dyn., 237(10), 2643--2656.

Nawshad, A. \& Hay, E. (2003). TGFbeta3 signaling activates transcription of the LEF1 gene to induce epithelial mesenchymal transformation during mouse palate development. J. Cell Biol., 163(6), 1291--1301.

Ng, D., Thakker, N., Corcoran, C., Donnai, D., Perveen, R., \& Schneider, A. et al. (2004). Oculofaciocardiodental and Lenz microphthalmia syndromes result from distinct classes of mutations in BCOR. Nat. Genet., 36(4), 411--416.

Ng, S., Bigham, A., Buckingham, K., Hannibal, M., McMillin, M., \& Gildersleeve, H. et al. (2010). Exome sequencing identifies MLL2 mutations as a cause of Kabuki syndrome. Nat. Genet., 42(9), 790--793.

Ng, S., Buckingham, K., Lee, C., Bigham, A., Tabor, H., \& Dent, K. et al. (2010). Exome sequencing identifies the cause of a mendelian disorder. Nat. Genet., 42(1), 30--35.

Niemann, S., Zhao, C., Pascu, F., Stahl, U., Aulepp, U., \& Niswander, L. et al. (2004). Homozygous WNT3 mutation causes tetra-amelia in a large consanguineous family. Am. $J$. Hum. Genet., 74(3), 558--563.

Nomura, M. \& Li, E. (1998). Smad2 role in mesoderm formation, left-right patterning and craniofacial development. Nature, 393(6687), 786--790.

Ohbayashi, N., Shibayama, M., Kurotaki, Y., Imanishi, M., Fujimori, T., Itoh, N., \& Takada, S. (2002). FGF18 is required for normal cell proliferation and differentiation during osteogenesis and chondrogenesis. Genes Dev., 16(7), 870--879.

Orioli, D., Henkemeyer, M., Lemke, G., Klein, R., \& Pawson, T. (1996). Sek4 and Nuk receptors cooperate in guidance of commissural axons and in palate formation. EMBO J., 15(22), 6035--6049. 
Oshima, M., Oshima, H., \& Taketo, M. (1996). TGF-beta receptor type II deficiency results in defects of yolk sac hematopoiesis and vasculogenesis. Dev. Biol., 179(1), 297--302.

Oskarsdottir, S. (2004). Incidence and prevalence of the 22q11 deletion syndrome: a populationbased study in Western Sweden. Archives Of Disease In Childhood, 89(2), 148-151. http://dx.doi.org/10.1136/adc.2003.026880

Packham, E. \& Brook, J. (2003). T-box genes in human disorders. Hum. Mol. Genet., 12 Spec No $1,37--44$.

Pavri, S. \& Forrest, C. (2013). Demographics of Orofacial Clefts in Canada From 2002 to 2008. The Cleft Palate-Craniofacial Journal, 50(2), 224-230. http://dx.doi.org/10.1597/10-223

Porter, F. (2000). RSH/Smith-Lemli-Opitz syndrome: a multiple congenital anomaly/mental retardation syndrome due to an inborn error of cholesterol biosynthesis. Mol. Genet. Metab., 71(1-2), 163--174.

Proetzel, G., Pawlowski, S., Wiles, M., Yin, M., Boivin, G., \& Howles, P. et al. (1995). Transforming growth factor-beta 3 is required for secondary palate fusion. Nat. Genet., 11(4), 409--414.

Quaderi, N., Schweiger, S., Gaudenz, K., Franco, B., Rugarli, E., \& Berger, W. et al. (1997). Opitz G/BBB syndrome, a defect of midline development, is due to mutations in a new RING finger gene on Xp22. Nat. Genet., 17(3), 285--291.

Reardon, W., Winter, R., Rutland, P., Pulleyn, L., Jones, B., \& Malcolm, S. (1994). Mutations in the fibroblast growth factor receptor 2 gene cause Crouzon syndrome. Nat. Genet., 8(1), 98-103 .

Rice, R., Spencer-Dene, B., Connor, E., Gritli-Linde, A., McMahon, A., \& Dickson, C. et al. (2004). Disruption of Fgf10/Fgfr2b-coordinated epithelial-mesenchymal interactions causes cleft palate. J. Clin. Invest., 113(12), 1692--1700.

Robertson, S., Twigg, S., Sutherland-Smith, A., Biancalana, V., Gorlin, R., \& Horn, D. et al. (2003). Localized mutations in the gene encoding the cytoskeletal protein filamin A cause 
diverse malformations in humans. Nat. Genet., 33(4), 487--491.

Roessler, E., Belloni, E., Gaudenz, K., Jay, P., Berta, P., \& Scherer, S. et al. (1996). Mutations in the human Sonic Hedgehog gene cause holoprosencephaly. Nat. Genet., 14(3), 357--360.

Roessler, E., Du, Y., Mullor, J., Casas, E., Allen, W., \& Gillessen-Kaesbach, G. et al. (2003). Loss-of-function mutations in the human GLI2 gene are associated with pituitary anomalies and holoprosencephaly-like features. Proc. Natl. Acad. Sci. U.S.A., 100(23), 13424--13429.

Romitti, P., Lidral, A., Munger, R., Daack-Hirsch, S., Burns, T., \& Murray, J. (1999). Candidate genes for nonsyndromic cleft lip and palate and maternal cigarette smoking and alcohol consumption: evaluation of genotype-environment interactions from a population-based case-control study of orofacial clefts. Teratology, 59(1), 39--50.

Sabbagh, H., Alamoudi, N., Abdulhameed, F., Innes, N., Al-Aama, J., \& Hummaida, T. et al. (2015). Environmental Risk Factors in the Etiology of Nonsyndromic Orofacial Clefts in the Western Region of Saudi Arabia. The Cleft Palate-Craniofacial Journal. http://dx.doi.org/10.1597/14-136

Sabbagh, H., Innes, N., Sallout, B., Alamoudi, N., Hamdan, M., \& Alhamlan, N. et al. (2015). Birth prevalence of non-syndromic orofacial clefts in Saudi Arabia and the effects of parental consanguinity. Saudi Medical Journal, 36(9), 1076-1083. http://dx.doi.org/10.15537/smj.2015.9.11823

Sadler, T. \& Langman, J. (2010). Langman's medical embryology. Philadelphia: Lippincott William \& Wilkins.

Saelens, X., Festjens, N., Vande Walle, L., van Gurp, M., van Loo, G., \& Vandenabeele, P. (2004). Toxic proteins released from mitochondria in cell death. Oncogene, 23(16), 2861-2874.

Sakahira, H., Enari, M., \& Nagata, S. (1998). Cleavage of CAD inhibitor in CAD activation and DNA degradation during apoptosis. Nature, 391(6662), 96--99.

Sanford, L., Ormsby, I., Gittenberger-de Groot, A., Sariola, H., Friedman, R., \& Boivin, G. et al. 
(1997). TGFbeta2 knockout mice have multiple developmental defects that are nonoverlapping with other TGFbeta knockout phenotypes. Development, 124(13), 2659--2670.

Schoenwolf, G. \& Larsen, W. (2009). Larsen's human embryology. Philadelphia: Churchill Livingstone/Elsevier.

Schulze-Osthoff, K. (2008). apoptosis, cytotoxicity, and cell proliferation manual (4th ed.). Mannheim: Roche Applied Science. Retrieved from https://lifescience.roche.com/wcsstore/RASCatalogAssetStore/Articles/05242134001_05.08 .pdf

Schuster, N. \& Krieglstein, K. (2002). Mechanisms of TGF-beta-mediated apoptosis. Cell Tissue Res., 307(1), 1--14.

Science in School,. (2015). Representation of cell death: apoptosis and necrosis. Retrieved from http://www.scienceinschool.org/sites/default/files/articleContentImages/31/socientize/socie ntize3.jpg

Serbedzija, G., Bronner-Fraser, M., \& Fraser, S. (1989). A vital dye analysis of the timing and pathways of avian trunk neural crest cell migration. Development, 106(4), 809--816.

Serbedzija, G., Bronner-Fraser, M., \& Fraser, S. (1992). Vital dye analysis of cranial neural crest cell migration in the mouse embryo. Development, 116(2), 297--307.

Serbedzija, G., Burgan, S., Fraser, S., \& Bronner-Fraser, M. (1991). Vital dye labelling demonstrates a sacral neural crest contribution to the enteric nervous system of chick and mouse embryos. Development, 111(4), 857--866.

Sgonc, R. \& Gruber, J. (1998). Apoptosis detection: an overview. Exp. Gerontol., 33(6), 525-533.

Shah, R., Schuing, R., Benkhaial, G., Young, A., \& Burdett, D. (1991). Genesis of hadacidininduced cleft palate in hamster: morphogenesis, electron microscopy, and determination of DNA synthesis, cAMP, and enzyme acid phosphatase. Am. J. Anat., 192(1), 55--68. 
Shapiro, B. \& Sweney, L. (1969). Electron microscopic and histochemical examination of oral epithelial-mesenchymal interaction (programmed cell death). J. Dent. Res., 48(5), 652--660.

Shuler, C. (1995). Programmed cell death and cell transformation in craniofacial development. Crit. Rev. Oral Biol. Med., 6(3), 202--217.

Shuler, C., Guo, Y., Majumder, A., \& Luo, R. (1991). Molecular and morphologic changes during the epithelial-mesenchymal transformation of palatal shelf medial edge epithelium in vitro. Int. J. Dev. Biol., 35(4), 463--472.

Shuler, C., Halpern, D., Guo, Y., \& Sank, A. (1992). Medial edge epithelium fate traced by cell lineage analysis during epithelial-mesenchymal transformation in vivo. Dev. Biol., 154(2), 318--330.

Snead, M. \& Yates, J. (1999). Clinical and Molecular genetics of Stickler syndrome. J. Med. Genet., 36(5), 353--359.

Soo, K., O'Rourke, M., Khoo, P., Steiner, K., Wong, N., Behringer, R., \& Tam, P. (2002). Twist function is required for the morphogenesis of the cephalic neural tube and the differentiation of the cranial neural crest cells in the mouse embryo. Dev. Biol., 247(2), 251-270 .

Stanier, P. \& Moore, G. (2004). Genetics of cleft lip and palate: syndromic genes contribute to the incidence of non-syndromic clefts. Human Molecular Genetics, 13(90001), 73R-81. http://dx.doi.org/10.1093/hmg/ddh052

Stenvers, K., Tursky, M., Harder, K., Kountouri, N., Amatayakul-Chantler, S., \& Grail, D. et al. (2003). Heart and liver defects and reduced transforming growth factor beta2 sensitivity in transforming growth factor beta type III receptor-deficient embryos. Mol. Cell. Biol., 23(12), 4371--4385.

Suzuki, K., Hu, D., Bustos, T., Zlotogora, J., Richieri-Costa, A., Helms, J., \& Spritz, R. (2000). Mutations of PVRL1, encoding a cell-cell adhesion molecule/herpesvirus receptor, in cleft lip/palate-ectodermal dysplasia. Nat. Genet., 25(4), 427--430. 
Takigawa, T. \& Shiota, K. (2004). Terminal differentiation of palatal medial edge epithelial cells in vitro is not necessarily dependent on palatal shelf contact and midline epithelial seam formation. Int. J. Dev. Biol., 48(4), 307--317.

Tallquist, M. \& Soriano, P. (2003). Cell autonomous requirement for PDGFRalpha in populations of cranial and cardiac neural crest cells. Development, 130(3), 507--518.

Taya, Y., O'Kane, S., \& Ferguson, M. (1999). Pathogenesis of cleft palate in TGF-beta3 knockout mice. Development, 126(17), 3869--3879.

Thiery, J. \& Sleeman, J. (2006). Complex networks orchestrate epithelial-mesenchymal transitions. Nat. Rev. Mol. Cell Biol., 7(2), 131--142.

Tolarova, M. \& Cervenka, J. (1998). Classification and birth prevalence of orofacial clefts. Am. J. Med. Genet., 75(2), 126--137.

Tonkin, E., Wang, T., Lisgo, S., Bamshad, M., \& Strachan, T. (2004). NIPBL, encoding a homolog of fungal Scc2-type sister chromatid cohesion proteins and fly Nipped-B, is mutated in Cornelia de Lange syndrome. Nat. Genet., 36(6), 636--641.

Trokovic, N., Trokovic, R., Mai, P., \& Partanen, J. (2003). Fgfr1 regulates patterning of the pharyngeal region. Genes Dev., 17(1), 141--153.

van den Boogaard, M., Dorland, M., Beemer, F., \& van Amstel, H. (2000). MSX1 mutation is associated with orofacial clefting and tooth agenesis in humans. Nat. Genet., 24(4), 342-343.

Vaziri Sani, F., Hallberg, K., Harfe, B., McMahon, A., Linde, A., \& Gritli-Linde, A. (2005). Fate-mapping of the epithelial seam during palatal fusion rules out epithelial-mesenchymal transformation. Dev. Biol., 285(2), 490--495.

Vermes, I. \& Haanan, C. (1994). Apoptosis and programmed cell death in health and disease. Adv. Clin. Chem, 31, 177.

Vieira, A., Modesto, A., Meira, R., Barbosa, A., Lidral, A., \& Murray, J. (2007). Interferon 
regulatory factor 6 (IRF6) and fibroblast growth factor receptor 1 (FGFR1) contribute to human tooth agenesis. Am. J. Med. Genet. A, 143A(6), 538--545.

Vissers, L., van Ravenswaaij, C., Admiraal, R., Hurst, J., de Vries, B., \& Janssen, I. et al. (2004). Mutations in a new member of the chromodomain gene family cause CHARGE syndrome. Nat. Genet., 36(9), 955--957.

Vrouwe, S., Lowry, R., Olson, J., \& Wilkes, G. (2013). The Birth Prevalence of Cleft Lip and Palate in Canadian Aboriginal Peoples. Plastic And Reconstructive Surgery, 131(4), 649e650e. http://dx.doi.org/10.1097/prs.0b013e318289d045

Wagner, T., Wirth, J., Meyer, J., Zabel, B., Held, M., \& Zimmer, J. et al. (1994). Autosomal sex reversal and campomelic dysplasia are caused by mutations in and around the SRY-related gene SOX9. Cell, 79(6), 1111--1120.

Waldrip, W., Bikoff, E., Hoodless, P., Wrana, J., \& Robertson, E. (1998). Smad2 signaling in extraembryonic tissues determines anterior-posterior polarity of the early mouse embryo. Cell, 92(6), 797--808.

Wallis, D., Roessler, E., Hehr, U., Nanni, L., Wiltshire, T., \& Richieri-Costa, A. et al. (1999). Mutations in the homeodomain of the human SIX3 gene cause holoprosencephaly. Nat. Genet., 22(2), 196--198.

Wang, E. (1997). Regulation of apoptosis resistance and ontogeny of age-dependent diseases. Exp. Gerontol., 32(4-5), 471--484.

Wang, Y., Dai, Y., Li, X., Chen, C., Li, W., \& Yu, Z. (2011). Inhibition of Smad signaling is implicated in cleft palate induced by all-trans retinoic acid. Acta. Biol. Hung., 62(2), 142-150.

Waterham, H., Koster, J., Romeijn, G., Hennekam, R., Vreken, P., \& Andersson, H. et al. (2001). Mutations in the 3beta-hydroxysterol Delta24-reductase gene cause desmosterolosis, an autosomal recessive disorder of cholesterol biosynthesis. Am. J. Hum. Genet., 69(4), 685-694. 
Weinstein, M., Yang, X., Li, C., Xu, X., Gotay, J., \& Deng, C. (1998). Failure of egg cylinder elongation and mesoderm induction in mouse embryos lacking the tumor suppressor smad2. Proc. Natl. Acad. Sci. U.S.A., 95(16), 9378--9383.

Wilcox, A., Lie, R., Solvoll, K., Taylor, J., McConnaughey, D., \& Abyholm, F. et al. (2007). Folic acid supplements and risk of facial clefts: national population based case-control study. BMJ, 334(7591), 464-464. http://dx.doi.org/10.1136/bmj.39079.618287.0b

Wilkie, A., Slaney, S., Oldridge, M., Poole, M., Ashworth, G., \& Hockley, A. et al. (1995). Apert syndrome results from localized mutations of FGFR2 and is allelic with Crouzon syndrome. Nat. Genet., 9(2), 165--172.

Wu, J., Fairman, R., Penry, J., \& Shi, Y. (2001). Formation of a stable heterodimer between Smad2 and Smad4. J. Biol. Chem., 276(23), 20688--20694.

Wu, X. \& Ding, H. (2007). Generation of conditional knockout alleles for PDGF-C. Genesis, 45(10), 653--657.

Wu, Y., Li, Q., Zhou, X., Yu, J., Mu, Y., \& Munker, S. et al. (2012). Decreased levels of active SMAD2 correlate with poor prognosis in gastric cancer. Plos ONE, 7(4), 35684.

Wyllie, A. (2010). "Where, O death, is thy sting?" A brief review of apoptosis biology. Mol. Neurobiol., 42(1), 4--9.

Wyszynski, D. (2002). Cleft lip and palate. Oxford: Oxford University Press.

Xu, L., Zhou, X., Wang, Q., Zhou, J., Liu, Y., \& Ju, Q. et al. (2015). A Case-control Study of Environmental Risk Factors for Nonsyndromic Cleft of the Lip and/or Palate in Xuzhou, China. Biomed. Environ. Sci., 28(7), 535--538.

Xu, X., Han, J., Ito, Y., Bringas, P., Urata, M., \& Chai, Y. (2006). Cell autonomous requirement for Tgfbr2 in the disappearance of medial edge epithelium during palatal fusion. Dev. Biol., 297(1), 238--248.

Yang, J., Mani, S., Donaher, J., Ramaswamy, S., Itzykson, R., \& Come, C. et al. (2004). Twist, a 
master regulator of morphogenesis, plays an essential role in tumor metastasis. Cell, 117(7), 927--939.

Yang, J., Wahdan-Alaswad, R., \& Danielpour, D. (2009). Critical role of Smad2 in tumor suppression and transforming growth factor-beta-induced apoptosis of prostate epithelial cells. Cancer Res., 69(6), 2185--2190.

Yang, L. \& Kaartinen, V. (2007). Tgfb1 expressed in the Tgfb3 locus partially rescues the cleft palate phenotype of Tgfb3 null mutants. Dev. Biol., 312(1), 384--395.

Yang, L., Li, W., \& Kaartinen, V. (2008). Tissue-specific expression of Cre recombinase from the Tgfb3 locus. Genesis, 46(2), 112--118.

Yang, X., Letterio, J., Lechleider, R., Chen, L., Hayman, R., \& Gu, H. et al. (1999). Targeted disruption of SMAD3 results in impaired mucosal immunity and diminished T cell responsiveness to TGF-beta. EMBO J., 18(5), 1280--1291.

Yang, X., Li, C., Xu, X., \& Deng, C. (1998). The tumor suppressor SMAD4/DPC4 is essential for epiblast proliferation and mesoderm induction in mice. Proc. Natl. Acad. Sci. U.S.A., 95(7), 3667--3672.

Yang, Y., Topol, L., Lee, H., \& Wu, J. (2003). Wnt5a and Wnt5b exhibit distinct activities in coordinating chondrocyte proliferation and differentiation. Development, 130(5), 1003-1015 .

Yoshimoto, T., Fujita, T., Kajiya, M., Matsuda, S., Ouhara, K., Shiba, H., \& Kurihara, H. (2015). Involvement of smad 2 and Erk/Akt cascade in TGF-ÃŽ $\hat{A}^{2} 1$-induced apoptosis in human gingival epithelial cells. Cytokine, 75(1), 165--173.

Yoshiura, K., Machida, J., Daack-Hirsch, S., Patil, S., Ashworth, L., Hecht, J., \& Murray, J. (1998). Characterization of a Novel Gene Disrupted by a Balanced Chromosomal Translocation t(2;19)(q11.2;q13.3) in a Family with Cleft Lip and Palate. Genomics, 54(2), 231-240. http://dx.doi.org/10.1006/geno.1998.5577

Yu, W., Kamara, H., \& Svoboda, K. (2008). The role of twist during palate development. Dev. 
Dyn., 237(10), 2716--2725.

Yu, W., Serrano, M., Miguel, S., Ruest, L., \& Svoboda, K. (2009). Cleft lip and palate genetics and application in early embryological development. Indian J Plast Surg, 42 Suppl, 35--50.

Zhang, Y. (2009). Non-Smad pathways in TGF-beta signaling. Cell Res., 19(1), 128--139.

Zhu, Q., Ma, C., Wang, Q., Song, Y., \& Lv, T. (2016). The role of TWIST1 in epithelialmesenchymal transition and cancers. Tumour Biol., 37(1), 185--197. 